Theaterpolitik an dem langfristigen Ziel der Errichtung einer deutschen „kulturellen Hegemonie“ orientierte.

\title{
2. Deutsche Filme in Frankreich - Unterhaltung und propagandistischer Filmeinsatz
}

Es gibt heute viele Länder und viele Völker, die Deutschland überhaupt nur durch den Rundfunk und den Film kennen. Sie sehen keinen Deutschen, jedenfalls keinen Nationalsozialisten. [...] Sie müssen also ihre Rückschlüsse auf Deutschland aus diesen beiden Dokumenten schöpfen. [...] Es mußte hier also eine Konkurrenzsetzung zwischen dem, was die Welt sagt, und dem, was wir sind, stattfinden. Und ich muß konstatieren mit tiefer Befriedigung, wie ich schon sagte, daß unsere deutschen Filmschaffenden dieses Problem nicht nur erkannt, sondern auch gelöst haben ${ }^{421}$.

Goebbels sprach diese Worte während einer Rede anläßlich der Kriegstagung der Reichsfilmkammer am 15. Februar 1941 in Berlin. Demnach sollten deutsche Filme im Ausland zu einem positiveren Bild des "neuen Deutschland“ beitragen. Diese generelle Sorge um das Ansehen des nationalsozialistischen Staates im Ausland gehörte zu Goebbels kulturpolitischen Grundsätzen ${ }^{422}$. Weniger in Frankreich, wo deutsche Produktionen vorwiegend in französischer Synchronisation liefen, als vor allem in den besetzten Ostgebieten sollte der deutsche Film zusätzlich zur Verbreitung der deutschen Sprache beitragen. In seiner Rede vor den Filmschaffenden am 28. Februar 1942 in Berlin meinte Goebbels: „Wir können nicht ein Weltreich besitzen, ohne gleichzeitig eine Weltsprache zu besitzen. Die besten Verbreiter der deutschen Sprache aber sind der Rundfunk und der Film. Allein in dieser Beziehung also ist der deutsche Film ein nationalpolitisches Behelfsmittel allererster Klasse ${ }^{* 423}$. Trotzdem war der Film nach den Vorstellungen der Nationalsozialisten vor allem ein sogenanntes Erziehungs- und Führungsmittel, das sich an das deutsche Volk richtete. Goebbels hat dies immer wieder betont. In der genannten Rede vor Filmschaffenden hat der Propagandaminister zum Filmeinsatz im Dritten Reich gesagt, der Staat habe ein eminentes Interesse an der Führung des Filmes, der nicht nur ein bloßes Mittel zur Unterhaltung sei, sondern auch ein "nationales Führungsmittel“424. Weiter heißt es: „Wobei ich nicht etwa die Auffassung von der Hand weisen wollte, daß der Film selbstverständlich auch zur Unterhaltung da ist, da die Unterhaltung ja besonders in Kriegszeiten einen nationalen Faktor ersten Ranges darstell ${ }^{\text {“425. }}$.

421 Goebbels Rede anläßlich der Kriegstagung der Reichsfilmkammer am 15. 2.1941 in Berlin, abgedruckt in: ALBRECHT, Nationalsozialistische Filmpolitik, S. 479.

422 MATHIEU, Kunstauffassungen, S. 132-134.

423 Rede vor den Filmschaffenden am 28. 2. 1942 in Berlin, zit. n.: ALBRECHT, Nationalsozialistische Filmpolitik, Dokument 6, S. 488.

424 Ibid.

425 Ibid. 
Demnach sollte der deutsche Film im Inland gerade während des Krieges die Bevölkerung unterhalten und außerdem ein Mittel zur gezielten Beeinflussung sein. Die deutsche Filmproduktion rangierte damit zwischen Unterhaltung und Propaganda, wobei die Grenzen hier fließend waren. So konnte beispielsweise eine Filmkomödie im Dritten Reich unterschwellig nationalsozialistische Vorstellungen von Ehe und Mutterschaft propagieren und trotzdem vorwiegend unterhaltsam sein. Es ist also grundsätzlich problematisch, die gesamte deutsche Filmproduktion etwa in Kategorien wie reine Unterhaltungs- oder Propagandafilme einteilen zu wollen. Trotzdem sind Filme wie "Jud Süß" (Veit Harlan, 1940) oder "Ohm Krüger" (Hans Steinhoff, 1941) eindeutig als Propagandafilme einzustufen ${ }^{426}$. Neben propagandistischen Spielfilmen und der Deutschen Wochenschau konnten auch die sogenannten Kulturfilme ${ }^{427}$, d.h. die dokumentarischen Kurz- oder Langfilme, propagandistische Inhalte transportieren. In seiner Untersuchung zur nationalsozialistischen Filmpolitik hat beispielsweise Gerd Albrecht das Angebot an Spielfilmen im Dritten Reich, die zwischen 1933 und 1945 uraufgeführt wurden, in vier Gruppen eingeteilt. Er unterscheidet zwischen A-Filmen (Filme aktionsbetonender Grundhaltung mit nur latenter politischer Funktion), E-Filmen (Filme ernster Grundhaltung mit nur latenter politischer Funktion), H-Filmen (Filme heiterer Grundhaltung mit nur latenter politischer Funktion) und P-Filmen (Filme mit manifester politischer Funktion ohne Rücksicht auf ihren sonstigen Inhalt und ihre Grundhaltung). Die deutsche Filmproduktion bestand laut Albrecht aus 47,8 Prozent H-Filmen, 27 Prozent E-Filmen, 14 Prozent P-Filmen und 11 Prozent A-Filmen; zu Beginn des Krieges wurden nur noch 36,1 Prozent H-Filme produziert. Das Jahresangebot in den deutschen Filmtheatern aber zeigte konstant um die 50 Prozent H-Filme an ${ }^{428}$. Selbst diese differenzierte Einteilung Albrechts ist nicht unproblematisch, da beispielsweise die latente politische Funktion ei-

426 Zu der problematischen Einstufung der Werke, die das Prädikat „staatspolitisch besonders wertvoll" erhielten siehe die Einleitung bei KaNZOG, Staatspolitisch besonders wertvoll, S. 13-53; Kanzog bezeichnet vor allem Dokumentarfilme als „unverhüllte Propagandafilme“. Zu "unpolitischer Unterhaltung" und Propaganda vor dem Krieg siehe bei KreIMEIER, Die Ufa-Story, S. 320-337.

$427 \mathrm{Zu}$ den Kulturfilmen im Dritten Reich siehe DREWNIAK, Der deutsche Film, S. 5056. Er schreibt: „Alle Filme, denen keine Spielhandlung zugrunde liegt, lassen sich, unter Vorbehalten, in die große Familie des Kulturfilms einreihen. Um die Definition des Begriffes ,Kulturfilm‘ bemühen sich zahlreiche Theoretiker seit je, aber der endgültige Bescheid blieb weiterhin aus.[...] Kulturfilme sollen, zum großen Teil wenigstens, in einer unterhaltsamen Form belehren. Es gab jedoch nicht wenige Beispiele dafür, daß das Lehrhafte zu stark betont war" (Ibid. S. 50). In den Akten des Referats Film der Propaganda Staffel werden propagandistische Kurzfilme, und auch längere "dokumentarische" Propagandafilme wie „Der ewige Jude", als Kulturfilme bezeichnet. Im folgenden soll der Begriff in diesem Sinne gebraucht werden. Aus praktischen Gründen wird darauf verzichtet, ihn in Anführungszeichen zu setzen.

428 AlbreCHT, Nationalsozialistische Filmpolitik, S. 186. 
nes Filmes auch von der Interpretation dieses Werkes durch die Zuschauer abhing.

Der Einsatz von Filmpropaganda war im Ausland grundsätzlich schwieriger als im Inland, da sich die deutsche Filmindustrie mit der Produktion der Filme auf das jeweilige Land hätte einstellen müssen. Was die Spielfilme anbelangt, wurden deswegen nur relativ wenige Propagandafilme ins Ausland exportiert, die dort nicht sehr beliebt waren, wie die Auslandsabteilung des RMVP im März 1943 konstatierte ${ }^{429}$. Im Ausland sollten deutsche Spielfilme vorwiegend unterhalten, möglichst von der angeblich hohen Qualität deutscher Kultur überzeugen und ein positives Bild des nationalsozialistischen Deutschland vermitteln. Auch im besetzten Frankreich sollte das Gros der deutschen Spielfilme unterhalten, Sympathien für Deutschland wecken und die Akzeptanz der allgemeinen Besatzungspolitik steigern. Den Einsatz von offen propagandistischen Spielfilmen, Kulturfilmen und der Deutschen Wochenschau handhabte die Besatzungsmacht relativ vorsichtig; das französische Volk sollte auch keineswegs etwa zu Nationalsozialisten erzogen werden. Propagandafilme sollten nur im Einklang mit der allgemeinen Besatzungspolitik eingesetzt werden. Die Propaganda Abteilung hatte schon zu Beginn der Okkupation durchgesetzt, daß die Betreiber der Filmtheater vor dem Hauptfilm einen französischen oder deutschen Kulturfilm und die Wochenschau zeigen mußten; damit sollte die Filmpropaganda vor allem über die Kulturfilme und die Wochenschau gesichert werden. Die deutsche Filmexportpolitik umfaßte also vor allem Spielfilme, die der Unterhaltung dienen sollten. Wie sahen nun die Grundzüge dieser Politik aus und mit welchen Mitteln wurde sie von den deutschen Dienststellen und Filmverleihfirmen im besetzten Frankreich umgesetzt?

\subsection{Deutsche Filmexportpolitik und Unterhaltungsfilme}

Die deutsche Filmexportpolitik war während des Krieges neben ökonomischen Interessen vor allem geprägt von dem Ziel der Errichtung einer kulturellen deutschen Hegemonie in Europa. In diesem Sinne sollte der deutsche Film eine führende Position im Ausland gewinnen. Entscheidend waren hierbei freilich die militärischen Siege, die dem Deutschen Reich zu politischer und wirtschaftlicher Macht in den besetzten und annektierten Gebieten verhalfen. Wie wichtig dieser Aspekt war, zeigen die Ausführungen zum Auslandsgeschäft in den Berichten der Ufa. Dort heißt es zu den Geschäftsjahren 1937/38 und 1938/39, das Auslandsgeschäft müsse als wenig befriedigend bezeichnet werden ${ }^{430}$. Für das Geschäftsjahr 1939/40 dagegen wird be-

429 PA-AA, 1125 b, Kult 12 Nr. 4, RMVP, Abteilung Ausland, Vertraulich, Die Lage des deutschen Films in Europa, Anfang 1943, 29. 3. 1943.

430 BA-KO, R109 I/1046, Geschäftsberichte der Universum-Film Aktiengesellschaft für das Geschäftsjahr 1937/38, S. 10, und Geschäftsbericht für das Geschäftsjahr 1938/ 39. 
tont, im Auslandsgeschäft eröffneten sich nun neue Möglichkeiten, die stete Aufwärtsentwicklung des Unternehmens habe durch die „zusätzlichen Möglichkeiten des großdeutschen Wirtschaftsraumes weitere Fortschritte ge-

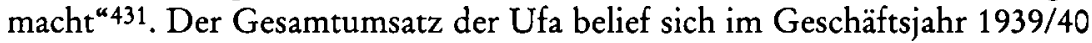
auf 166179000 Reichsmark, während es im Vorjahr nur 142409000 Reichsmark gewesen waren. Für das darauffolgende Geschäftsjahr vermerkte die Ufa, in den meisten europäischen Ländern habe der deutsche Film nun eine dominierende Stellung. Der Gesamtumsatz betrug 207594000 Reichsmark ${ }^{432}$ und 1941/42 stieg er auf 242082000 Reichsmark an ${ }^{433}$. Obwohl die Umsätze im Ausland ihren Anteil an dieser Entwicklung hatten, stieg der Gesamtumsatz der Ufa allerdings auch aufgrund der zunehmenden Besucherzahlen im Inland. In der oben erwähnten Rede vom Februar 1942 erläuterte Goebbels, der deutsche Film sei bereits im Inland amortisationsfähig. Weiter sagte er:

Dazu kommt nun aber eine Basis, die wir außerhalb des Reiches besitzen, und zwar haben wir diese Basis nicht etwa durch den Film selbst errungen, sondern durch die militärischen Erfolge. Ich habe nun nichts unversucht gelassen, eine solche Situation weidlich auszunutzen. Sie können sich vorstellen, daß wir so günstige Verhältnisse, wie wir sie augenblicklich im besetzten Frankreich oder in Belgien oder in den Niederlanden oder im Südosten auffinden, niemals mehr antreffen werden. Auch hier gilt das Wort: Schmiede das Eisen solange es glüht. Im Kriege sind die Eigentumsverhältnisse niemals so ganz genau festzustellen ${ }^{434}$.

Goebbels nutzte die Situation des Krieges, um durch Ankäufe oder Beschlagnahmungen von Filmtheaterparks dem deutschen Film einen Absatz in Europa auch über das Ende des Krieges hinaus zu sichern. So wurde der deutsche Film, wie Drewniak schreibt, während des Krieges „zu einem Hauptversorgungsfaktor der europäischen Märkte “435. Seit 1939/40 war in Europa der Import von Filmen aus Übersee zurückgegangen und diese Lücke konnte zum Teil durch deutsche Filme gefüllt werden. Bis zum Geschäftsjahr 1943/ 44 stiegen die Erträge aus dem deutschen Filmexport an. Dieser Trend wurde

${ }^{431}$ Ibid. Geschäftsbericht der Universum-Film Aktiengesellschaft für das Geschäftsjahr 1939/40, S. 7.

432 Ibid. Geschäftsbericht der Universum-Film Aktiengesellschaft für das Geschäftsjahr 1940/41, S. 3f.

433 Ibid. Geschäftsbericht der Universum-Film Aktiengesellschaft für das Geschäftsjahr 1941/42.

434 Rede vor den Filmschaffenden am 28. 2. 1942 in Berlin, abgedruckt in: ALBRECHT, Nationalsozialistische Filmpolitik, Dokument 6, S. 486. Siehe auch Goebbels Rede anläßlich der Kriegstagung der Reichsfilmkammer am 15. 2. 1941 in Berlin, abgedruckt in: ALBRECHT, Nationalsozialistische Filmpolitik, S. 471: „Diese Konkurrenten sind abgeschüttelt worden, und zwar nicht durch das Verdienst des deutschen Films, sondern durch die militärischen Ereignisse. Deutschland ist heute in der Lage, den gesamten europäischen Kontinent zu beherrschen, und wir sind heute allein dominierend in Europa, die einzigen Filmmacher, die überhaupt ernsthaft in Frage kommen [...]“.

435 DREWNIAK, Der deutsche Film, S. 692. 
durch die sich verändernde Weltkriegslage erst im Sommer 1944 gestoppt ${ }^{436}$. Die Position des deutschen Filmes in Europa war während der Zeit der Okkupation somit relativ stabil. So betonte Goebbels in der genannten Rede:

$\mathrm{Ob}$ wir diese oder jene Gebiete ganz in unseren Besitz nehmen oder wieder zum Teil räumen, ob wir da nur unseren wirtschaftlichen oder finanziellen oder politischen oder militärischen Einfluß spielen lassen, jedenfalls sind unsere privaten Einflüsse wirtschaftlicher Art so gefestigt, daß man sagen kann, der größte Teil Europas ist für uns Absatzgebiet geworden ${ }^{437}$.

Die Mittel zur Erreichung dieses Zieles waren in den verschiedenen vom Reich besetzten oder annektierten Gebieten unterschiedlich ${ }^{438}$. In Holland lag beispielsweise durch Beschlagnahmungen und Ankäufe ein Großteil der Filmtheater in den Händen der Besatzungsmacht; offiziell gehörten sie zur Internationalen Tobis-Cinema N.V. in Amsterdam, einer Tochtergesellschaft der holländischen Intertobis. Die Besitzverhältnisse waren so nicht offensichtlich, zumal die Tobis in den Augen der Bevölkerung als holländisches Unternehmen galt ${ }^{439}$. In den besetzten Ostgebieten beschlagnahmte die Militärverwaltung fast vollständig die Filmtheater und Produktionsanlagen der Filmindustrie. Im sogenannten Generalgouvernement für die besetzten polnischen Gebiete waren laut Kreimeier von 123 Filmtheatern 17 allein für Deutsche reserviert, 62 gaben Vorstellungen getrennt für Deutsche und Einheimische und die übrigen 44 dienten „der schnellen Amortisation billigster Unterhaltungsware aus den reichsdeutschen Konzernen " 440 , weil dort die einheimische Bevölkerung fast ausschließlich deutsche Produktionen zu sehen bekam.

Anders waren die Verhältnisse in Frankreich, wo deutsche Filme nicht in diesem Umfang durch Beschlagnahmungen und Ankäufe von Filmtheatern durchgesetzt werden konnten. Die deutsche Filmexportpolitik kann hier im Vergleich zu den besetzten Gebieten im Osten als relativ zurückhaltend bezeichnet werden. Die Besatzungsmacht wollte zudem Unruhen und Demonstrationen in französischen Filmtheatern vermeiden. Wenn etwa das Filmangebot auf dem französischen Markt zu hundert Prozent aus deutschen Filmen bestanden hätte, wären ein weitaus geringerer Besuch der Filmtheater oder gar offene Proteste nicht auszuschließen gewesen. Immerhin hatte

436 Ibid. S. 692-694.

437 Goebbels Rede vor den Filmschaffenden am 28.2. 1942 in Berlin, abgedruckt in: ALBRECHT, Nationalsozialistische Filmpolitik, Dokument 6, S. 487.

438 Zur Filmpolitik im besetzten Ausland siehe bei KREIMEIER, Die Ufa-Story, S. 389398; zur deutschen Exportpolitik in den von Deutschland besetzten oder annektierten Gebieten sowie in Italien siehe die Darstellung von DREWNIAK, Der deutsche Film, S. 691-812.

439 BECKER, Film und Herrschaft, S. 220.

440 KreImeIER, Die Ufa-Story, S. 393; vgl. DrewniaK, Der deutsche Film, S. 720. Demnach gab es im "Generalgouvernement " insgesamt 200 Filmtheater, von denen 25 nur für Deutsche reserviert waren, 62 waren nur für Polen, 59 für Polen und Deutsche, 8 nur für Ukrainer, 37 für Polen und Ukrainer etc. 
Frankreich vor dem Kriege im Gegensatz zu den Ländern Osteuropas eine hochentwickelte Filmindustrie besessen. Das Publikum war vorwiegend an die Vorführung französischer und amerikanischer Filme gewöhnt. Kreimeier meint zu der im besetzten Frankreich verfolgten deutschen Filmexportpolitik: „Gegenüber den Ansprüchen des französischen Kinopublikums bestanden begründete, wenn auch uneingestandene Minderwertigkeitskomplexe" ${ }^{441}$. So maßvoll die deutsche Filmexportpolitik in Frankreich auch war, so war sie verglichen mit der im Bereich des Theaters verfolgten Politik weit weniger zurückhaltend.

Im Gegensatz zum Bereich des Theaters waren Beschlagnahmungen und besonders Ankäufe von Filmtheatern und Produktionsstätten durch deutsche Firmen wesentliche Maßnahmen zur Durchsetzung deutscher Kulturpropaganda. Die großen Pariser Erstaufführungstheater waren im Besitz der Greven-Gesellschaften. Goebbels hat im Februar 1942 in seiner Rede vor Filmschaffenden in Berlin gesagt:

Denn Sie wissen ja, meine Damen und Herren, daß wir im Verlaufe der letzten 21/2 Jahre allmählich einen Theaterpark angeschafft haben, der für den Nichtkenner vollkommen unübersehbar ist. Ich kann das in diesem Kreise sagen, daß wir heute in Frankreich die größten Theater haben. Das ist unser Eigentum. Das weiß ja niemand. [...] Wir bauen hier, unsichtbar vor der Öffentlichkeit, einen Filmmarkt in Europa auf, der dann, wenn die entscheidende Stunde nach dem Kriege kommt, die Konkurrenz mit der amerikanischen gut aufnehmen kann ${ }^{42}$.

In diesen Filmtheatern liefen die deutschen Filme und die französischen Filme der von Greven geleiteten Continental. Den Vertrieb übernahmen deutsche Verleihfirmen. Seit Beginn des Jahres 1942 wurde generell der Auslandsvertrieb der Tobis, Terra und Bavaria mit dem der Ufa zusammengelegt und von letzterer zentral geführt. In Frankreich und in einigen anderen Ländern blieben jedoch „aufgrund der besonderen Marktverhältnisse" 443 zwei Firmen bestehen, die Ufa/ACE (im folgenden ACE) und die Tobis. Da ein Teil der Filmtheater in deutschen Händen lag, waren die Firmen hier weniger auf die Kooperationsbereitschaft französischer Filmtheaterbesitzer angewiesen. Darüber hinaus übte das Referat Film auch direkten Druck auf die Filmtheaterbesitzer aus. Im April 1941 heißt es beispielsweise: „Die bereits zugelassenen Theater wurden mit Rundschreiben über die Staffeln und Außenstellen auf die Notwendigkeit des Abschlusses deutscher Filme hingewiesen"444. Obgleich sich der tatsächliche Druck allein über Aktenmaterial kaum nachvollziehen läßt, findet sich in einem Bericht des Referats von Ende Okober 1941 ein Beleg dafür. Der Gaumont-Konzern hatte den Referatslei-

441 Kreimeier, Die Ufa-Story, S. 394.

442 Goebbels Rede vor Filmschaffenden am 28.2. 1942 in Berlin, abgedruckt in: ALBRECHT, Nationalsozialistische Filmpolitik, Dokument 6, S. 493.

443 PA-AA, 1125b, Kult 12 Nr. 4, RMVP, Abteilung Ausland, Vertraulich, Die Lage des deutschen Films in Europa, Anfang 1943, 29. 3. 1943.

444 BA-MA, RW35 220, Tätigkeitsbericht, 17. 4.-24. 4. 1941. 
ter Diedrich darüber informiert, daß im Monat Dezember der deutsche UfaFilm „Herz der Königin“ (Carl Froelich, 1940) mit Zarah Leander - im französischen Titel „Marie Stuart" - in den Filmtheatern Madeleine und Le Colisée des Konzerns laufen würde. Offenbar hatte Gaumont diesen Film mit anti-britischer Tendenz nicht ganz freiwillig in das Programm aufgenommen. Diedrich hatte "gelegentlich dem Präsidenten des Gaumont-Konzerns, Le Duc, gegenüber erwähnt, daß ihm aufgefallen sei, daß in dem Filmtheater Madeleine des Gaumont-Konzerns seit dessen Wiedereröffnung noch kein deutscher Film gelaufen sei “ ${ }^{\text {" }} 45$. Nach Verhandlungen von Gaumont und ACE zeigten nun die genannten Filmtheater "Herz der Königin“. Weiteren Aufschluß über das Vorgehen der deutschen Dienststellen gibt der Bericht zur Tagung der Filmreferenten der Staffeln am 15. Mai 1942 in Paris. Darin heißt es, die Verleihfirmen sähen das Verhältnis deutscher und französischer Produktionen auf dem Filmmarkt als Erfolg:

Darüber hinaus darf im Augenblick kein weiterer Druck auf französische Filmtheaterbesitzer, noch mehr deutsche Programme abzuschließen, ausgeübt werden. Im übrigen sind die deutschen Firmen darauf hingewiesen worden, daß im Interesse der Propaganda bei der Vermietung deutscher Filme weniger nach kaufmännischen Gesichtspunkten zu verfahren ist $t^{46}$.

Die deutschen Filme dürften nicht wie in einigen Gebieten Frankreichs zu teuer vermietet werden. Die Verleihsätze, so der Bericht, sollten unbedingt im Interesse der Erhaltung der Filmtheater auf ein vernünftiges Maß beschränkt sein. Die Ausübung von Druck hatte also ihre Grenzen und die Besatzer strebten zumindest kurzfristig keine völlige Beherrschung des französischen Filmmarktes durch den deutschen Film an. Abgesehen davon, daß die Anzahl der neueren deutschen Produktionen zur vollständigen Versorgung des französischen Marktes nicht ausgereicht hätte ${ }^{447}$, befürchtete die Besatzungsmacht ablehnende Reaktionen des französischen Publikums. Schließlich konnte die Besatzungsmacht die Bevölkerung ebenso wie im Bereich des Theaters nicht zu einem Besuch der Filmtheater zwingen. Um die Filmtheaterbesitzer dennoch zum Einsatz deutscher Filme zu bewegen, durften ACE und Tobis nicht zu hohe Verleihsätze für deutsche Filme verlangen. Deutsche ökonomische Interessen sollten hier ausdrücklich hinter propagandistischen Aspekten und hinter Gründen der Sicherung der Ruhe und Ordnung im besetzten Frankreich zurückstehen. In einem Bericht des

445 BA-MA, RW35 224, Tätigkeitsbericht, 24. 10.-31. 10. 1941.

446 BA-MA, RW35 226, Gr.Film, Tätigkeitsbericht, 15.-23. 5. 1942. Anwesend waren auch Vertreter der ACE und Tobis sowie von Eicke von der Continental.

447 Goebbels selbst hat in seiner Rede vor den Filmschaffenden am 28. 2.1942 in Berlin gesagt: „Das Entscheidende in dieser Frage ist nun, daß wir die nötige Anzahl von Filmen zur Verfügung haben, um die leeren Räume auszufüllen. Denn das von uns besetzte und politisch und militärisch beeinflußte Europa gleicht heute einer ausgedörrten Wüste, auf die hin und wieder ein leichter Regen niedergeht. Der Bedarf an Filmen kann durchaus nicht von uns gedeckt werden" (zit. n. ALBRECHT, Nationalsozialistische Filmpolitik, Dokument 6, S. 487). 
Referats Film vom Juli 1941 heißt es zu einer wöchentlichen Besprechung Grevens mit Diedrich und den Vertretern der ACE und Tobis: So ermahnte Diedrich die deutschen Verleihfirmen, es sei ihre zentrale propagandistische Aufgabe mit allen Mitteln durchzusetzen, „daß in jeder französischen Gemeinde die deutschen Filme und die unter deutscher Leitung hergestellten französischen Filme (Spiel- und Kulturfilme sowie die Wochenschau) regelmäßig zur Vorführung gelangen" 448 .

Angesichts dieses propagandistischen Auftrags stellt sich die Frage, in welchem Umfang die deutschen Verleihfirmen in Frankreich welche deutschen Unterhaltungsfilme vertrieben und wie erfolgreich diese waren. Welche Funktion war ihnen von der Besatzungsmacht zugedacht und wie waren die Reaktionen des französischen Publikums? Abgesehen von den Schwierigkeiten, rückblickend die Rezeption durch die Zuschauer nachzuvollziehen, liefern Angaben über die Entwicklung der Anzahl deutscher Filme auf dem französischen Filmmarkt sowie deren Einspielergebnisse zumindest Anhaltspunkte für die Bemessung des Erfolges oder Mißerfolges deutscher Filme. Diese statistischen Angaben haben jedoch angesichts der oben dargelegten deutschen Filmexportpolitik, die mit allen Mitteln auf eine Verbreitung deutscher Filme abzielte, einen sehr begrenzten Aussagewert. Zudem gibt die Statistik keinen Aufschluß darüber, ob ein Film qualitativ überzeugend war oder dem französischen Publikum besonders gefallen oder mißfallen hat. Gar nichts sagen die Umsatzzahlen oder die Anteile deutscher Filme am französischen Markt etwa über die kulturpropagandistische Wirkung der Filme aus.

Trotzdem sah das Referat Film in dem steigenden Anteil deutscher Filme am französischen Markt einen Erfolg deutscher Kulturpropaganda. Diese Steigerung beruhte allerdings in erster Linie auf den durch die militärischen Siege bedingten günstigen Rahmenbedingungen der deutschen Filmexportpolitik. Der Ankauf der wichtigsten französischen Filmtheater spielte hier ebenso eine Rolle wie die deutschen Zensurbestimmungen. Dementsprechend verschwand der amerikanische Film vom französischen Markt, auf den neben französischen Filmen vor allem deutsche und einige italienische Importe gelangten. Eine wesentliche Maßnahme zur Förderung des Absatzes deutscher Filme in Frankreich war die sogenannte Marktbereinigung, auf die bereits in den Ausführungen zur Zensur näher eingegangen wurde. Mit Hilfe dieser Zurückziehung älterer französischer Produktionen stieg der Anteil deutscher Filme in französischen Filmtheatern im Laufe der Besatzungszeit an. Während 1935 mit 60 Filmen der Anteil deutscher Filme in Frankreich vor der Besatzungszeit seinen Höhepunkt erreicht hatte und im ersten Halbjahr des Jahres 1940 auf vier Filme abgesunken war, wurden im Februar 1942 laut eines Berichtes des Referats Film 125 deutsche und 374 französische Filme, einschließlich der Produktionen der Continental, in Frankreich ange- 
boten. Die Planung sah für die nächste Saison nach einer weiteren Marktbereinigung ein Verhältnis von 285 französischen zu 127 deutschen Filmen vor. Diese Angaben bezogen allerdings auch ältere deutsche und französische Filme mit ein ${ }^{449}$. Die Entwicklung des Anteils deutscher Filme am gesamten Filmangebot auf dem französischen Markt stieg zwar zu Beginn der Okkupation an, konnte jedoch die Wünsche des Referats Film keineswegs zufriedenstellen. Außerdem folgte die absolute Anzahl neuerer deutscher Produktionen auf dem französischen Markt dieser Entwicklung nicht. Laut einer Veröffentlichung der Zeitschrift Le Film Français waren 194024 neuere deutsche Filme, 1941 55, 1942 39, 194328 und 19448 in französischen Filmtheatern zu sehen. Der Anteil deutscher Filme am aktuellen Gesamtangebot soll demnach 194014 Prozent, 1941 56, 1942 30, 194322 und 194415 Prozent betragen haben 450 . Während sich diese Angaben also auf die neueren Produktionen beschränkten, heißt es in einem Bericht der Auslandsabteilung des RMVP über die Lage des deutschen Films in Europa vom März 1943, das Gesamtfilmangebot einschließlich älterer Filme habe im März 1943 zusammen mit der Produktion von 1942/43 in Frankreich insgesamt 635 Filme umfaßt, davon waren 183 deutsche Filme, was einen Anteil von 29 Prozent ausmachte. Das Angebot der neuen Produktionen der Saison 1942/43 belief sich auf 133 Filme, wovon 33 deutsche Filme waren; dies entsprach einem Anteil von 25 Prozent ${ }^{451}$. Entsprechend der Tatsache, daß mehr und mehr ältere französische Spielfilme durch die deutsche Zensur vom Markt verschwanden, war nach den letztgenannten Angaben der Anteil deutscher Filme am Gesamtangebot um vier Prozent höher als der Anteil deutscher Filme an den neueren Produktionen. Vergleicht man allerdings den Anteil von 29 Prozent deutscher Filme am Gesamtfilmangebot in Frankreich mit dem des deutschen Filmes in anderen Ländern, so wird deutlich, daß dieser Anteil relativ niedrig war. Nach dem erwähnten Bericht vom März 1943 war er in anderen besetzten Westgebieten höher; so betrug der Anteil deutscher Produktionen am belgischen Markt 51 Prozent, in Holland waren es 86, in Norwegen 58, in

449 BA-MA, RW35 225, Prop.Abt., Gr.Film, Tätigkeitsbericht, 20. 2.-27. 2. 1942.

450 Le Film Français, Nr. 611-12, 1956, hier zit. n. François Garçon, The Film Propaganda in Occupied France, in: David WelCH (Hg.), Nazi Propaganda. The Power and the Limiations, Beckenham 1983, S. 166; diese Angaben wurden auch von DREWNIAK, Der deutsche Film, S. 730, übernommen. Die genannte Anzahl deutscher Filme in Frankreich für die Jahre 1936-1939 stimmt allerdings nicht mit dem überein, was die Untersuchung der Commission Consultative des Dommages et des Réparations, CCDR, veröffentlicht hat (CCDR, L'Emprise (Cinéma), S. 13, Tabelle III). Zum Anteil deutscher Filme am französischen Markt während der Okkupation finden sich dort keine Angaben. Allgemein ist zu bedenken, daß der französische Filmmarkt erst im Februar 1942 einheitlich wurde, und bis dahin die Märkte im besetzten und unbesetzten Gebiet getrennt zu sehen waren.

451 PA-AA, 1125 b, Kult 12 Nr. 4, RMVP, Abteilung Ausland, Vertraulich, Die Lage des deutschen Films in Europa, Anfang 1943, 29. 3. 1943. 
Dänemark allerdings nur 23 Prozent. Im verbündeten Italien hatten die deutschen Filme nur einen Anteil von 26 Prozent am Filmmarkt ${ }^{452}$.

Obgleich auch die Umsatzzahlen nur begrenzt etwas über den Erfolg deutscher Filme aussagen, sah die Auslandsabteilung des RMVP offenbar einen direkten Zusammenhang $z$ wischen den Umsätzen und der Wirkung der Filme. In dem genannten Bericht zur Lage des deutschen Filmes in Europa trägt das Kapitel zu den Umsätzen deutscher Filme in den jeweiligen Ländern die Überschrift "der propagandistische Wirkungsradius“453. Eine steigende Anzahl deutscher Filme in den jeweiligen Ländern bedeutete jedoch freilich noch lange nicht, daß diese Filme auch hohe Umsätze erzielten. In der Saison 1938/39 hatte der Anteil der Umsätze deutscher Filme in Frankreich gemessen an dem Gesamtumsatz auf dem französischen Filmmarkt nur 6 Prozent betragen. In der Saison 1942/43 waren es 23 Prozent, worin allerdings die neueren Produktionen von 1942/43 noch nicht eingeschlossen waren. Der Anteil deutscher Filme am französischen Filmangebot betrug 25 Prozent und entsprach somit in etwa dem Anteil am Gesamtumsatz. In Italien dagegen betrug der Anteil deutscher Filme am italienischen Filmangebot 26 Prozent, die Verleihfirmen erzielten damit aber nur 11 Prozent des Gesamtumsatzes am italienischen Filmmarkt. In Frankreich war der Anteil am Gesamtumsatz verglichen mit dem in anderen Ländern gering; in Belgien betrug er 73 Prozent und in Holland 81454. Die deutschen Filme waren demnach in Frankreich weit davon entfernt, einen Großteil des französischen Filmmarktes tatsächlich zu beherrschen. Diese Niederlage für die deutschen Funktionsträger wog umso schwerer als Frankreich nach Italien das europäische Land mit den meisten Filmtheatern war. Laut obigem Bericht des RMVP kamen 1943 im besetzten französischen Gebiet auf 36700000 Einwohner 2400 Filmtheater ${ }^{455}$; in Italien gab es bei einer Bevölkerung von 45000000 Einwohnern etwa 4300 Filmtheater. Im besetzten Gebiet von Belgien und Nordfrankreich kamen auf 8300000 Einwohner 752 Filmtheater. Frankreich war also einer der wichtigsten Filmmärkte Europas. Gleichzeitig sah das RMVP in der französischen Filmindustrie neben der italienischen einen Hauptkonkurrenten auf dem europäischen Filmmarkt. Neben der Anzahl der neueren Produktionen fürchtete die deutsche Seite vor allem die Qualität französischer Filme ${ }^{456}$. Wie wichtig der französische Markt für den

452 Ibid. Italien wurde erst im Herbst 1943 von den Deutschen besetzt, nachdem der ehemalige Bündnispartner einen Waffenstillstand mit den Alliierten geschlossen und damit einen Bruch mit dem nationalsozialistischen Deutschland herbeigeführt hatte. 453 Ibid.

454 Ibid.

455 Nach einem Bericht der ACE waren es sogar 3700 Filmtheater, siehe PA-AA, 1114, Kult 12 Nr. 4g, ACE, Reinegger, Geschäftsjahr 1943/44, Entwicklung des Verleihs deutscher und Continental-Filme in Frankreich, 2.6. 1944; vermutlich rührten diese unterschiedlichen Zahlenangaben daher, daß die Angabe des ACE Berichtes auch die nur für Schmalfilme $(16 \mathrm{~mm})$ ausgerüsteten Filmtheater mit berücksichtigte.

456 PA-AA, 1125 b, Kult 12 Nr. 4, RMVP, Abteilung Ausland, Vertraulich, Die Lage 
Absatz deutscher Filme war und wie hoch die dortigen deutschen Investitionen, zeigt die Verlustrechnung der Ufa vom November 1944, als nach den deutschen militärischen Niederlagen mehr und mehr besetzte Gebiete ausfielen. Die Ufa bezifferte den sogenannten Investitionsverlust in Frankreich auf mindestens 5585000 Reichsmark und den jährlichen Ausfall an Lizenzeinnahmen aus dem Verleihgeschäft auf 8622000 Reichsmark. Die Verluste der Ufa durch Investitionen und fehlende Lizenzeinnahmen waren in Frankreich verglichen mit denen in anderen Ländern wie Belgien, Bulgarien, Finnland, Griechenland, den Ostgebieten, Rumänien, Serbien und der Türkei am höchsten. Für Belgien verzeichnete sie mit 6207000 Reichsmark die zweithöchste Zahl für den Ausfall im Verleihgeschäft, bezifferten den Investitionsverlust aber nur auf 370000 Reichsmark. Insgesamt sprach die Ufa 1944 von 10903000 Reichsmark Investitionsverlust und 27296000 Reichsmark Verlust an jährlichen Lizenzeinnahmen ${ }^{457}$. Daß allein der Ankauf französischer Filmtheater noch lange nicht den Erfolg der dort gespielten deutschen Filme garantierte, wird in dem Bericht der Ufa über Ergebnis und Bilanz der angekauften französischen Filmtheater 1942 deutlich. Diese Filmtheater durften nach Meinung der Ufa nicht zu viele deutsche Filme spielen:

Der richtige Einsatz der deutschen Filme, abwechselnd mit französischen Filmen eigener oder fremder Produktion, erfordert viel Fingerspitzengefühl, wenn einerseits die Theater dem französischen Publikum nicht uninteressant, andererseits der von der deutschen Filmwirtschaft anzustrebende Einsatz deutscher Filme erreicht werden soll 458 .

Eine zu hohe Anzahl deutscher Filme machte das Filmtheater also uninteressant, hatte sinkende Besucherzahlen zur Folge und hätte damit dem Ziel geschadet, mit deutschen Filmen möglichst viele französische Zuschauer zu erreichen. Trotzdem hatte 1942 nahezu die Hälfte der Programme der angekauften Filmtheater aus deutschen Filmen bestanden. Die Ufa bedauerte: „Dieser starke Einsatz des deutschen Films muß allerdings mit verhältnismäßig bescheidenen finanziellen Erfolgen bezahlt werden “459. Demnach spielten die deutschen Filme nur ein Drittel der Gesamteinnahmen der Filmtheater ein und erbrachten lediglich 13 Prozent des Überschusses der in der Statistik erfaßten Theater. Die Continental-Filme erzielten mit nur 29 Prozent

des deutschen Films in Europa, Anfang 1943, 29. 3. 1943. Hauptkonkurrent war grundsätzlich der amerikanische Film, der im Jahre 1943 noch in Ländern wie der Schweiz, Spanien, Portugal, Schweden, Finnland und Griechenland zu sehen war.

457 BA-KO, R109 III/3, Der Reichsbeauftragte für die deutsche Filmwirtschaft, Winkler, an die Firmenchefs und Produktionschefs der reichsmittelbaren deutschen Filmgesellschaften, Betr.: Gemeinsame Firmen- und Produktionschefsitzung vom 13.11. 1944, 20. 11. 1944; Anlage, Unsere Auslandsbeteiligungen, ihre Lizenzerträge im Jahre 1943/44 und ihre voraussichtliche Entwicklung in 1944/45, Generaldirektor Fritz Kaelber.

458 BA-KO, R109 I/2025, Ufa, Ergebnis und Bilanz der französischen Theaterbetriebe 1942, ohne Datum.

459 Ibid. 
der Spieltermine dagegen 62 Prozent des Überschusses; sie schnitten damit sogar besser ab als die übrigen französischen Filme. Die Ufa betonte weiter, aufgrund der schlechten Ergebnisse der deutschen Filme bedürfe es einer sorgfältigen Führung dieser Filmtheater, „um den Interessen der drei Zweige unseres französischen Filmwirtschaftens - größtmöglicher Einsatz deutscher Filme, Kostendeckung der Continental-Filme, ausgeglichene Theaterbetriebsrechnung - gerecht zu werden" 460 . Wirtschaftliche und propagandistische Interessen waren hier eng miteinander verknüpft, wobei offenbar den letzteren der Vorzug gegeben wurde. Die angekauften Filmtheater spielten mit 50 Prozent der Spieltermine ein ökonomisch gerade noch vertretbares Maximum deutscher Filme, obgleich sie damit relativ wenig Einnahmen erzielten.

Aufgrund der nach Meinung der deutschen Funktionsträger so hohen Ansprüche des Pariser Publikums, sollten im besetzten Paris nur qualitativ gute Gastspiele aufgeführt werden. Bei den nach Frankreich exportierten Filmen wurde dieses Kriterium kaum beachtet. Grundsätzlich prüfte das RMVP zwar die deutschen Filme auf ihre Eignung für den Export, doch war hier weniger die Qualität der Filme ausschlaggebend. Einen Überblick über die Kriterien für die Einteilung deutscher Produktionen in exportgeeignete und exportungeeignete Filme liefert der bereits zitierte Bericht des RMVP vom März 1943 über die Lage des deutschen Films in Europa ${ }^{461}$. Allerdings handelte es sich hier keineswegs um offizielle Richtlinien für den Export deutscher Filme. Vielmehr waren offenbar in die Aufstellung dieser Kriterien die bisherigen Erfahrungen aus dem Filmexport in die besetzten Gebiete eingeflossen. Winkler sollte die Probleme der als ungeeignet befundenen Filme anschließend Goebbels vortragen. Letztlich war die Aufstellung der exportungeeigneten Filme als Hinweis für die deutsche Filmproduktion gedacht, zukünftig eine genügend hohe Anzahl an exportgeeigneten Filmen herzustellen. Für den Export nach Frankreich und in die übrigen besetzten Gebiete ungeeignet waren demnach sogenannte Aufruhr-Filme. Gemeint waren Filme über Freiheits- und Revolutionsthemen, welche die Auslandszensur und die deutsche vor Ort in allen von Deutschland besetzten Gebiete verbieten sollte. In diese Kategorie fielen bezeichnenderweise Filme über Probleme von Bevölkerungsminderheiten oder Filme „welche die Unterdrückung kleiner Völker durch große“ 462 behandelten. Als Beispiel wurden etwa „Heimkehr", „Feinde“, „Menschen im Sturm“ und „Friesennot" genannt. Da Propagandafilme wie „Ohm Krüger" und „Der Fuchs von Glenarvon“ die Unterdrückung eines Volkes zum Gegenstand hatten, wurden sie hier zwar als

460 Ibid.

461 PA-AA, 1125 b, Kult 12 Nr. 4, RMVP, Abteilung Ausland, Vertraulich, Die Lage des deutschen Films in Europa, Anfang 1943, 29. 3. 1943. Zu dem Aspekt exportgeeigneter Filme siehe bei DREWNIAK, Der deutsche Film, S. 693.

462 PA-AA, 1125 b, Kult 12 Nr. 4, RMVP, Abteilung Ausland, Vertraulich, Die Lage des deutschen Films in Europa, Anfang 1943, 29. 3. 1943. 
exportungeeignet bezeichnet. Weil sie anti-englische Propaganda enthielten, liefen beide Filme trotzdem im besetzten Frankreich. Des weiteren sollten auch Filme mit sogenannten Milieu-Entgleisungen für die meisten besetzten Gebiete und für Frankreich verboten werden. Gemeint war hier beispielsweise die negative Zeichnung italienischer Charaktere in deutschen Filmen, über die sich die italienische Botschaft in Berlin beschwert hatte. In diese Kategorie fielen „Die große Liebe“, „Die Nacht in Venedig“, „So gefällst Du mir" und "Liebesschule“. Abgesehen von der Rücksichtnahme auf sogenannte befreundete Länder sollten in den besetzten Gebieten auch keine deutschen Filme gezeigt werden, an denen die Kirche Kritik hätte üben können wie etwa Ehescheidungsdramen sowie die Verarbeitung von Themen wie Selbstmord und uneheliche Kinder. Der Bericht empfahl, die deutsche Filmproduktion solle vorzugsweise überhaupt keine Filme mehr mit versteckter Tendenz gegen die katholische Kirche herstellen. Auf dem europäischen Filmmarkt dürfe sich der deutsche Filmexport keinen Kampf mit der katholischen Kirche erlauben, denn diese verfüge immerhin über $180000000 \mathrm{Men}-$ schen in Europa. Zudem sollten die Verleihfirmen nur bedingt Filme über innerdeutsche Themen exportierten. Das RMVP sprach diesen von vornherein jeglichen Erfolg ab, da im Ausland das Interesse an diesen Inhalten fehle. Gemeint waren Filme über deutsche Künstler, Erfinder oder Produktionen mit ausgeprägtem Lokalkolorit wie „Hochzeitsnacht“, „Im Schatten des Berges“, „Der laufende Berg“, „Violante“, „Der Ochsenkrieg“, „Links der Isar, rechts der Spree“, „Männerwirtschaft“, „Der scheinheilige Florian“, „Das sündige Dorf“ und „Der verkaufte Großvater“. Auch karikierende Filme wie „Das leichte Mädchen“ und „Der Kleinstadtpoet" würden im Ausland, so das RMVP, häufig mißverstanden; dies bedeutete, daß sie kein gutes, sondern vor allem ein lächerliches Bild von Deutschland lieferten. Insbesondere für Frankreich sollten nach Meinung des RMVP vor allem die sogenannten Aufruhr-Filme sowie die Filme, an denen die katholische Kirche Anstoß nehmen könnte, verboten werden ${ }^{463}$.

Diese Hinweise zu exportungeeigneten Filmen waren jedoch nicht strenger Grundsatz der deutschen Filmprüfstelle in Paris, welche die deutschen Filme auf ihre politische Verträglichkeit für Frankreich prüfte. So mußte beispielsweise aus dem Film „Der Gasmann“ (Carl Froelich, 1941) mit Heinz Rühmann der sogenannte Hitlergruß, der von Willi Dohm in einer Szene geleistet wird, herausgeschnitten werden. Die Filmprüfstelle meinte, diese und andere Stellen könnten „einem mißgünstigen Publikum in Frankreich leicht zu Mißverständnissen Anlaß geben" ${ }^{464}$. Die Darstellung der Situation in Deutschland sei nicht positiv genug, da sich der Film zum Teil über Polizeiund Finanzbeamte im Reich lustig mache. Erst nach erneuter Prüfung ent-

${ }^{463}$ Ibid.

464 AN, AJ40 1005, Prop. Abt., Filmprüfstelle, Meldungen an den Leiter des Referats Film vom 6. 10. 1941 und vom 14. 10.1941. 
schied Kommandeur Schmidtke, den Film „Der Gasmann“ nach Herausschneiden der bemängelten Szene zuzulassen ${ }^{465}$. Schmidtke persönlich prüfte im Mai 1941 auch den Film „Bismarck“ (1940) von Wolfgang Liebeneiner: „Er wurde für Frankreich nicht zugelassen, da er eine Kenntnis deutscher Geschichte und der deutschen Vergangenheit voraussetzt, die bei Franzosen nicht vorausgesetzt werden kann" ${ }^{466}$. Schmidtke befürchtete, das französische Publikum könne den Film deshalb falsch verstehen und dieser einen unerwünschten Einfluß ausüben. Freilich war nicht nur die angebliche mangelnde Kenntnis deutscher Geschichte beim französischen Publikum für das Verbot ausschlaggebend. Außerdem dürfte hier auch die französische Sicht auf den historischen Stoff des Filmes eine andere gewesen sein ${ }^{467}$.

Die deutschen Verleihfirmen vertrieben vor allem solche Filme, die bereits in Deutschland erfolgreich waren, in der Hoffnung, Inlandserfolge würden auch zu Auslandserfolgen. Die Auslandsabteilung des RMVP konstatierte, grundsätzlich sei der Geschmack des in- und ausländischen Filmpublikums nicht sehr verschieden. Trotzdem seien im Inland erfolgreiche Filme nicht immer auch im Ausland erfolgreich ${ }^{468}$. Insbesondere drei Kategorien von Filmen waren nach Einschätzung des RMVP erfolgreich: sogenannte Starfilme mit den auch im Ausland beliebten Schauspielern, Filme von besonderer Qualität im Hinblick auf Stoff, Regie und Darstellung sowie Filme, deren Milieu nach Meinung des RMVP im Ausland gut ankam - etwa Musikfilme, Revue- und Zirkusfilme, Filmlustspiele, Filmkomödien, Ausstattungsfilme, Kriminalfilme, Abenteuer- und Sensationsfilme. Allerdings waren nur sehr wenige Produktionen gleichmäßig in allen Exportgebieten erfolgreich; das RMVP nannte diese Filme "Totalerfolge “469. Abgesehen von diesen Ausnahmen hatten in jedem der Gebiete unterschiedliche deutsche Filme Erfolge zu verzeichnen.

Nach den vom RMVP aufgestellten Hitlisten deutscher Filme stand beispielsweise der historische Kostümfilm „Tanz mit dem Kaiser“ (Georg Jacoby, 1941) mit Marika Rökk allein im besetzten Frankreich sowie im besetzten Belgien an erster Stelle. In Frankreich folgte dann „Eine Nacht im Mai“

465 Ibid.

466 BA-MA, RW35 221, Prop.Abt., Ref.Film, Tätigkeitsbericht, 22. 5.-28. 5. 1941. Ferner wurde der Film „Das unsterbliche Herz" für Frankreich nur zugelassen, falls die für Frankreich als untragbar bezeichneten Stellen und ein Teil der Szenen mit der Rede Luthers ausgeschnitten würden. Nicht zugelassen wurde auch der Film „Kampfgeschwader Lützow" (Ibid. Tätigkeitsbericht, 5. 6.-11. 6. 1941).

${ }_{467} \mathrm{Zu}$ Liebeneiners Interpretation deutsch-preußischer Geschichte durch den Film „Bismarck“ siehe bei KANZOG, Staatspolitisch besonders wertvoll, S. 235-245; laut Kanzog ist das zentrale Paradigma dieser Produktion „das Versagen des Parlaments und die zwingende Notwendigkeit autoritärer Staatsführung (mit permanenter Verunglimpfung der demokratischen Kräfte des Staates)" (Ibid, S. 244); siehe auch DREWNIAK, Der deutsche Film, S. $196 \mathrm{f}$.

468 PA-AA, 1125 b, Kult 12 Nr. 4, RMVP, Abteilung Ausland, Vertraulich, Die Lage des deutschen Films in Europa, Anfang 1943, 29. 3. 1943.

469 Ibid. 
(Georg Jacoby, 1938) ebenfalls mit Marika Rökk, „Herz der Königin“ (Carl Froelich, 1940), „Bel ami“ (Willi Forst, 1939) und Karl Antons „Weiße Sklaven" (lief auch unter „Panzerkreuzer Sewastopol“, 1937), ein anti-bolschewistischer Film ${ }^{470}$. In Belgien belegte dagegen „Wunschkonzert" (Eduard Borsody, 1940) Platz zwei gefolgt von „Annelie“ (Josef von Baky, 1941) und der „Opernball“ (Geza von Bolvary, 1939). Die Listen der zehn beliebtesten Filme - bezogen auf das Gesamtangebot - zeigten allerdings in Frankreich keinen einzigen deutschen Film. An erster Stelle stand der Fernandel-Film "La Fille du Puisatier“ (Marcel Pagnol, 1940), gefolgt von „Fièvres“ (Jean Delannoy, 1941), „Madame sans gêne“ (Roger Richebé, 1941) und „La Duchesse de Langeais" (Jacques de Baroncelli, 1941). Die Continental-Filme kamen erst dahinter: „Premier rendez-vous“ (Henri Decoin, 1941) belegte den siebten Platz, gefolgt von "Le Dernier des six“ (Georges Lacombe, 1941), "Symphonie fantastique“ (Christian-Jaque, 1941) und „Les Inconnus dans la maison" (Henri Decoin, 1941). In Belgien dagegen belegten die ContinentalFilme in der Gesamthitliste Platz eins bis vier und ab Platz sieben folgten "Wunschkonzert“, „Annelie“ und „Opernball“. Vor allem in Frankreich gaben die Zuschauer also den französischen Produktionen den Vorzug; das belgische Publikum sah in erster Linie französische, aber auch deutsche Filme. In Italien standen ebenfalls die Eigenproduktionen an erster Stelle, während in Holland fast nur deutsche Filme in der Hitliste vorkamen ${ }^{471}$. Besonders in Ländern mit einer ausgeprägten nationalen Filmproduktion wie im besetzten Frankreich und im verbündeten Italien war der Erfolg der deutschen Filme also grundsätzlich geringer, weil das Publikum die eigenen Produktionen bevorzugte.

Will man den Ausführungen des Referats Film der Propaganda Abteilung in Paris Glauben schenken, dann war die Resonanz des Publikums auf deutsche Produktionen und besonders auf Unterhaltungsfilme zumindest zeitweise in Frankreich relativ gut. Diese Einschätzung war sicherlich auch darin begründet, daß es zu Beginn der Besatzung an neueren französischen Produktionen mangelte. In einem Bericht über eine Tagung der Filmreferenten der Propaganda Staffeln vom Mai 1941 notierte das Referat Film: „Im allgemeinen ergab sich, daß deutsche Filme in allen Bereichen des besetzten französischen Gebietes in zunehmender Weise Verständnis beim französischen Publikum finden. Besonders beachtlich ist jedoch, daß der Wunsch nach unterhaltenden, leichten Filmen sehr stark ist" ${ }^{\text {472 }}$. Da der Bericht hier das angeblich wachsende Verständnis des französischen Publikums so betonte,

$470 \mathrm{Zu}$ dem Film, der in Finnland und der Schweiz von der Zensur verboten wurde, siehe Kapitel III. 2.2. dieser Arbeit.

471 PA-AA, 1125 b, Kult 12 Nr. 4, RMVP, Abteilung Ausland, Vertraulich, Die Lage des deutschen Films in Europa, Anfang 1943, 29. 3. 1943.

472 BA-MA, RW35 221, Prop.Abt., Ref.Film, Tätigkeitsbericht, 8. 5.-14. 5. 1941; Ausführungen zu einer Tagung der Filmreferenten der Propaganda Staffeln bei der Propaganda Abteilung am 14. 5. 1941. 
können die deutschen Filme demnach nicht sonderlich beliebt gewesen sein. Dem angeblichen Wunsch der Zuschauer nach leichten Stoffen lagen zudem auch deutsche Vorstellungen vom sogenannten leichten Wesen der Franzosen zugrunde. Nicht alle leichten deutschen Unterhaltungsfilme waren in Frankreich erfolgreich.

Ein Mißerfolg war beispielsweise die Ausstattungsoperette "Wiener Blut" (1942) von Willi Forst. Nach Drewniak war dieser Film generell in Deutschland und auch im Ausland zwar durchaus beliebt, stand jedoch im Schatten des in den dreißiger Jahren so erfolgreichen Filmes „Der Kongreß tanzt"; gemeinsam mit Willy Fritsch spielte in "Wiener Blut" nicht Lilian Harvey, sondern Maria Holst. Hans Moser und Theo Lingen waren für komische Einlagen engagiert ${ }^{473}$. In einem Bericht der ACE heißt es, „Wiener Blut" habe in Paris zunächst einige gute Ergebnisse erzielt. Grundsätzlich habe aber seinem Erfolg im Wege gestanden, daß das französische Publikum beim Klang des Titels an die vielen mittelmäßigen deutschen Filme über Wien-Themen habe denken müssen. Die Zuschauer seien dieser Stoffe nun überdrüssig474. Auch ein weiterer Bericht der ACE vom Frühjahr 1943 betont, das französische Publikum habe zwei Jahre lang Wien-Filme gesehen, weshalb dieser Markt nun gewissermaßen saturiert sei ${ }^{475}$. Im Falle des Filmes "Wiener Blut" war offenbar auch der französische Titel schlecht gewählt: Der Kritiker François Daudet schrieb in der Action Française, die wörtliche Übersetzung des Titels, „Sang Viennois“, suggeriere eher ein blutiges Drama „à la Mayerling " ${ }^{476}$ als ein Lustspiel. Dennoch waren dies in Daudets Augen die einzig korrekt übersetzten Worte des Filmes, den er zudem als schlecht synchronisiert bezeichnete. Die Worte der handelnden Personen hätten nur einen sehr entfernten Bezug zu ihren Lippenbewegungen und ihrer Mimik, so daß sie dem Publikum wie Bauchredner erschienen. Daudet verriß den Film also nicht aufgrund des Wien-Themas, sondern wegen dessen schlechter Qualität. Der Kritiker meinte weiter, die Produzenten hätten wohl einen luxuriösen, amüsanten Film drehen wollen, dessen ausladende Paläste erschienen jedoch wie aus Karton gefertigt und die Lustigkeit wirke künstlich. Die Zuschauer sollten „Sang Viennois“ rasch vergessen ${ }^{477}$. Die Presseabteilung der Reichsregierung war allerdings der Ansicht, diese Kritik sei allein deswegen so schlecht, weil die Action Française als katholisch beeinflußte Zeitschrift ihre ehemalige politische Propaganda nun auf den kulturellen Bereich über-

473 DREWNIAK, Der deutsche Film, S. $463 \mathrm{f}$.

474 PA-AA, 1114, Kult $12 \mathrm{Nr}$. 4g, ACE, Rapport sur la situation cinématographique en France en 1942, ohne Angabe von Datum und Autor; der Bericht wurde vermutlich von französischen Mitarbeitern der ACE verfaßt.

475 Ibid. ACE, Rapport de presse du mois de janvier et février 1943.

476 Gemeint war hier der Film "De Mayerling à Sarajevo“ (Max Ophüls, 1939).

477 PA-AA, Kult 12 Nr. 4 II, 1218, Fançois DAUDET, „Le Sang Viennois“", in: L'Action Française, 27. 9. 1942. 
trage ${ }^{478}$. Auch der Film „Anuschka“ von Helmut Käutner (1942) war in Frankreich erfolglos. Er handelte von einem slowakischen Bauernmädchen, gespielt von Hilde Krahl, das als Zimmermädchen im Wien der Jahrhundertwende arbeitete. Von der Auslandsabteilung im RMVP war der Film für Frankreich als exportungeeignet eingestuft worden, weil darin die Slowaken positiver dargestellt waren, als die Österreicher. Letztere galt es jedoch historisch zu würdigen, da sie Jahrhunderte lang „die einzigen deutschen Repräsentanten " 479 im Südosten Europas gewesen waren. Zudem war das RMVP der Ansicht, daß diese deutschen Darstellungen über ein sogenanntes Auslandsmilieu - in diesem Falle die Slowakei - im Ausland auf wenig Verständnis stoßen würden ${ }^{480}$. In der Pariser Filmpresse lauteten die Gründe für den Mißerfolg des Filmes allerdings ganz anders. Die Ciné-Mondial verfuhr mit dem Film relativ nachsichtig indem sie konstatierte: „Cela eut pu faire un excellent vaudeville. Ce n'est pas très amusant. Mais c'est souvent agréable, bien joué par Hilde Krahl“481. Die Zeitschrift Révolution Nationale hielt ihn als comédie de moeurs für unerträglich und schrieb, dem Film ermangele es letztlich an „piquant, sel, une aisance de tour“. Nach Ansicht von Paris Midi war die Geschichte zu naiv und unwahrscheinlich. Dieser leichte Film wurde in Frankreich also keineswegs als amüsant empfunden.

Zur gleichen Zeit lief auch der "Meineidbauer", „Paysan Parjure“, (1941) von Leopold Hainisch mit Otto Wilhelm Fischer in der Hauptrolle im Februar 1943 in den Pariser Uraufführungstheatern Biarritz und Le Français an. Die Darstellung eines Erbschaftsstreits, die nicht etwa als leichter Stoff zu bezeichnen ist, erhielt gute Pressekritiken. Beim Publikum hatte der Film jedoch keinen Erfolg, angeblich weil er der französischen Mentalität nicht genügend entsprach ${ }^{482}$. Offenbar war dies nicht nur in Frankreich der Fall, denn eine Schweizer Pressekritik bemerkte zu der Produktion: „Die geschlossene Enge des Bergmilieus, in dem der Film spielt, bedingt eine gewisse Beschränkung in den filmischen Mitteln, und die Eintönigkeit bringt es mit sich, daß man oft das Gefühl hat: diese Szene habe ich schon einmal gesehen" 483 . Ebenfalls als erfolglos und ungeeignet für die französische Mentalität bezeichnete das RMVP den Film „Annelie“ (1941) von Josef von Baky mit Luise Ullrich in der Hauptrolle. Der in Deutschland sehr erfolgreiche Film erhielt zwar in Frankreich gute Kritiken, wurde jedoch vom Publikum

478 Ibid. AA an DBP, 31. 10. 1942.

479 PA-AA, 1125 b, Kult 12 Nr. 4, RMVP, Abteilung Ausland, Vertraulich, Die Lage des deutschen Films in Europa, Anfang 1943, 29. 3. 1943.

480 DREWNIAK, Der deutsche Film, S. 693, zu „Anuschka“ siehe S. $416 \mathrm{f}$.

481 Dieses u. die folgenden Zitate siehe PA-AA, 1114, Kult 12 Nr. 4g, ACE, Rapport de presse du mois de janvier et février 1943.

482 Ibid. Der Film war die Adaptation eines Romans von Ludwig Anzengruber.

483 Der Filmberater, Luzern, Nr. 2, Februar 1942, zit. n. DREWNIAK, Der deutsche Film, S. 546. 
nicht angenommen ${ }^{484}$. Er zeigte 70 Jahre im Leben einer Frau, von der Gründung des Deutschen Reiches 1871 über das Erlebnis des Ersten und dem Beginn des Zweiten Weltkrieges bis hin zum Jahre 1941. Drewniak zählt den Film, zu den Schnulzen der Reihe von deutschen Filmen über die „Mütter der Nation “485. Der Film zielte vor allem auf die sogenannte Opferbereitschaft der deutschen Frauen im Kontext des Krieges. Seine Kernaussage spricht Annelie zu ihrer verzweifelten Schwiegertochter, die ihren Mann vermißt: „Man hält es aus, mein Kind. Glaub mir, man hält alles aus im Leben. Es ist nicht leicht, ich weiß. Aber man lernt's schon mit der Zeit. Weißt Du, der Schmerz gehört nämlich genauso zum Leben wie die Freude" ${ }^{\text {"486. Die }}$ ACE berichtete im Frühjahr 1943, „Annelie“ werde nun doch nicht in der ehemaligen unbesetzten Zone Frankreichs gezeigt ${ }^{487}$. Als ebenfalls erfolglos und ungeeignet für die französische Mentalität wurde „Une femme comme toi" mit Brigitte Horney gemeldet ${ }^{488}$.

Deutsche Filme, die in Frankreich relativ gut ankamen, waren nach Berichten des Referats Film „Operette“ (1940), „Bel ami“ (1939) und „Frauen sind keine Engel“ (1943) von Willi Forst, „Opernball“ (1939) von Geza von Bolvary mit Hans Moser, Theo Lingen und Paul Hörbiger, das Lustspiel "Sieben Jahre Pech“ von Ernst Marischka ebenfalls mit Hans Moser. Das Referat nannte auch „Romanze in Moll“ (1943), ein weniger leichtes Ehe- und Liebesdrama von Helmut Käutner mit Marianne Hoppe, Paul Dahlke und Ferdinand Marian. Die Filme waren zumeist in französischer Synchronisation $\mathrm{zu}$ sehen ${ }^{489}$. Um die Reaktion des Publikums auf deutsche Filme zu überprüfen, besuchte Referatsleiter Diedrich gelegentlich selbst einige Filmtheater. Am 19. Oktober 1941 wohnte er gleichsam incognito einer Vorstellung des Filmes „Operette“ im Filmtheater Le Français bei, das zu drei Vierteln besetzt gewesen sein soll. Seiner Beobachtung nach soll der Film dem Publikum gefallen haben ${ }^{490}$.

${ }^{484}$ PA-AA, 1114, Kult 12 Nr. 4g, ACE, Bericht über die Lage auf dem französischen Filmmarkt für die Monate März und April 1943, 21. 5. 1943.

485 DREWNIAK, Der deutsche Film, S. 255.

486 Zit. n. KANZOG, Staatspolitisch besonders wertvoll, S. 285, zu dem Film siehe S. 278-286; der Film erhielt das Prädikat „staatspolitisch wertvoll, künstlerisch wertvoll, volkstümlich wertvoll“".

487 R109I/515b, ACE, Bericht über das Geschäftsjahr 1941/42, mit Ausblick auf den 31. Mai 1943.

488 PA-AA, 1218, Kult 12 Nr. 4 II, DBP, Knothe an Greven, Continental, 23. 10. 1942.

489 BA-MA, RW35 221, Tätigkeitsbericht, 1. 5.-7.5.1941; 8. 5.-14. 5. 1941; 22. 5.-

29. 5. 1943; 4. 3.-10. 3. 1944. Diese Berichte enthalten Aufstellungen der Verleihprogramme der deutschen Firmen.

490 Ibid. RW35 224, Tätigkeitsbericht, 17. 10.-24. 10. 1941. Siehe auch DREWNIAK, Der deutsche Film, S. 186 f.: „Übrigens enthielt im Krieg fast jeder Unterhaltungsfilm mehr oder weniger subtile Steuerungsabsichten. Auch Spielfilme ganz leichten Zuschnitts wie ,Operette $[\ldots$...] entstanden unter dem Zeichen: Die Schaffenswelt seiner Helden ist vom Privaten nicht mehr zu trennen. Die Lenkungsabsichten lagen hier bei der Propagierung der guten Arbeit ${ }^{\alpha}$. Diese Propaganda war aber ähnlich wie die Propagierung 
Der Erfolg deutscher Filme in Frankreich hing unter anderem davon ab, welche Schauspieler in ihnen mitwirkten. Die Darsteller der deutschen Produktionen waren abgesehen von Stars wie Zarah Leander oder Hans Albers, die schon vor dem Kriege in Frankreich in deutschen Filmen zu sehen gewesen waren, relativ unbekannt. Das Referat Film notierte im Oktober 1941, der Besuch der Filmtheater sei allgemein gut und die Erfolge der deutschen Filme glichen sich langsam an die Erfolge französischer Produktionen an. Auch in dieser vorsichtigen Formulierung klingt wieder eher ein grundsätzlicher Mißerfolg der deutschen Filme an. Den Grund dafür lieferte das Referat im folgenden Satz: „Es muß dabei berücksichtigt werden, daß der Franzose alte französische Filme mit bekannten Darstellern wie Danielle Darrieux, Fernandel usw. bevorzugt, selbst wenn er sie schon zwei- oder dreimal gesehen hat “491. Allmählich steige aber die Zahl der Besucher bei Vorführungen deutscher Filme an. Schauspielerinnen wie Marika Rökk und vor allem Zarah Leander - sie sang ihre Lieder auch in Französisch - würden immer bekannter. Die Schwedin Zarah Leander, die das Pariser Publikum noch 1939 zusammen mit Hans Albers in dem Film „Heimat" (1938) von Carl Froelich hatte sehen können, war in Paris während der Okkupation mit den Filmen "Es war eine rauschende Ballnacht" (1939) und „Das Herz der Königin“ (1940) von Carl Froelich, „Der Weg ins Freie“ (1941), „Die große Liebe“ (1941/42) und „Damals“ (1943) von Rolf Hansen vertreten. Laut Darmon hatte ganz Frankreich ihr Lied "Le vent m'a conté une chanson", („Der Wind hat mir ein Lied erzählt"), aus „La Habañera", auf den Lippen ${ }^{492}$. Die Propaganda Abteilung schrieb im Mai 1941, die Anwesenheit Zarah Leanders zu Filmarbeiten in Paris habe unter der Bevölkerung Aufsehen erregt: „Zweifellos wird dieser Besuch wesentlich dazu beitragen, den Erfolg der Filme Zarah Leanders, die in Frankreich durchaus als deutsche Künstlerin angesprochen wird, noch zu verstärken “493. Die Schauspielerin weilte zu diesem Zeitpunkt in Paris, um „Herz einer Königin“ und „Weg ins Freie" zu synchronisieren ${ }^{494}$. Georges Blond betonte 1943 in den Deutsch-französischen Monatsbeften in seinem Bericht zur Pariser Filmsaison den Erfolg Zahrah Leanders in Paris ${ }^{495}$. La France Socialiste schrieb am 23. Januar 1943: „Zarah Leander a des dons d'expression particulièrement suggestifs et les vibrations de sa voix, au timbre d'une gravité rare, résonnent au fonds des cœurs lorsqu'elle

von Kinderfreudigkeit in anderen Unterhaltungsfilmen an das deutsche Publikum gerichtet.

491 BA-MA, RW35 224, Prop.Abt., Ref.Film, Tätigkeitsbericht, 24. 10.-31. 10. 1941. Zur Rezeption deutscher Filme im Ausland siehe auch DREWNIAK, Der deutsche Film, S. 693; demnach hingen Erfolge und Mißerfolge deutscher Filme vom Filmstoff und den darstellerischen Leistungen der Schauspieler ab.

492 DARMON, Le Monde du cinéma, S. 191.

493 BA-MA, RW4/v. 219, Prop.Abt., Lagebericht, 20. 5. 1941.

494 BA-MA, RW35 221, Prop.Abt., Ref.Film, Tätigkeitsbericht, 15. 5. 1941.

495 Georges BLOND, Pariser Theater- und Filmbericht, in: DFMH 3-5 (1943) S. 109. 
chante" ${ }^{496}$. Marc Blanquet betonte in einem Artikel des Le Matin vom 3. Februar 1943, gerade weil die Handlung des Filmes wahrend des Krieges spiele, finde der Zuschauer darin viele der Gemütszustände wieder, die momentan jeder in sich spüre: „Un grand amour ${ }^{`}$ est à coup sur un des meilleurs films que nous ait présenté, tout jeux et toute voix dehors, la grande, l'incomparable Zarah Leander"497. „Die große Liebe“ war in Deutschland ein großer Erfolg - bis zum Oktober 1944 hatten ihn dort 27,8 Millionen Zuschauer gesehen und er hatte etwa 9,2 Millionen Reichsmark eingespielt ${ }^{498}$. Als der Auslandsbeirat der deutschen Filmwirtschaft im Juli 1944 darüber beriet, welche Konsequenzen jüngste anti-deutsche Äußerungen Zarah Leanders in Schweden für den Vertrieb ihrer Filme haben sollten, kam er zu dem Schluß, eine Zurückziehung ihrer Filme könne schwerwiegende wirtschaftliche Konsequenzen haben. Die Filme mit Zarah Leander seien im Ausland Zugpferde, die den Vertrieb einer Vielzahl anderer Filme ermöglichten. Würden diese Filme also ausfallen, laufe das gesamte deutsche Verleihprogramm Gefahr, abgelehnt zu werden ${ }^{499}$.

Marika Rökk war nach Ansicht des Referats Film in dem glitzernden Revuefilm „Kora Terry“ (1940) von Georg Jacoby mit Will Quadflieg und Musik von Peter Kreuder besonders erfolgreich ${ }^{500}$. Zudem landete die deutsche Schauspielerin ungarischer Herkunft mit dem oben erwähnten Film „Tanz mit dem Kaiser" („La Danse avec l'empereur“) in Frankreich einen Erfolg. Im Mai 1942 lobte der Kritiker Arthur Hoérée sie für diesen Film. Sie tanze, singe, schauspielere und vereine damit in sich alle Qualitäten einer guten Filmschauspielerin. Trotzdem fand Hoérée ihre Schauspielkunst nicht sonderlich subtil: „Sans doute, son style ne recherche pas expressément les subtilités, son visage ne trahit pas toujours les états fugitifs d'une mouvante psychologie et les moyens qu'elle met en œuvre sont plus péremtoires que persuasifs" 501 . Diese negative Kritik milderte er mit der Begründung, sie habe dennoch Schwung und „des fourmis dans les jambes comme toute Hongroise possédée de danse". Hoérée betonte damit ihre ungarische Exotik im deutschen Film. Zu dem Stil des Filmes merkte der Kritiker an, dieser sei ein we-

496 PA-AA, 1114, Kult $12 \mathrm{Nr}$. 4g, ACE, Rapport de presse du mois de janvier et février 1943.

497 Ibid.

498 R109 III/3, Der Reichsbeauftragte für die deutsche Filmwirtschaft, Winkler an die Herren Firmenchefs und Produktionschefs der reichsmittelbaren deutschen Filmgesellschaften, Betr.: Gemeinsame Firmen- und Produktionschefsitzung v. 13. 11. 1944, 20. 11. 1944; Anlage, Direktor H. Zimmermann, Der Inlands-Filmvertrieb, SachstandsReferat während der Firmen- und Produktionschef-Sitzung am 13. 2. 1944, streng vertraulich.

499 R109 III/8, Protokoll Nr. 35/44 der Sitzung des Auslandsbeirates der deutschen Filmwirtschaft vom 18. 7. 1944, 20.7. 1944.

500 Zum Erfolg von „Kora Terry“ in Frankreich siehe BA-MA, RW35 223, Prop.Abt., Ref.Film, Tätigkeitsbericht, 22. 8.-29. 8. 1941.

501 BIFI, Arthur HoÉRÉ, La Danse avec l'empereur, in: Comœedia, 16. 5. 1942. 
nig langsam, die Handlung ziehe sich in die Länge, doch sei Georg Jacobys Regiearbeit sauber und technisch einwandfrei ${ }^{502}$. Dagegen hieß es in $\mathrm{La}$ Gerbe, Jacoby habe die Geschichte mit den reichen österreichischen und ungarischen Kostümen des 19. Jahrhunderts brillant inszeniert ${ }^{503}$. Auch Les Nouveaux Temps betonte die historische östereichisch-ungarische Szenerie ${ }^{504}$. Bei dem Film „Tanz mit dem Kaiser" - laut obigem Bericht des RMVP 1942 die erfolgreichste deutsche Produktion in Frankreich - hob die französische Presse also vor allem die ungarisch tanzende Hauptdarstellerin in teilweise ungarischer Kulisse hervor. Dies entsprach wohl kaum den Vorstellungen der Besatzer von der Wirkung deutscher Kulturpropaganda. Besonders beliebt war nach einem Bericht der ACE in Frankreich auch Ilse Werner ${ }^{505}$. Tatsächlich wurden relativ viele Filme mit ihr gezeigt, so beispielsweise der 1939 produzierte Ufa-Film „Fräulein“" von Erich Waschneck und „Wunschkonzert" (1940) von Eduard Borsody mit Carl Raddatz in der männlichen Hauptrolle. In "Wunschkonzert", an dessen Drehbuch Goebbels zum Teil mitgearbeitet haben soll, spielte Ilse Werner eine Frau, die jahrelang auf die Rückkehr eines jungen Fliegerleutnants wartete, was ihr in Deutschland die Bezeichnung „Durchhaltemieze“ einbrachte. Der Film, eine Mischung aus Unterhaltung und Propaganda, war mit 26 Millionen Zuschauern sehr erfolgreich in den deutschen Filmtheatern ${ }^{506}$. Goebbels bezeichnete ihn neben "Jud Süß" als "großen Nationalfilm"507 und guten Unterhaltungsfilm. Mit Ilse Werner liefen in Frankreich ferner „Die schwedische Nachtigall“ (1941) von Peter Paul Brauer mit Karl Ludwig Diehl und Joachim Gottschalk, „Wir machen Musik" (1942) von Helmut Käutner mit Victor de Kowa und „Münchhausen“ (1943) von Josef von Baky.

Das RMVP beobachtete den Beliebtheitsgrad deutscher Schauspieler im Ausland. Demnach waren Marika Rökk, Zarah Leander, Kristina Söderbaum, Hilde Krahl, Jenny Jugo und Ilse Werner am beliebtesten, während bei den männlichen Darstellern Emil Jannings, Heinrich George, Hans Albers, Paul Hartmann, Heinz Rühmann, Johannes Heesters, Ferdinand Marian, Carl Raddatz, Viktor de Kowa und Hans Söhnker an der Spitze standen ${ }^{508}$. Daran, daß deutsche Stars eine wesentliche Rolle für die Resonanz deutscher

502 Ibid.

503 BIFI, Hélène Garcin, La Danse avec l'empereur, in: La Gerbe, 14. 5. 1942.

504 BIFI, La Danse avec l'empereur, in: Les Nouveaux Temps, 9. 5. 1942. Marika Rökks Operettenfarbfilm „Die Frau meiner Träume“ (1944), bei dem ebenfalls Jacoby Regie führte, wurde allgemein im Ausland auch nach dem Kriege noch erfolgreich gespielt, siehe DREWNIAK, Der deutsche Film, S. 678.

505 PA-AA, 1114, Kult 12 Nr. 4g, ACE, Rapport sur la situation cinématographique en France en 1942. Siehe auch DREWNIAK, Der deutsche Film, S. 731.

506 Friedemann Beyer, Die Ufa-Stars im Dritten Reich, München 1991, S. 259.

507 Goebbels Rede anläßlich der Kriegstagung der Reichsfilmkammer am 15. 2. 1941 in Berlin, abgedruckt in: ALBRECHT, Nationalsozialistische Filmpolitik, S. 470.

508 DREWNIAK, Der deutsche Film, S. 693 f. 
Filme in Frankreich gespielt haben, erinnert sich die Pariser Schauspielerin Colette Brossart:

Le public boudait un peu les films allemands. On allait les voir parce qu'on aimait le cinéma. J'aimais bien Marika Rökk et Heinz Rühmann qui est un très grand comique allemand. On allait les voir, parce que c'étaient des bons acteurs. Le public est le public, dans tous les pays du monde. Malgré tout, quand un film était bon, le film était bon. On a vu „Le Baron Münchhausen“. C'etait un très bon film, très bien réalisé. C'était un des premiers films en couleurs, alors que les films français n'étaient pas encore en couleurs. La Ufa faisait des films superbes, seulement, les Français préferaient aller au théâtre pour voir des acteurs français. Quand le film était très beau ils y allaient. Quand on aimait bien, on allait même voir les films français fait avec l'argent allemand. On allait voir "Le Corbeau" de Clouzot par exemple. C'était un chef-d'œuvre quand même ${ }^{509}$.

Im französischen Publikum herrschte demnach zwar generell eine den deutschen Produktionen abgeneigte Stimmung; ein guter Film besetzt mit beliebten Stars hatte aber gute Chancen, beim Pariser Publikum anzukommen. Die französischen Zuschauer mieden deutsche Filme also nicht etwa vorwiegend aus politischen Gründen ${ }^{510}$. Colette Brossart erwähnt hier jedoch einen weiteren Anreiz, sich einige der deutschen Filme anzusehen: die Neuheit des Farbfilms.

Die Pariser Filmtheater zeigten die Farbfilme „Die goldene Stadt“ (1942), "Immensee“ (1943), „Opfergang" (1944) - drei Filme von Veit Harlan mit Kristina Söderbaum - „Das Bad an der Tenne“ (1943) von Volker Collande, sowie den oben erwähnten „Münchhausen“ und „Die Frau meiner Träume“. Der Erfolg, den besonders „Die goldene Stadt" und „Münchhausen“ im besetzten Frankreich hatten, war vor allem darin begründet, daß das Publikum neugierig auf die ersten Farbfilme war. In den Deutsch-französischen Monatsheften betonte Georges Blond, das von Harlan verwendete AgfacolorVerfahren gebe dem Zuschauer einen ganz anderen Blick auf die Welt und bedeute das Ende bisheriger schlechterer Versuche der Farbfilmherstellung. „Die goldene Stadt“ („La Ville dorée“) sei der Beginn einer „Kunst mit noch unabsehbaren Möglichkeiten“511. Die Premiere des Filmes fand am 19. März 1943 im Pariser Filmtheater Normandie statt. In der ersten Woche hatte er 33725 Besucher, in der zweiten 34571 und bis zur 8. Woche sanken die Besucherzahlen auf etwa 21000. Laut ACE waren diese Zahlen mit denen erfolgreicher französischer Filme wie „Le Comte de Monte Christo“ oder „Picpus“ vergleichbar. Der erfolgreiche Continental-Film „Les Inconnus dans la maison" hatte beispielsweise in der ersten Woche 31929 und in der zweiten 34484 Besucher zu verzeichnen 512 . Für „Die goldene Stadt“ hatte die ACE

509 Interview mit Colette Brossart und Ehemann Robert Dhéry, 26. 4. 1992, Paris.

510 Darmon, Le Monde du cinéma, S. 190, allg. zur Invasion des deutschen Films in Frankreich, wie Darmon es nennt, siehe ibid. S. 189-192.

511 Georges BLOND, Die Pariser Filmsaison, in: DFMH 6-8 (1943) S. 176.

512 PA-AA, 1114, Kult 12 Nr. 4g, ACE, Bericht über die Lage auf dem französischen Filmmarkt für die Monate März und April 1943, 21.5. 1943; zum Erfolg des Filmes 
besonders viel Werbung vor allem in größeren französischen Städten gemacht; diese wurde zum Teil mit Werbung zum 25jährigen Jubiläum der Ufa gekoppelt. Zusätzlich brachte die ACE anläßlich des Jubiläums in den größeren Städten vor allem „Die große Liebe" und "Tanz mit dem Kaiser" ins Programm. Eine gewaltige Plakat-Reklame unterstützte diese Aktionen und Radio Paris sowie die Pariser Zeitungen und Filmzeitschriften brachten große Berichte über den Film und das Ufa-Jubiläum. Die ACE meinte:

Zum ersten Male haben wir in der Reklame so stark den Wert des deutschen Charakters des Filmes zum Ausdruck gebracht, indem wir betont haben, daß dieser Film das Ergebnis von 25 Jahren Anstrengung und Arbeit bedeutet. Es ist jetzt bewiesen, daß das französische Publikum keine Antipathie gegen den deutschen Film hat, wenn es sich um einen Qualitätsfilm handelt ${ }^{513}$.

Einmal mehr wird mit dieser Erfolgsnachricht der ACE deutlich, daß das französische Publikum deutsche Filme tendenziell eher ablehnte; allein die deutschen qualitativ guten fanden demnach das Gefallen der französischen Zuschauer. In Deutschland war „Die goldene Stadt“ ein großer Erfolg. Kristina Söderbaum spielte darin ein unschuldiges und properes Bauernmädchen, das in Prag von ihrem Cousin (Kurt Meisel) verführt und geschwängert wurde und schließlich, vom Vater verstoßen, ins Wasser ging. Weil sie sich in mehreren ihrer Filme, so auch in "Jud Süß“, ertränkte, bezeichnete das deutsche Publikum die Schauspielerin als „Reichswasserleiche“. Daß die Pariser Presse - ebenso wie das französische Publikum - weniger an der Geschichte des Filmes, als an der Neuheit des Farbfilms interessiert war, geht auch aus einem Bericht des Referats Film hervor. Dieses betonte, die französische Kritik befasse sich fast ausschließlich mit dem verwendeten Agfacolor-Verfahren: „Das Film-Sujet wird in auffallender Weise kaum gestreift, wo es aber geschieht, als nichtssagend bezeichnet. Regie und Schauspiel finden eine mittelmäßige Beurteilung “514. Die Kritik zeigte sich zudem auch von der farbigen Prager Kulisse begeistert. Nach eingehenden Schilderungen über die Farben des Films schrieb Arthur Hoérée: „Prague prend l'aspect d'une évocation des mille et une nuits, rutilante d'une lumière irréelle, fantasmagorique " 515 .

Ebenfalls im Frühjahr 1943 lief Joseph von Bakys „Münchhausen“ („Les Aventures fantastiques du baron Münchhausen “) in Pariser Filmtheatern an. Die Produktion mit Hans Albers, Brigitte Horney und Ilse Werner war einer der wenigen phantastischen Filme, die im Dritten Reich gedreht wurden. Die Produktion, die in Deutschland gefeiert wurde, soll in Frankreich den Erfolg der "goldenen Stadt" sogar noch übertroffen haben ${ }^{516}$. Zudem war die Pari-

siehe auch BA-MA, RW35 227, Prop.Abt., Filmprüfstelle, Tätigkeitsbericht, 27. 6.3. 7. 1943; ibid. Tätigkeitsbericht, 10. 4.-18. 4. 1943.

513 PA-AA, 1114, Kult 12 Nr. 4g, ACE, Bericht über die Lage auf dem französischen Filmmarkt für die Monate März und April 1943, 21. 5. 1943.

514 BA-MA, RW35 227, Prop.Abt., Filmprüfstelle, Tätigkeitsbericht, 27. 3.-3. 4. 1943.

515 BIFI, Arthur HoÉrÉE, La Ville dorée, in: Comœdia, 27. 3. 1943.

516 DREWNIAK, Der deutsche Film, S. 731. 
ser Presse in diesem Fall auch von der Geschichte des Filmes angetan. Die Zeitung Demain schrieb: „Quel thème magnifique pour le Cinéma, que ces aventures fantastiques" ${ }^{517}$. Dieser so magische Film entführe den Zuschauer auf eine Reise durch eine wundersame Welt bis zum Mond, wo die Menschen mit ihren Köpfen unter dem Arm herumliefen. Hier helfe die Farbe nicht, eine Realität zu verstärken, sondern eine imaginierte Welt zu kreieren ${ }^{518}$. Die Flucht in eine phantastische Welt traf offenbar den Geschmack des Publikums auch noch zum Ende der Besatzungszeit. Im Februar 1944 schrieb François Vinneuil über den anhaltenden Erfolg des Films: „Le succès de Münchhausen auprès du public parisien est étourdissant et doit battre je ne sais combien de records. L'instinct du public, en l'occurence, est bon"519. Ein vergleichbarer Erfolg war freilich nur den wenigen deutschen Farbfilmen in Paris beschert.

Für den Mißerfolg deutscher Filme machten die Besatzer häufig die französische Mentalität verantwortlich. Dies war der Fall bei „Der Schritt vom Wege“ (1938) von Gustaf Gründgens mit Marianne Hoppe, Karl-Ludwig Diehl, Paul Hartmann, Käthe Haack und Elisabeth Flickenschild. Die Verfilmung von Fontanes „Effi Briest“ fand im Dritten Reich durchweg gute Kritiken ${ }^{520}$. Diedrich besuchte am 6. Mai 1941 die französische Uraufführung des Filmes, der in Originalfassung mit französischen Untertiteln gezeigt wurde: „Der Hauptfilm selbst fand beim Publikum kein Verständnis. Beim Verlassen des Filmtheaters konnte der Referatsleiter z. B. eine Äußerung wie folgt, hören: ,Der Film entspricht dem deutschen Gemüt, ist jedoch für das französische Volk unverständlich““521. Das Referat Film beobachtete fortwährend durch Kontrollen in den Theatern die Reaktion des Publikums auf die deutschen Filme ${ }^{522}$. Da diese Berichte für die vorgesetzten Dienststellen im Reich bestimmt waren, besteht freilich generell die Gefahr, daß sie in bezug auf die Erfolge deutscher Filme übertrieben. Umso interessanter ist es deshalb, daß etwa seit Ende des Jahres 1942 die positiven Schilderungen über die Rezeption deutscher Filme in Frankreich mehr und mehr durch Berichte über deren Mißerfolge abgelöst werden. So vermerkte das Referat Film noch im April 1941, deutsche synchronisierte Filme würden „eine außergewöhn-

517 BIFI, Une nouvelle féérie, Les aventures fantastiques du baron Münchhausen, in: Demain, 23. 4. 1943.

518 Ibid.

519 BIFI, François VINNEUIL, Les Aventures fantastiques du baron Münchhausen, in: Je suis partout, 18. 2. 1944; siehe auch ibid. Arthur HOÉÉE, Les Aventures fantastiques du baron Münchhausen, in: Comcedia, 4. 4. 1944.

520 DrewniaK, Der deutsche Film, S. 495. Der Film wurde in Deutschland am 9. 2. 1939 uraufgeführt und erhielt das Prädikat „künstlerisch wertvoll“.

521 BA-MA, RW35 221, Prop.Abt., Ref.Film, Tätigkeitsbericht, 1. 5.-7. 5. 1941. „Der Schritt vom Wege" soll laut Drewniak in Frankreich übrigens dennoch relativ gute Erfolge erzielt haben; DrEWNIAK, Der deutsche Film, S. 731.

522 BA-MA, RW35 220, Prop.Abt., Ref.Film, Tätigkeitsbericht, 20. 3.-26. 3. 1941. 
lich gute Aufnahme" 523 finden und eine Woche später heißt es, die deutschen Filme erfreuten sich eines überdurchschnittlichen Besuchs, das Publikum bezeichne sie als qualitativ besser als die französischen Filme ${ }^{524}$. Allerdings dürfte dieses Urteil kaum dem des französischen Publikums entsprochen haben. Ein Jahr später, im April 1942 bemerkte das Referat sogar, der deutsche Film gewinne mehr und mehr an Boden und allgemein verlaufe die Entwicklung befriedigend ${ }^{525}$. Die anschließenden vermehrten Klagen über Mißerfolge deutscher Filme sind fast immer verbunden mit Bemerkungen über Erfolge italienischer Produktionen. Im November 1942 heißt es: „Wie festgestellt wurde, haben die italienischen Filme in synchronisierter Fassung in Frankreich durchschnittlich einen sehr guten Erfolg "526. Die Besucherzahlen seien verglichen mit denen der deutschen, französisch synchronisierten Filme höher ${ }^{527}$. Goebbels schrieb am 23. April 1942 in sein Tagebuch:

Die italienischen Filme in Deutschland spielen viel mehr Geld ein, als die deutschen Filme in Italien. Die Ufa arbeitet einen neuen Exportplan aus, mit dem wir uns allmählich den gesamten italienischen Filmexport in Europa in die Hände spielen können. Hoffentlich fallen die Italiener darauf herein ${ }^{528}$.

Schilderungen zu Aktivitäten der italienischen Filmindustrie in Frankreich nehmen in den Berichten des Referats Film einen relativ großen Raum ein. Diese machen deutlich, daß in Frankreich eine große Konkurrenz zwischen den Filminteressen Italiens und Deutschlands bestanden hat, doch kann im Rahmen dieser Arbeit hierauf nicht näher eingegangen werden ${ }^{529}$. Zu Beginn der Okkupation waren nur sehr wenige italienische Filme in Frankreich zugelassen, was sich in der Folge jedoch änderte. Nach einem Bericht der Filmprüfstelle liefen im Jahre 1942 drei italienische Spielfilme in französischen Filmtheatern, in der folgenden Saison sollten es dreißig $\operatorname{sein}^{530}$. Als Grund dafür, daß deutsche Filme weniger erfolgreich waren als italienische, führte die Filmprüfstelle im Dezember 1942 an:

Es muß immer wieder festgestellt werden, daß die deutsche in Frankreich zum Verleih gebrachte Filmproduktion mit wenig Ausnahmen ungeeignet ist, kulturpolitisch für

523 Ibid. Tätigkeitsbericht, 17. 4.-24. 4. 1941.

524 Ibid. Tätigkeitsbericht, 25. 4.-30. 4. 1941.

525 BA-MA, RW35 225, Gr.Film, Tätigkeitsbericht, 18. 4.-25. 4. 1942.

526 BA-MA, RW35 227, Prop.Abt., Filmprüfstelle, Tätigkeitsbericht, 21. 11.-28. 11. 1942.

527 Zum deutschen Filmexport nach Italien siehe DREWNIAK, Der deutsche Film, S. 697-701.

528 LOCHNER, Goebbels Tagebücher, S. 171.

529 Zum Thema der italienischen Filminteressen in Frankreich während der Okkupation siehe grundlegend BA-MA, RW35 224, Prop.Abt., Ref.Film, die Tätigkeitsberichte, 28. 11.-5. 12. 1941, 12. 12.-19. 12. 1941 und 30. 1. 1942-6. 2. 1942 (RW35 225). Der Tätigkeitsbericht vom 28. 11.-5. 12. 1941 enthält einen ausführlichen Bericht zu den deutsch-italienischen Filmbesprechungen in München vom 24. 11.-27. 11. 1941. 530 BA-MA, RW35 225, Prop.Abt., Gr.Film, Tätigkeitsbericht, 20. 2.-27. 2. 1942. 
Deutschland zu werben, oder von dem geistigen Vermögen Deutschlands zu überzeugen ${ }^{531}$.

Zudem seien die Filme sogar in Bezug auf ihren Unterhaltungswert unbefriedigend. Die Resonanz selbst auf qualitativ schlechtere italienische Filme sei besser, weil jene der Schaulust, die in Frankreich gewünscht werde, näher kämen als deutsche Produktionen. In italienischen Spielfilmen seien auch französische Darsteller zu sehen, was sehr werbewirksam sei ${ }^{532}$. In einem Bericht vom März 1943 erwähnte die Filmprüfstelle erneut die positive Wirkung französischer Schauspieler im italienischen Film. Hauptgrund für den Mißerfolg der deutschen Filme im Vergleich zu den italienischen, sei ihr Abweichen von der französischen Mentalität ${ }^{533}$. Wenig später klagte die Filmprüfstelle, abgesehen von Spitzenfilmen, stehe das französische Publikum deutschen Filmen ablehnend gegenüber, und zwar nicht aufgrund der politischen $\mathrm{Hal}$ tung, sondern wegen der schlechten Qualität des Durchschnitts der deutschen Produktionen, die in Frankreich gezeigt werden ${ }^{534}$.

Die zunehmenden Klagen der Filmprüfstelle über die mangelnde Qualität der in Frankreich gezeigten deutschen Filme beinhalteten eine Kritik an der deutschen Filmexportpolitik. Im Sommer 1942 beschwerte sie sich darüber, die deutschen Verleihfirmen ACE und Tobis ließen die Filme schon vor der Zensur durch die Filmprüfstelle synchronisieren. Sie forderte mehr Verantwortung: „Hinsichtlich der Qualität der eingereichten deutschen Filme wäre aus kulturpolitischen Gründen wie aus Gründen des Ansehens des Reiches der Verzicht auf einen Film wertvoller, als das kommerzielle Interesse “535. Doch nicht nur die Filmprüfstelle, sondern auch die deutschen Verleihfirmen in Paris klagten über die schlechte Qualität der von ihnen vertriebenen deutschen Filme. Im März 1943 erhielten ACE und Tobis mit Emil Reinegger einen neuen Leiter, der in seinem Geschäftsbericht vom Juni 1944 die bisherige deutsche Verleihpolitik stark kritisierte. Er bemängelte die Qualität der nach Frankreich exportierten deutschen Filme, die seiner Ansicht nach entscheidend zum Mißerfolg des deutschen Films in diesem Lande beigetragen hatte: "Nicht die Anzahl ist maßgebend, sondern einzig und allein die Qualität" ${ }^{\text {536. }}$. $\mathrm{Da}$, so Reinegger, die Filmauswahl nicht sorgfältig genug gewesen sei, habe die ACE bisher vor allem für die französische Mentalität ungeeignete und qualitativ schlechte Filme vertrieben, was dem deutschen Film einen schlech-

531 BA-MA, RW35 227, Prop.Abt., Filmprüfstelle, Tätigkeitsbericht, 5. 12.-12. 12. 1942.

532 Ibid. Zu italienisch-französischen Koproduktionen während der Okkupation siehe BA-MA, RW35 224, Prop.Abt., Ref.Film, die Tätigkeitsberichte, 12. 12.-19. 12. 1941 und RW35 225, 30. 1. 1942-6. 2. 1942.

533 BA-MA, RW35 227, Prop.Abt., Filmprüfstelle, Tätigkeitsbericht, 27. 2.-6. 3. 1943.

534 Ibid. Tätigkeitsbericht, 27. 3.-3. 4. 1943.

535 Ibid. Prop.Abt., Filmprüfstelle, Tätigkeitsbericht, 1.6.-6.61942.

536 PA-AA, 1114, Kult 12 Nr. 4g, ACE, Emil Reinegger, Geschäftsjahr 1943/44, 1. 6. 1943-31. 5. 1944, Entwicklung des Verleihs deutscher und Continental-Filme in Frankreich, 2. 6. 1944. 
ten Ruf in den Augen des französischen Publikums eingebracht hätte. Deswegen zog Reinegger zu Beginn seiner Tätigkeit rund 56 Filme des deutschen Verleihprogramms aus dem Verkehr, da diese Produktionen dem Ansehen des deutschen Films nur schaden konnten. In diesen schwachen Filmen sah Reinegger auch den Grund dafür, daß die Theaterbesitzer sich im Falle der Programmierung deutscher Filme eher passiv verhielten:

Die Filme wurden vielfach nur deshalb abgeschlossen, weil ein gewisser Druck ausgeübt wurde. Dieses ungesunde und auf die Dauer unhaltbare System mußte geändert werden, denn die Verärgerung der Theaterbesitzer war groß und die Einnahmen mit vielen unserer Filme gering. Der deutsche Film wurde nicht mehr um seiner selbst willen gespielt, sondern, weil man eben auch hier und da deutsche Filme in das Programm aufnehmen mußte. Daß dies für uns nicht von Vorteil war und der Kulturpropaganda keineswegs diente, ist klar. Wir lassen unsere Filme aufführen, damit sich das Publikum dieselben ansieht, und das können wir nur erreichen, wenn die Auswahl unserer Produktion den hiesigen Ansprüchen einigermaßen genügt ${ }^{537}$.

Ähnlich wie die Funktionsträger im Bereich des Theaters hob Reinegger das anspruchsvolle französische Publikum hervor. Ebenso wie das deutsche Theater sollte der deutsche Film gleichsam um seiner selbst willen von den Besitzern der Filmtheater gespielt und vom Publikum anerkannt werden. Reinegger war der Ansicht, seine neue Verleihpolitik habe bereits erste $\mathrm{Er}$ folge gezeitigt, denn im Geschäftsjahr 1943/44 hatte die ACE trotz einer geringeren Anzahl von deutschen Filmen mehr Kopien ausgeliefert als im Geschäftsjahr 1942/43. Allerdings hatte der Umsatz nicht die gleiche Entwicklung genommen. Die Einnahmen der Filmtheater sanken generell aufgrund der zurückgehenden Anzahl an Vorstellungen, was durch die schlechte Elektrizitätslage sowie die Evakuierungen und Bombardierungen bedingt war. Während der Gesamtumsatz in Frankreich 1942/43 rund 236 Millionen Francs betrug, waren es 1943/44 etwa 207 Millionen. Reinegger bezifferte die Anzahl der französischen Filmtheater im Jahr 1942/43 auf etwa 3700 Filmtheater und der Anteil von ACE und Tobis an deren Programmierung betrug etwa 20 Prozent, im Geschäftsjahr 1943/44 waren es aufgrund der durch die Restriktionen bedingten Schließungen nur noch 3500 Filmtheater, der Anteil der deutschen Verleihfirmen an der Programmierung belief sich 35 Prozent ${ }^{538}$. Hierzu hatten allerdings die wenigen Farbfilme entscheidend beigetragen. Zum Schluß resümierte Reinegger:

Wir stehen und fallen mit der Qualität unserer Verleihprogramme, und es ist zu wünschen, daß die deutsche Produktion auch im kommenden Jahr in der Lage ist, uns Filme zur Verfügung zu stellen, die nicht nur unserem Geschäft, sondern auch der deutschen Kulturpropaganda im Ausland Nutzen bringen ${ }^{539}$.

Dieses Plädoyer für eine bessere Qualität deutscher Produktionen mutet rückblickend illusorisch an, denn Reinegger verfaßte diesen Bericht nur we-

537 Ibid.

538 Ibid.

539 Ibid. 
nige Tage vor der Landung der Alliierten in der Normandie. Gerade im Verlaufe des Jahres 1943 und im Frühjahr 1944 stellte die Weltkriegslage sowie die politische Lage in Frankreich ein weit größeres Problem für den deutschen Filmverleih als etwa die fehlende Qualität deutscher Filme dar.

$\mathrm{Daß}$ diese Faktoren mehr und mehr an Bedeutung gewannen, zeigen die Akten der ACE. Im Februar 1943 berichtete sie, der Einzug französischer Zwangsarbeiter zum Arbeitsdienst nach Deutschland sowie die Aktionen der französischen Polizei während der morgendlichen Filmvorstellungen beispielsweise in Bordeaux reduzierten die Zuschauerzahlen. Die Polizei hatte in den Filmtheatern Razzien veranstaltet, um französische Männer zum STO nach Deutschland einzuziehen. Aufgrund dieser Umstände wären in Städten wie Bordeaux auch für französische Filme fast bis zu 50 Prozent weniger Einnahmen zu verzeichnen ${ }^{540}$. Im März 1943 klagte die ACE in einem Schreiben an die Deutsche Botschaft über mehrere Brandanschläge, die auf ihre Filialen in der Provinz begangen worden waren und bat um mehr Schutz. In die Lyoner ACE-Filiale war im Februar 1943 eine Brandbombe geworfen worden, wenig später wurde eine weitere Bombe in das ACEFilmlager in Oullens geworfen. Während hier noch Mitarbeiter der ACE eingegriffen hatten, richtete bald darauf ein Brand in der Lyoner Filiale erheblichen Schaden an. Die Filiale in Toulouse erhielt Bombendrohungen ${ }^{541}$. Auch in dem oben zitierten Schreiben vom Juni 1944 schrieb Reinegger, die Rahmenbedingungen für das Geschäftsjahr 1943/44 seien wenig glücklich gewesen, da sich die politische und wirtschaftliche Entwicklung negativ auf das Verleihgeschäft ausgewirkt habe ${ }^{542}$. Offenbar konnten zum Ende der Besatzung selbst kostenlose Vorführungen deutscher Filme nicht zu deren Erfolg beitragen. Im März 1944 berichtete die Filmprüfstelle, daß die Propaganda Abteilung einige Gratisveranstaltungen mit deutschen Spielfilmen organisiert hatte, was den deutschen Verleihfirmen finanziell geschadet hätte: „Es entspricht im übrigen der Erfahrung der Filmprüfstelle, daß die Kulturpropaganda, die den Besucher einen Beitrag kostet, wirksamer ist, als Gratisvorführungen. Die deutschen Verleiher haben darüber hinaus noch die Aufgabe, für das Reich Devisen aufzubringen" 543 . Einmal mehr wird hier das Wechselspiel zwischen propagandistischen und ökonomischen Interessen deutlich.

Obgleich die deutschen Funktionsträger durchaus auch unterschiedlicher Ansicht darüber waren, welche deutschen Filme - in welcher Qualität und Quantität - nach Frankreich exportiert werden sollten, kann die deutsche Filmexportpolitik im Vergleich zum Theater dennoch als relativ einheitlich

540 PA-AA, 1114, Kult 12 Nr. 4g, ACE, Rapport de presse du mois de janvier et février 1943.

541 PA-AA, 1143b Kult 12 Nr. 4, ACE, an Knothe, DPB, 15. 3. 1943.

542 PA-AA, 1114, Kult 12 Nr. 4g, ACE, Emil Reinegger, Geschäftsjahr 1943/44, 1. 6. 1943-31. 5. 1944, Entwicklung des Verleihs deutscher und Continental-Filme in Frankreich, 2. 6. 1944.

543 AN, AJ40 1001, Prop.Abt., Filmprüfstelle, Tätigkeitsbericht, 26.2.-4.31944. 
bezeichnet werden. Auch waren hier Kompetenzstreitigkeiten keineswegs so ausgeprägt wie im Bereich des Theaters. Sie lassen sich vor allem für den Bereich der Filmwerbung in Frankreich belegen. Um die Werbung für deutsche Filme zu gewährleisten, kontrollierte die Propaganda Staffel die Pariser Filmpresse. Zudem sorgte das Referat Film für umfangreiche Vorankündigungen deutscher Filme in der Presse, noch bevor diese anliefen. Zu den Erfolgen der Beeinflussung der Filmpresse berichtete das Referat Film im April 1941: „Die Vorpropaganda für deutsche Filme macht im ganzen besetzten Frankreich weitere Fortschritte. Die französischen Zeitungen berichten in verstärktem Maße über die deutschen Filme. Die Schriftleiter der maßgebenden Zeitungen werden zu Erstaufführungen nunmehr eingeladen"544. Dieses Resultat mag kaum erstaunen, wenn man bedenkt, daß Anträge auf erneute oder weitergehende Herausgabe von Filmzeitschriften nur dann genehmigt wurden, wenn auf seiten der Besatzer ein besonderes propagandistisches Interesse bestand ${ }^{545}$. Im April 1941 lehnte das Referat Film beispielsweise die Genehmigung der Herausgabe von Le Film européen, Bordeaux ciné und La Semaine cinématographique $\mathrm{ab}^{546}$. Stattdessen genehmigte es im Einvernehmen mit der Deutschen Botschaft die Filmzeitschrift Ciné-Mondial des Verlages Le Pont, der über Strohmänner im Besitz der Botschaft war. Hauptschriftleiter und späterer Geschäftsführer war Robert Muzard. Dieser war außerdem Geschäftsführer der ebenfalls im Besitz der Botschaft befindlichen Zeitschrift Vedettes, die neben Filmthemen auch über Theater, Radio und Music-Halls berichtete ${ }^{547}$.

Muzard sollte eine positive Berichterstattung der Ciné-Mondial über deutsche Filme garantieren. Diese erhielt offiziell die Aufgabe, der sogenannten deutsch-französischen Zusammenarbeit im Filmbereich zu dienen ${ }^{548}$, was freilich auf eine verstärkte Werbung für den deutschen Film hinauslief. Die Continental Films, ACE, Tobis und die Pariser Außenstelle der Deutschen Wochenschau sollten zu diesem Zweck mit dem Hauptschriftleiter ständig Kontakt halten. Außerdem sollten wöchentlich wichtige Angelegenheiten mit dem Referat Film besprochen werden, das für die Zensur sämtlicher Artikel zuständig war ${ }^{549}$. Die erste Ausgabe erschien am 8. August $1941^{550}$. Allerdings verlief in der Folge die Werbung für deutsche Filme nicht so reibungslos, wie das zu Anfang geplant war. Grundsätzlich hatte das RMVP keineswegs befürwortet, daß Ciné-Mondial und Vedettes über Stroh-

544 BA-MA, RW35 220, Tätigkeitsbericht, 17.4.-24. 4. 1941; zur Beeinflussung der Pressekritiken und Ankündigungen deutscher Filme siehe auch RW35 224, Tätigkeitsbericht, 24. 10.-31. 10. 1941.

545 BA-MA, RW35 220, Ref.Film, Tätigkeitsbericht, 13. 3.-19. 3. 1941.

546 Ibid. Tätigkeitsbericht, 3. 4.-10. 4. 1941.

547 Zur Person von Muzard, dem Leiter der Nova-Films, die unter deutschem Einfluß französische Propagandafilme herstellte, siehe Kapitel III. 2.3. dieser Arbeit.

548 BA-MA, RW35 222, Ref.Film, Tätigkeitsbericht, 2. 7.-9. 7. 1941.

549 Ibid.

550 Ibid. Tätigkeitsbericht, 1.8.-7.81941. 
männer in den Besitz der Botschaft gelangten. Das RMVP kritisierte vor allem, die Zeitschriften verfolgten rein kommerzielle Zwecke und machten nicht genügend Werbung für deutsche Filme. Das Propagandaministerium war zudem generell gegen finanzielle Beteiligungen der Botschaft im französischen Filmbereich eingestellt ${ }^{551}$. Der Vorwurf, diese Zeitschriften würden nicht genügend für deutsche Filme werben, ging jedoch vor allem von Alfred Greven aus, da dieser gerne beide Zeitschriften unter eigener Kontrolle gehabt hätte. Daher gab die Continental Films im Februar 1943 eine Studie in Auftrag, die ermittelte, wie oft und in welcher Form die besagten Zeitschriften 1942 für deutsche Filme geworben hatten ${ }^{552}$. Die Untersuchung ergab, daß die insgesamt 45 Nummern der Ciné-Mondial generell 58 Prozent Werbung und 42 Prozent Redaktion enthielten. Deutsche Filme erschienen 14 Mal auf der Titelseite, französische $19 \mathrm{Mal}$ und Continental-Filme $10 \mathrm{Mal}$, italienische nur 2 Mal. In allen Ausgaben waren 1942 immerhin 83,5 Seiten dem deutschen Film gewidmet, 129,5 dem französischen, allerdings nur 25 Seiten den Produktionen der Continental und 10 Seiten den italienischen Filmen. In den 50 Heften von Vedettes waren 1942 nur 32 Prozent der Zeitschrift für Filmwerbung reserviert; 4,4 Prozent beinhaltete Werbung für deutsche Filme, die für italienische Filme betrug 2,5 Prozent während die Werbung für französische Filme 23,2 Prozent umfaßte, für ContinentalFilme aber nur 3 Prozent. Immerhin waren aber deutsche Filme $12 \mathrm{Mal}$ auf der Titelseite erschienen, französische $17 \mathrm{Mal}$ und Continental Filme 8 $\mathrm{Mal}^{553}$. Die Ciné-Mondial warb demnach durchaus in einem angemessenen Umfang für deutsche Filme - verglichen mit der Werbung für französische Filme, die ja die Leser weit mehr interessierten; schließlich mußte die Zeitschrift auch die Wünsche ihrer Kunden berücksichtigen. Dagegen hatte sie aber vor allem die Werbung für die Continental-Filme vernachlässigt, was erklärt, weshalb Greven diese Studie in Auftrag gegeben hatte.

In der Folge versuchte Greven, die Botschaft davon zu überzeugen, ihm persönlich die geschäftliche und redaktionelle Leitung beider Zeitschriften zu übergeben. Greven wollte diese inhaltlich nach den Richtlinien des RMVP ausrichten und geschäftlich führen. Schließlich behauptete er, die Zusage der Botschaft in einem Gespräch mit Geheimrat Dr. Schwendemann erhalten zu haben ${ }^{554}$. Einige Monate später fragte Greven erbost an, weshalb die Übergabe der Leitung der Zeitschriften an ihn noch immer nicht vollzogen sei. In seiner Funktion als Reichsbeauftragter der Deutschen Filmwirtschaft in Frankreich vertrete er doch die gleichen Interessen wie die Botschaft. Er habe

551 PA-AA, 1113 Kult 12 Nr. 4, RMVP, Fries, Vermerk, Abschrift an Abteilung Ausland, RMVP, 31. 3. 1943.

552 PA-AA, 1125 b, Kult 12 Nr. 4, Continental, Greven an Knothe, DBP, 16. 2. 1943. 553 Ibid. A. Paullet, Rapport sur la publicité concernant les films allemands, italiens, français et Continental-Films parue dans Ciné Mondial et Vedettes, 16. 2. 1943.

554 PA-AA, 1143a, Kult 12 Nr. 4, Continental, Greven an Knothe, DBP, 22. 6. 1943; Anlage, Aktennotiz vom 22.6. 1943. 
den Auftrag, in Frankreich eine Filmzeitschrift zu erwerben oder zu gründen und werde nun auch ohne Entscheidung der Botschaft handeln. Greven beabsichtigte, ein eigene Zeitschrift zu gründen, um daraufhin den Zeitschriften der Deutschen Botschaft jede Existenzgrundlage zu nehmen. Dem fügte er hinzu: "Ich bedauere außerordentlich, daß dann durch das Verschulden der Deutschen Botschaft zwei deutsche Stellen sich hier Konkurrenz machen auf einem Gebiet, welches wohl dem Propagandaministerium alleine zusteht ${ }^{\text {“555. }}$. Allerdings behauptete Schwendemann seinerseits, Greven die Übernahme der beiden Filmzeitschriften nicht zugesagt zu haben. Er hatte lediglich vorgeschlagen, einen Beauftragten für die Filmzeitschriften zu benennen, der Grevens Wünsche hinsichtlich der Filmwerbung in Zukunft vertreten solle. Dies sei bisher nicht geschehen ${ }^{556}$. Greven beharrte jedoch auf seiner Position und äußerte die Ansicht, innerhalb der Botschaft liege ein organisatorischer Fehler vor, da er mehrmals mit Knothe über diese Frage verhandelt habe und Schwendemann davon gewußt haben müsse ${ }^{557}$. Abgesehen von den direkten Angriffen auf die Botschaft hatte Greven zunächst auch versucht, sein Ziel durch weitere Kritik an der Arbeit der Zeitschriften zu erreichen. So behauptete er, diese lieferten zu wenig Werbung für deutsche Filme und veranlaßte die ACE und Tobis dazu, ihre Verträge für Anzeigen bei der CinéMondial zu kündigen; nach diesen Verträgen hatte die Zeitschrift bisher pauschal und zu günstigen Tarifen Werbung für deutsche Filme gemacht. Die Botschaft vermutete dahinter zu recht einen weiteren Schachzug Grevens, um den Beweis führen zu können, die Zeitschrift berichte zu wenig über deutsche Filme. Nach Kündigung der Verträge, so die Botschaft, werde die Ciné-Mondial sicher nur noch ungern deutsche Filme besprechen 558.

In jedem Falle verhinderte dieses Vorgehen zunächst einmal jedwede Werbung für deutsche Filme in der Zeitschrift. Chefredakteur Pierre Heuzé verteidigte die fehlende Werbung für deutsche Filme mit dem Argument, ACE und Tobis hätten bisher zu spät und zu wenig Werbematerial für ihre Filme zugesandt. Er habe sich an die Werbeleiter der beiden Firmen gewandt, die jedoch betonten, sie wünschten keinen Kontakt mehr mit der Ciné-Mondial. Seit Erscheinen der ersten Nummer dürften deren Redakteure die Studios der Continental nicht einmal betreten. Dagegen seien die französischen Firmen Pathé und Gaumont weitaus kooperativer ${ }^{559}$. Die Deutsche Botschaft stellte sich auf die Seite Heuzés und war der Ansicht, Greven versuchte absichtlich der Zeitschrift zu schaden. Die Botschaft betonte die Zuverlässigkeit Heuzés in jeder Hinsicht - der Journalist galt als deutschfreundlich. Im

555 PA-AA, 1113 Kult 12 Nr. 4, Continental, Greven an Geheimrat Dr. Schwendemann, DBP, in Kopie an Knothe, 8. 10. 1943.

556 PA-AA, 1113 Kult 12 Nr. 4, DBP, Schwendemann an Greven, Continental, 9. 10. 1943.

557 Ibid. Continental, Greven an Schwendemann, DBP, 14. 10. 1943.

558 Ibid. DBP, Hibbelen an Schwendemann, Betr.: Herrn Greven, 5. 7. 1943.

559 Ibid. Ciné Mondial, Heuzé an Hibbelen, DBP, 16. 7. 1943. 
März 1942 hatte Heuzé als Journalist eine Gruppe von französischen Filmschauspielern nach Deutschland begleitet und war dort unter anderem auch von Goebbels empfangen worden. Die ACE behauptete wiederum, es handle sich um ein Mißverständnis, denn sie habe der Ciné-Mondial stets Werbematerial zur Verfügung gestellt ${ }^{560}$. Im November 1943 beschwerte sich die ACE ihrerseits bei der Botschaft, die Zeitschrift weigere sich, für den anlaufenden Film „Münchhausen“ auf der Titelseite zu werben, obwohl sie dazu genügend Material erhalten hatte ${ }^{561}$. Schließlich erschien der Artikel dort relativ spät ${ }^{562}$. Obgleich Greven in der Folge nicht, wie angekündigt, eine eigene Konkurrenz-Zeitschrift gründete und die Ciné-Mondial auch nicht vollkommen ihre Werbung für deutsche Filme einstellte, so zeigt dieser Vorgang dennoch, wie stark die von den deutschen Dienststellen verfolgte Politik der Werbung für deutsche Filme durch Konkurrenz und Streitigkeiten behindert wurde. Offenbar bot auch der Besitz der beiden Filmzeitschriften durch die Botschaft noch lange keine Garantie für eine intensive Werbung für deutsche Filme.

Die deutsche Filmexportpolitik in Frankreich war grundsätzlich nicht Gegenstand von Konkurrenzkämpfen, zumal die Kompetenzen klarer verteilt waren als etwa im Bereich des Theaters. Der Vertrieb der deutschen Filme lag in den Händen der Verleihgesellschaften ACE und Tobis, während die Filmprüfstelle die politische Zulässigkeit der Filme für Frankreich prüfte. Die Verleihgesellschaften hielten engen Kontakt mit Greven, der Propaganda Abteilung sowie der Deutschen Botschaft; die deutschen Dienststellen und Funktionsträger flankierten gleichsam den Vertrieb deutscher Filme durch Maßnahmen wie der Marktbereinigung, des Ankaufs von Filmtheatern, der Ausübung von Druck auf französische Filmtheaterbesitzer und der Werbung für deutsche Filme in der Presse. Diese Politik war weitaus rigoroser, planvoller und auf den ersten Blick auch erfolgreicher als die im Bereich des Theaters verfolgte Kulturpropaganda.

Die deutschen Stellen verfolgten etwa bis 1943 hier erfolgreich eine Politik, die eine möglichst hohe Anzahl deutscher Filme in französischen Filmtheatern zum Ziele hatte. Diese Filme erzielten allerdings bis auf wenige Spitzenfilme verglichen mit den Continental-Filmen und den französischen Produktionen relativ geringe Umsätze. Das Publikum zog französische Filme vor, denn immerhin war Frankreich trotz der Krise des französischen Films während der dreißiger Jahre ein Land mit einer eigenen hochentwickelten Filmindustrie; die Zuschauer waren an die heimischen Produktionen und die französischen Stars gewöhnt. Seit 1943 klagten die Verleihgesellschaften vermehrt über die fehlende Qualität der exportierten deutschen Filme, was den

560 PA-AA, 1113 Kult 12 Nr. 4, ACE an Heuzé, in Kopie an Knothe, 2. 8. 1943; ibid. ACE, Grell an Knothe, DBP, 2. 3.1944.

561 Ibid. ACE an Knothe, DBP, 17. 11. 1943.

562 Ibid. ACE an Ciné Mondial, ohne Angabe von Datum und Autor (etwa Februar/ März 1944). 
Konflikt zwischen propagandistischen und ökonomischen Interessen deutlich macht. Zur Amortisierung deutscher Filme war es theoretisch sinnvoll, ein Maximum zu exportieren; im Hinblick auf deutsche Kulturpropaganda sollten aber vor allem die besten Filme nach Frankreich gelangen. Auch der durch Marktbereinigung und den Ankauf der Filmtheater künstlich erhöhte Anteil deutscher Filme am Gesamtmarkt führte also nicht zum Erfolg des deutschen Films in Frankreich, da die Filme das ohnehin reservierte Publikum nicht überzeugen konnten. Das Ziel deutscher Kulturpropaganda, das französische Publikum von der angeblich so hohen Qualität der deutschen Kultur zu überzeugen, wurde im Bereich des Filmes also erst in den letzten Jahren der Besatzung gezielter verfolgt, und zwar als die deutschen Dienststellen beim Publikum mehr und mehr die Unbeliebtheit der deutschen Filme beobachteten.

Den Erfolgen einiger herausragender Farbfilme wie "Münchhausen" oder "Die goldene Stadt" standen etliche Mißerfolge deutscher Produktionen gegenüber. Sicherlich haben hier nicht nur die angeblich so schlechte Qualität deutscher Filme, sondern auch die französische und italienische Konkurrenz sowie Mentalitätsunterschiede eine Rolle gespielt. Die Resonanz auf das Gros der deutschen Filme verschlechterte sich zudem seit Ende des Jahres 1942 immer mehr. Ebenso wie im Bereich des Theaters, wo die Theaterdirektoren immer weniger zur Aufführung deutscher Stücke bereit waren, führte auch im Bereich des Filmes die veränderte Weltkriegslage und die politische Situation in Frankreich zu einer Verschlechterung der Resonanz auf deutsche Filme. Außerdem gelangten seit der Wiederaufnahme der französischen Filmproduktion im Frühjahr 1941 neue französische Produktionen - während der gesamten Zeit der Okkupation waren es über 200 - in die Pariser Filmtheater, die das Publikum vorzog.

\subsection{Propagandistischer Filmeinsatz}

Vor allem die Propaganda Abteilung aber auch die Botschaft waren mit Aktivitäten im Bereich der Propaganda befaßt. Über Vorträge, Ausstellungen, Plakate, Handzettel, Broschüren, Presseartikel sowie den Rundfunksender Radio Paris verbreitete die Besatzungsmacht in Frankreich deutsche Propaganda - die Filmpropaganda stellte hier nur einen Aspekt dieser Politik dar ${ }^{563}$. Weil die deutschen Dienststellen negative Reaktionen der Zuschauer während der Vorstellungen in den Filmtheatern befürchteten, handhabten sie gerade die Filmpropaganda in Frankreich grundsätzlich mit Vorsicht. Die deutschen Propagandafilme - zumindest die Spielfilme - produzierte die deutsche Filmindustrie in erster Linie für das deutsche Publikum; sie sollten im Inland ihre spezifische Funktion erfüllen. Im Ausland übernahmen die 1991, S. 49-77; UMBREIT, Der Militärbefehlshaber, S. 150-171. 
Verleihfilialen der Ufa den Vertrieb der Propagandafilme, wobei deren Einsatz jedoch vor allem vom RMVP und der Propaganda Abteilung geplant wurde. Erst im Sommer 1944 konstatierte der Auslandsbeirat der deutschen Filmwirtschaft in einem Sitzungsprotokoll, die Errichtung einer sogenannten Auslandsvertriebsstelle für Propagandafilme sei nun dringlich ${ }^{564}$.

Die Hauptthemen der deutschen Propaganda - wie sie vor allem in großen Plakataktionen verbreitet wurden - sind auch Gegenstand einiger Propagandafilme gewesen. Zunächst einmal betrafen diese Themen die sogenannten Feinde des Reiches: Seit Beginn der Besatzung nahm die anti-englische Propaganda einen großen Raum ein, zu der seit Ende 1941 eine anti-amerikanische Richtung hinzu kam. Die anti-englische Propaganda war mitunter auch gekoppelt an anti-jüdische, letztere dominierte die Themen der deutschen Propaganda und wurde im Vorfeld der Einführung des Judensterns im Sommer 1942 noch verstärkt. Seit dem Überfall auf die Sowjetunion im Sommer 1941 betrieben die deutschen Dienststellen verstärkt anti-kommunistische bzw. anti-bolschewistische Propaganda. Demnach führte Deutschland einen Krieg, um Europa vor dieser sogenannten Gefahr zu retten. Ein weiteres wichtiges Anliegen deutscher Propaganda war die Demonstration deutscher Stärke und Siegesgewißheit, ebenso wie die angebliche Überlegenheit des "neuen Deutschland“ in allen Bereichen des sozialen, wirtschaftlichen und auch kulturellen Lebens ${ }^{565}$.

Der wohl bekannteste unter den in Frankreich gezeigten abendfüllenden Propagandafilmen ist "Jud Süß" (1940) von Veit Harlan. Seine französische Uraufführung in synchronisierter Fassung war am 14. Februar 1941 im Pariser Filmtheater Le Colisée zu sehen. Der Film soll in Frankreich angeblich ebenso erfolgreich wie „Die goldene Stadt" gewesen sein ${ }^{566}$. Goebbels selbst hatte diesen stark anti-jüdischen Film in Auftrag gegeben. Das Drehbuch stammte von Ludwig Metzger und Wolfgang Möller. Die Geschichte Joseph Süß Oppenheimers, 1732-1737 Finanzberater und sogenannter Hofjude beim Herzog von Württemberg, der gehenkt worden war, weil er das Volk wegen seiner Steuerpolitik gegen sich aufgebracht hatte ${ }^{567}$ war bereits von Wilhelm Hauff (1827) und Lion Feuchtwanger (1925) literarisch bearbeitet worden. Doch orientierte sich das Drehbuch kaum an diesen Vorlagen ${ }^{568}$.

564 BA-KO, R 109 III/8, Protokoll Nr. 35/44 der Sitzung des Auslandsbeirates der deutschen Filmwirtschaft vom Dienstag, dem 18. 7. 1944, 20. 7.1944.

565 Siehe allg. bei Rosssignol, Histoire de la Propagande, S. 62-65.

566 DreWNIAK, Der deutsche Film, S. 731; zu dem Film siehe bei KANZOG, Staatspolitisch besonders wertvoll, S. 219-234; auch bei DreWNIAK, Der deutsche Film, S. 312316. Als weiterer anti-jüdischer Spielfilm wurde „Die Rothschilds“ (1941) von Erich Waschneck mit Erich Ponto, Albert Lippert, Hilde Weißner und Gisela Uhlen in Frankreich gezeigt; doch bereits in Deutschland hatte dieser Film keinen großen Erfolg; siehe DREWNIAK, Der deutsche Film, S. 312.

$567 \mathrm{Zu}$ Joseph Süß Oppenheimer siehe Hellmut G. HaAsIs, Joseph Süß Oppenheimer, genannt Jud Süß. Finanzier. Freidenker. Justizopfer. Reinbek bei Hamburg 1998.

${ }_{568}$ Zum verwendeten literarischen Material siehe bei KANZOG, Staatspolitisch beson- 
Der Film erhielt im Reich die Prädikate „staatspolitisch und künstlerisch besonders wertvoll“" sowie ,jugendwert". Drewniak schreibt zu "Jud Süß“: „Harlans Film machte Süß zum Prototyp des verbrecherischen Juden" ${ }^{\text {"569. }}$ Goebbels, der die Herstellung von "Jud Süß" laufend verfolgt hatte, lobte ihn als ersten wirklich antisemitischen Film und meinte, die Endfassung sei genial. Zu seinem Erfolg im Ausland notierte er, der Film sei in Ungarn besonders gut aufgenommen worden und nahm dies als Beweis der Wirkkraft der Propaganda. Gleichwohl konnte der Film vor allem deswegen Erfolge verzeichnen, weil er in erster Linie vom Publikum als melodramatische Unterhaltung aufgefaßt wurde ${ }^{570}$. Nach der französischen Uraufführung im $\mathrm{Fe}$ bruar 1941 meinte die Zeitschrift Le Film: „Le sujet authentique, la réalisation somptueuse faite avec art et conscience, l'interpretation enfin font de ce film une très grande œuvre, peut-être la plus grande qu'il nous eut été donné de voir depuis longtemps" $" 571$. Der Autor lobte die Machart des Films, die Regiearbeit und das Spiel der Schauspieler; das Thema bezeichnete er als authentisch. Einige Monate später zeigten auch Filmtheater im unbesetzten Gebiet „Jud Süß“. Ende April 1941 berichtete das Referat Film über seinen "sensationellen, durchschlagenden Erfolg " ${ }^{572}$ in Marseille. Zur gleichen Zeit lief er in Lyon und Toulouse an, wo das Publikum ihn ebenso begeistert aufgenommen haben soll. Angeblich sollen sich französische Studenten in Marseille als Schutzgarde zur Verfügung gestellt haben, um die Vorführungen vor Demonstrationen, angeblich von jüdischer Seite, zu schützen. Angeblich sollen einige Stellen des Films von den Zuschauern mit Worten wie "auch aus Marseille müssen die Juden verschwinden " 573 kommentiert worden sein. Das Referat Film notierte zu den Vorführungen in Marseille:

ders wertvoll, S. 227-229. In dem Film verkörpert Heinrich George einen genußsüchtigen und schwächlichen Herzog, der von seinems sogenannten Hofjuden beherrscht wird. Jener bereichert sich selbst und setzt die Aufhebung des Judenbanns in der Stadt durch. Ferdinand Marian umwirbt als Süß Oppenheimer Dorothea Sturm (Kristina Söderbaum), die Tochter eines Beraters des Herzogs. Diese verlobt sich jedoch mit dem Jüngling ihres Herzens, wird von Oppenheimer erpreßt und läßt sich von ihm vergewaltigen, um ihren Verlobten zu retten. Dorothea ertränkt sich schließlich vor Scham. Süß Oppenheimer wird daraufhin verhaftet und vor Gericht unter Betonung der „Rassenschande " zum Tode verurteilt und gehängt. Alle Juden müssen die Stadt verlassen. Fast sämtliche anderen Rollen von Juden spielt in dem Film der Schauspieler Werner Krauss.

569 DREWNIAK, Der deutsche Film, S. 314.

570 Siehe bei MOELLER, Der Filmminister, S. 243-245.

571 CDJC, Le Film 9 (15. 2. 1941).

572 BA-MA, RW35 220, Prop.Abt., Ref.Film, Tätigkeitsbericht, 25. 4.-30. 4. 1941 und 1. 5.-7. 5. 1941.

573 Ibid. Zum angeblichen Erfolg von „Jud Süß“ in Marseille siehe beispielsweise CDJC, Le Film 15 (10.5. 1941): „Cependant la preuve la plus évidente du succès du Juif Süss en zone non occupée est l'empressement que montrent les directeurs des salles a programmer le film. Dès que les premiers résultats de Marseille furent connus, le film a été aussitôt loué à Toulouse, Nice, Cannes, Toulon, Perpignan, Nîmes, Avignon, Martigues, Port de Bonc, Vichy“. 
Das Publikum bekundete ebenso einstimmig wie kräftig, daß es die Ansichten des Films über das Judenproblem völlig teile. Nicht nur Stellen wie die Ausweisung der Juden aus Stuttgart [...] sondern auch z. B. die Stelle am Schluß des Films, wo gesagt wird „wenn aber ein Jude [...] sich fleischlich verbindet" wurden nachhaltigst beklatscht. Der Erfolg des Films, der in der politischen Presse des unbesetzten Gebiets, also nicht etwa nur im Filmteil besprochen wurde, wurde von den Zeitungen als Kennzeichen für die Stimmung der dortigen Bevölkerung angesehen, über die in der französischen Öffentlichkeit bis jetzt weitgehend insofern falsche Vorstellungen geherrscht haben dürften, als man das unbesetzte Gebiet als judenfreundlich oder doch zumindest neutral ansah ${ }^{574}$.

Es wird sich letztlich nicht klären lassen, inwieweit diese stark übertriebenen Aussagen auch nur ansatzweise zuverlässig sind. Da das Referat Film grundsätzlich auch über negative Reaktionen auf deutsche Filme berichtete, kann zumindest davon ausgegangen werden kann, daß "Jud Süß“ in Frankreich bedingt erfolgreich war. Inwieweit der Film jedoch tatsächlich eine anti-jüdische propagandistische Wirkung auf das französische Publikum hatte ist außerordentlich fraglich. Ein begrenzter Erfolg des Filmes in Frankreich ließe sich allenfalls mit dem Bekanntheitsgrad der Darsteller erklären, was vor allem auf Heinrich George zutrifft. So schrieb beispielsweise die Zeitung Le Parisien im Februar 1941: „Die eigentlichen Stars des Films ,Jud Süßs sind jedoch Heinrich George, den wir nächste Woche in der Comédie-Française erleben werden, und Werner Krauss. Ihre Kunst ist seit langem bekannt. Es ist aber zu unterstreichen, daß George wieder ausgezeichnet ist [...] Was für großartige Schauspieler sind doch die beiden“575. Die Presse warb für „Jud Süß" immer wieder mit dem Hinweis auf die Person Georges und auf den in Frankreich im November 1940 erfolgreich gezeigten Film „Der Postmeister“ (Gustav Ucicky, 1940), in dem George die Hauptrolle spielt. Paris Soir hatte diese Produktion als das kinematographische Ereignis der Gegenwart bezeichnet ${ }^{576}$. Daß der Erfolg von "Jud Süß“ allerdings nur begrenzt war, zeigen die Aufstellungen der Terra Filmkunst $\mathrm{GmbH}$ über die auf den Herstelleranteil erzielten Erträge ihrer Filme im Ausland. Ein Vergleich der Anteile, welche die Terra mit "Jud Süß" von Juli 1942 bis Mai 1944 in Frankreich erzielte, mit den Anteilen, die sie dort im gleichen Zeitraum mit „Opernball“ erreichte, zeigt, daß die Einspielergebnisse von "Jud Süß“ immerhin sehr weit hinter denen des „Opernballs“ lagen ${ }^{577}$. Obgleich sich beide Filme freilich nicht miteinander vergleichen lassen und auch die Kopienanzahl sowie andere Faktoren eine Rolle spielen, relativiert dies dennoch die obigen positiv gefärbten Berichte. Als der Film zum Ende der Besatzungszeit erneut in

574 BA-MA, RW35 220, Prop.Abt., Ref.Film, Tätigkeitsbericht, 1. 5.-7. 5. 1941.

575 Le Parisien, 21. 2. 1941, zit. n. der Übersetzung von WULF, Theater und Film, S. 454. 576 Paris Soir, 14. 11. 1940, zit. n. Garçon, The Film Propaganda, S. 163. Zu dem Erfolg des „Postmeisters“ siehe BA-MA, RW4/v. 218, Prop.Abt., Ref.Film., Tätigkeitsbericht, 4. 11,-10.11. 1940.

577 BA-KO, R109I/1677, Filmmäßige Nachweisung der in den einzelnen Auslandsgebieten im Monat Juli 1942 auf den Herstelleranteil erzielten Erträgnisse, Produktion: Terra; siehe Tabellen bis zum Monat Mai 1944. 
Frankreich gezeigt wurde, konnte von Erfolg keine Rede mehr sein. In einem Bericht der Filmprüfstelle vom März 1944 heißt es, sogenannte Terroristen bedrohten nun jene Theaterbesitzer, die deutsche Produktionen und insbesondere propagandistische Filme zeigten: „Der jüngste Bombenanschlag in einem Toulouser Filmtheater bei der Vorführung des Filmes Jud Süss', hat, neben Attentaten älteren Datums, seine abschreckende Wirkung auf die französischen Theaterbesitzer nicht verfehlt und eine Angstpsychose hervorgerufen" 578 .

Eine anti-britische Stoßrichtung hatten die Spielfilme „Das Herz der Königin" (Carl Froelich, 1940), Hans Steinhoffs "Ohm Krüger" (1941) und „Der Fuchs von Glenarvon“ (1940) von M.W. Kimmich mit Olga Tschechowa, Karl-Ludwig Diehl und Ferdinand Marian und „Titanic“579 (1943) von Herbert Selpin und Werner Klingler mit Sybille Schmitz ${ }^{580}$. Der 1940 gedrehte Ufa Film „Das Herz der Königin“ mit Zarah Leander, Willy Birgel und Will Quadflieg zeigte die Lebensgeschichte von „Maria Stuart“ und vor allem ihre Rivalität zu Königin Elisabeth von England ${ }^{581}$. Trotz seiner allgemein anti-englischen Tendenz äußerte das Referat Film im Juni 1941 Bedenken, ihn in Frankreich zu zeigen.

Gerade bei dem jetzigen Stande des französisch-englischen Verhältnisses [...] erscheint die Schlußtendenz, daß3 Elisabeth von England nur richtig gehandelt hat, während $\mathrm{Ma}$ ria eindeutig verurteilt wird, propagandistisch unerwünscht, der Herr Reichsminister hat sich der vorgebrachten Bedenken voll angeschlossen ${ }^{582}$.

Nur eine Woche später wurde der Film allerdings auf Anweisung von Kommandeur Schmidtke für den Herbst des Jahres zugelassen ${ }^{583}$. Bei der französischen Uraufführung am 16. November 1941 soll das Filmtheater Le Colisée überfüllt gewesen sein. Diedrich, der die Vorstellung besuchte, berichtete über Kommentare von französischen Besuchern, sie hätten den Film interessant gefunden ${ }^{584}$. Dieses Urteil sowie die angebliche Überfüllung des Filmtheaters ließe sich allenfalls auf die Beliebtheit Zarah Leanders zurückführen,

578 AN, AJ40 1001, Prop.Abt., Filmprüfstelle, Tätigkeitsbericht, 4. 3.-10. 3. 1944.

579 Ibid. S. 340-342. Der Film über den Untergang der Titanic wurde nach der Fertigstellung zum Vertrieb in Deutschland nicht zugelassen. DREWNIAK vermutet: „Vielleicht lag die Ursache des Inlandsverbotes in den neuen propagandistischen Richtlinien zum Thema des See-Krieges" (Ibid. S. 341). Für das Ausland wurde der Film allerdings zugelassen. Im November 1943 lief er in Paris an.

580 „Ohm Krüger“ und „Der Fuchs von Glenarvon“ hatte die Auslandsabteilung im RMVP jedoch grundsätzlich für den Export in Länder wie Frankreich als ungeeignet befunden, siehe PA-AA, 1125 b, Kult 12 Nr. 4, RMVP, Abteilung Ausland, Vertraulich, Die Lage des deutschen Films in Europa, Anfang 1943, 29. 3. 1943. Zu dem Aspekt exportgeeigneter Filme siehe bei DREWNIAK, Der deutsche Film, S. 693.

581 Ibid. S. 334 f. "Das Herz der Königin“ wurde am 1. 11. 1940 in Hamburg und München uraufgeführt und erhielt das Prädikat „künstlerisch wertvoll“.

582 BA-MA, RW35 221, Prop.Abt., Ref.Film, Tätigkeitsbericht, 5. 6.-11. 6. 1941.

583 BA-MA, RW35 222, Prop.Abt., Ref.Film, Tätigkeitsbericht, 25. 6.-1. 7. 1941.

584 BA-MA, RW35 224, Prop.Abt., Ref.Film, Tätigkeitsbericht, 14. 11.-21. 11. 1941. 
obwohl dieser Film nicht gerade zu ihren größten Erfolgen zählte. Der stark anti-britische Streifen „Ohm Krüger" lief auf Goebbels Anordnung in Frankreich in einer veränderten Auslandsfassung585. Hans Steinhoff - in einigen Szenen auch Herbert Maisch und Karl Anton - führten Regie. Der Film erzählte die Geschichte des Buren Paul Krüger, der nach dem Kampf gegen die Engländer 1880/81 seit dem Jahre 1883 Präsident der Südafrikanischen Republik war; Emil Jannings spielte Ohm Krüger, in der Rolle seines britischen Gegners Cecil Rhodes war Ferdinand Marian zu sehen und Gustaf Gründgens stellte Kolonialminister Chamberlain dar. Weitere Mitwirkende waren Otto Wernicke, Elisabeth Flickenschild, Gisela Uhlen und Lucie Höflich. Der Film zeichnete das Bild eines kleinen Burenvolkes, das lediglich in Freiheit und Frieden leben wollte und sich gegen das große England zur Wehr setzen mußte; er erinnerte an den Burenkrieg und die englischen Konzentrationslager. Ohm Krüger verkörperte darin die enge Verbundenheit eines Führers mit seinem Volk. Das Presseheft zu dem Film betonte die Rolle des Films in der korrigierenden Ausdeutung der damaligen Geschichte mit zeitgenössischem Blick ${ }^{586}$. Der Illustrierte Film-Kurier schrieb: „Als England einsieht, daß es das kleine Volk, dessen Heldenkampf von der gesamten Welt jubelnd begrüßt wird, mit Kanonen und Gewehren nicht niederzwingen kann, entschließt man sich zu einer der größten Gemeinheiten der Weltgeschichte. Der Kampf wird von nun an nicht mehr gegen die reguläre Ar-

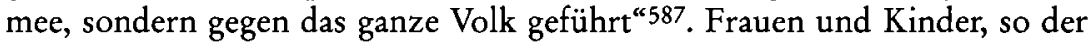
Filmkurier, hätten in den Konzentrationslagern der Engländer leiden müssen, weil jene die Widerstandskraft der kämpfenden Männer hätten brechen wollen. Drewniak hat dazu bemerkt, das nicht einmal langsam denkende $\mathrm{Zu}-$ schauer den politischen Gehalt des Filmes übersehen konnten ${ }^{588}$. Der 5,5 Millionen Reichsmark teure Film machte trotz eines großen Publikumserfolges in Deutschland Verluste. Goebbels hat diesen Kostenaufwand in einer Rede vor Filmschaffenden im Februar 1942 verteidigt. Er war der Meinung, der nationalpolitische Zweck derartiger Filme würde die hohen Ausgaben rechtfertigen. Weiter sagte er: „Daß ein Film beispielsweise wie der ,Ohm Krüger' sowohl innerpolitisch als außenpolitisch von einer ungeheuren Bedeutung gewesen ist und heute noch ist, das bedarf keiner Erwähnung "589.

Trotz dieser auch außenpolitisch angeblich so großen Bedeutung war die Besatzungsmacht mit dem Einsatz von "Ohm Krüger" in Frankreich wie

585 BA-MA, RW35 221, Prop.Abt., Ref.Film, Tätigkeitsbericht, 12.6.-18. 6. 1941. Es konnte nicht ermittelt werden, worin sich die Inlands- und Auslandsfassung genau unterschieden. Siehe bei KANZOG, Staatspolitisch besonders wertvoll, S. 253-265; DREWNIAK, Der deutsche Film, S. 337-340.

586 BA-FA, Presseheft zu „Ohm Krüger“.

587 BA-FA, Illustrierter Film-Kurier, Ohm Krüger, Ein Emil Jannings-Film der Tobis.

588 DREWNIAK, Der deutsche Film, S. 338.

589 Goebbels Rede vor Filmschaffenden am 28. 2. 1942, abgedruckt in: ALBRECHT, Nationalsozialistische Filmpolitik, S. 489. 
auch in anderen besetzten Gebieten relativ vorsichtig, weil angesichts der Darstellung der unfreien Buren befürchtet wurde, das Publikum könne Parallelen zur eigenen Situation ziehen. Im September 1941 heißt es in den Akten des Referats, die französische Uraufführung von „Ohm Krüger“ sei aus militärischen Gründen nicht genehmigt worden ${ }^{590}$. Am 5. Oktober 1941 lief er schließlich doch im Pariser Filmtheater Normandie in französischer Synchronisation an. Diedrich besuchte die Premiere und berichtete, am Schluß des Filmes hätten sich sämtliche Zuschauer in dem ausverkauften Filmtheater Beifall klatschend von den Plätzen erhoben: „Der Referatsleiter hatte den Eindruck, daß sich der Film nicht nur durchsetzen sondern im Hinblick auf sein Thema dem Interesse des französischen Publikums begegnen wird" 591. Wenig später heißt es in einem Bericht des Referats, "Ohm Krüger" habe beträchtliches Aufsehen erregt, jedoch gebe es keine Demonstrationen. Dennoch habe die Abwehrleitstelle Bedenken gegen die weitere Vorführung des Filmes angemeldet, weil sie befürchte, das französische Volk ziehe möglicherweise Parallelen zwischen dem Schicksal der Buren und seinem eigenen. In einer gemeinsamen Konferenz sei jedoch beschlossen worden, den Film aufgrund seines propagandistischen Wertes auch weiterhin zu zeigen ${ }^{592}$. Die deutsche Presse berichtete, der Film hätte in Frankreich ein breites Publikum gewonnen ${ }^{593}$. Inwieweit dieser doch relativ erfolgreiche Streifen nun tatsächlich in Richtung auf eine anti-britische Stimmung im Publikum gewirkt haben mag, sei hier dahingestellt; immerhin konnten sich die französischen $\mathrm{Zu}-$ schauer theoretisch auch mit dem im Film dargestellten unterdrückten Burenvolk identifizieren ${ }^{594}$. Wie die Sicht des Publikums die Wirkung deutscher Propagandafilme ins Gegenteil verkehren konnte, zeigt das Beispiel des ebenfalls anti-englischen Filmes „Der Fuchs von Glenarvon“, der von dem Freiheitskampf der Iren handelte ${ }^{595}$. Olga Tschechowa verkörpert die Irin Gloria; ihr Mann (Ferdinand Marian), als „Fuchs von Glenarvon“ ein englischer Spitzel, hintergeht sie. Carl Ludwig Diehl spielt einen irischen Freiheitskämpfer, der sich zu Gloria bekennt. Die Propaganda Staffel St. Germain meldete im Juli 1942 dieser Film sei trotz seiner eindeutigen Haltung

590 BA-MA, RW35 223, Prop.Abt., Ref.Film, Tätigkeitsbericht, 5. 9.-12. 9. 1941.

591 BA-MA, RW35 224, Prop.Abt., Ref.Film, Tätigkeitsbericht, 10. 10.-17. 10. 1941.

592 Ibid.

593 DREWNIAK, Der deutsche Film, S. 339.

$594 \mathrm{Daß}$ die Wirkung „Ohm Krügers“ rückblickend freilich eine ganz andere sein kann, zeigt die Reaktion des Publikums auf den Film, der 1962 im Filmclub des Londoner National Film Theaters in der Reihe "Wie andere uns sehen" lief; er rief bei den Zuschauern Lachausbrüche hervor; die meist jüngeren englischen Zuschauer sollen sich besonders über die Karikierung der Queen Viktoria und Chamberlains amüsiert haben. Ein englischer Student meinte: „Warum haben uns die Deutschen den Film vorenthalten? Blendend die schauspielerische Leistung - und blendend wie wir Engländer durch den Kakao gezogen werden“ (BA-FA, Die Welt, Londoner lachten über den „OhmKrüger"-Film, 18. 7. 1962).

595 Siehe dazu Drewniak, Der deutsche Film, S. 335 f. Der Film wurde am 24. 4. 1940 in Deutschland uraufgeführt und erhielt das Prädikat „künstlerisch wertvoll“. 
gegen England für propagandistische Sondervorführungen in Frankreich ungeeignet. Zur Reaktion des Publikums heißt es: „Es wurde applaudiert, als am Ende des Films die Iren marschierend das Lied von der Freiheit singen" ${ }^{596 .}$.

Der anti-kommunistische Propagandafilm „Hitlerjunge Quex“ von Hans Steinhoff mit Heinrich George war bereits im Jahre 1933 gedreht worden und wurde innerhalb der nationalsozialistischen Filmpropaganda auch während des Krieges noch eingesetzt, so auch in Frankreich. In einem Bericht des Referats Film vom Ende März 1942 heißt es, der Film sei nach Genehmigung der Untertitel rasch vorbereitet, geprüft und unbeschränkt auch für Jugendliche zugelassen worden. Zur seiner Rezeption wird gesagt: „Der Film Hitlerjunge Quex, der am Anfang mäßig anlief, wurde in den letzten Tagen ständig besser, so daß er weiterhin verlängert wurde. Die Kritiken des Filmes waren durchwegs ausgezeichnet "597. Offenbar war dieser Film also weniger erfolgreich als „Jud Süß" oder „Ohm Krüger“. Er wurde im Februar/März 1944 in Paris wieder aufgenommen, doch dürfte die Resonanz zu diesem Zeitpunkt noch geringer gewesen $\operatorname{sein}^{598}$. Ein weiterer anti-kommunistischer Spielfilm, den das französische Publikum zu sehen bekam, war "GPU“ (1942) von Karl Ritter mit Lale Andersen ${ }^{599}$. Karl Antons „Weiße Sklaven“ (1937), "Croiseur Sébastopol“ war nach Ansicht der Propaganda Staffel St. Germain für den propagandistischen Filmeinsatz gut geeignet. Angeblich sollen die Zuschauer bei einer Vorführung in Cherbourg immer dann Beifall gespendet haben, „wenn einer der roten Terroristen fiel“600. Aus La Rochelle meldete die Außenstelle der Staffel, der Film stehe an der Spitze der Erfolge deutscher Filme, weil er der französischen Mentalität zusage ${ }^{601}$. Grundsätzlich ist es jedoch fraglich, inwieweit die deutschen propagandistischen Spielfilme auch nur ansatzweise die gewünschte Wirkung erzielten.

Mehr noch als über propagandistische Spielfilme betrieb die Besatzungsmacht über die Vorführung von Kulturfilmen Propaganda. Diese meist dokumentarischen Kurzfilme wurden als „hervorragendes Instrument volkskultureller Arbeit" 602 gesehen und im Gegensatz zu den deutschen Spielfil-

596 BA-MA, RW35 226, Prop.Abt., Gr.Film, Tätigkeitsbericht, 27.6.-3.71942.

597 BA-MA, RW35 225, Prop.Abt., Gr.Film, Tätigkeitsbericht, 28. 3. 1942.

598 BA-MA, RW35 227, Prop.Abt., Filmprüfstelle, Tätigkeitsbericht, 26.2.-4.31944.

$599 \mathrm{Zu}$ diesem Film siehe DREWNIAK, Der deutsche Film, S. 351 f. Dieser Propagandafilm, der am 14. 8. 1942 in Deutschland uraufgeführt wurde und keine Prädikate erhielt, soll relativ schlecht gewesen sein.

600 BA-MA, RW35 226, Prop.Abt., Gr.Film, Tätigkeitsbericht, 27. 6.-3. 7. 1942. Zu dem Film, der in Finnland und der Schweiz verboten wurde, siehe bei DREWNIAK, Der deutsche Film, S. 346.

601 BA-MA, RW35 227, Prop.Abt., Gr.Film, Tätigkeitsbericht, 30. 8.-4. 9. 1942.

602 BA-MA, RW35 223, Prop.Abt., Ref.Film, Tätigkeitsbericht, 3. 10.-10. 10. 1941; Bericht über die erste Reichswoche für den deutschen Kulturfilm in München vom 20. 9.25. 9. 1941; Staatssekretär Gutterer benutzte in seiner Rede diese Bezeichnung für den Kulturfilm. 
men nicht sofort nach Beginn der Okkupation eingesetzt. In einem Bericht des Referats Film heißt es beispielsweise im März 1941, auf französischer Seite sei die Nachfrage nach deutschen Kulturfilmen groß:

Es ist bedauerlich, daß die deutschen Verleihfirmen nicht das unbedingt Erforderliche tun. Ganz konkret werden sehr oft Wünsche dahin geäußert, daß man die auf der Weltausstellung gezeigten Kulturfilme gern noch einmal sehen würde. Mit allem Nachdruck muß im Interesse der deutschen Propaganda und Wirtschaft die Forderung nach dem Einsatz synchronisierter deutscher Kulturfilme in Mengen erhoben werden ${ }^{603}$.

Sicherlich war nicht die Nachfrage nach deutschen Kulturfilmen so groß, sondern wohl eher der Wunsch Diedrichs, diese vermehrt einzusetzen. Doch wird hier deutlich, daß sich die deutschen Dienststellen bis zu diesem Zeitpunkt im Bereich des propagandistischen Filmeinsatzes eher noch zurückhielten. Die Ursache hierfür lag offenbar in einem Mangel an geeigneten Filmen, denn im April 1941 bat des Referat Film das RMVP erneut darum, deutsche Kulturfilme nach Paris zu schicken. Neben Filmen über die Schönheit Deutschlands, wünschte das Referat Produktionen über die Vielfältigkeit der deutschen Wirtschaft, Landwirtschaft und der kulturellen Leistungen sowie aufklärende Produktionen über das nationalsozialistische Deutschland. Der Bericht verwies zudem auf die Filme der Weltausstellung von 1937, die so erfolgreich gewesen seien. Die Propaganda Abteilung wollte aus propagandistischen Gründen so schnell als möglich solche Filme einsetzen $^{604}$.

Diedrich dachte hier also generell an Werbematerial, um in Frankreich ein möglichst positives Bild des „neuen Deutschland“ zu verbreiten. Im September 1941 besuchte er die erste Reichswoche für den deutschen Kulturfilm in München. Bei dieser Gelegenheit erkundigte er sich in der Kulturfilmzentrale in Berlin, welche Kulturfilme für den propagandistischen Sondereinsatz in Frankreich besonders geeignet wären ${ }^{605}$. Die Auswahl der Filme war also weder vom RMVP noch von Diedrich bereits klar umrissen worden, was sicherlich auch zu einer Verzögerung des Einsatzes deutscher Kulturfilme beitrug. Nicht alle deutschen Kulturfilme waren nach Meinung der Besatzungsmacht dazu geeignet, in Frankreich gezeigt zu werden. Nach längerem Zögern entschied Schmidtke beispielsweise, daß Leni Riefenstahls „Triumph des Willens" in Frankreich nicht gezeigt werden sollte, da so viele Schnitte gemacht werden müßten, „daß ein Einsatz auch im propagandistischen Interesse nicht erwünscht" 606 war. Die Tobis durfte dieses Werk ebensowenig

603 BA-MA, RW35 220, Prop.Abt., Ref.Film, Tätigkeitsbericht, 20. 3.-26. 3. 1941.

604 Ibid. 'Tätigkeitsbericht, 17. 4.-24. 4. 1941.

605 BA-MA, RW35 223, Prop.Abt., Ref.Film, Tätigkeitsbericht, 3. 10.-10. 10. 1941; Bericht über die erste Reichswoche für den deutschen Kulturfilm in München vom 20. 9.25. 9. 1941; Diedrich nahm daran teil und begab sich anschließend zu Besprechungen mit dem RMVP nach Berlin (26. 9.-1.10. 1941).

606 BA-MA, RW35 221, Prop.Abt., Ref.Film, Tätigkeitsbericht, 12.6.-18. 6. 1941. 
wie den „Olympia-Film“ in Frankreich vertreiben. Von gezielter Propaganda, wie sie die späteren anti-bolschewistischen Kulturfilme oder die Filme zur Anwerbung französischer Arbeitskräfte für den Einsatz in Deutschland enthielten, war hier noch nicht die Rede. Dies entsprach den Gegebenheiten der allgemein von den Deutschen verfolgten, sich seit 1942 entsprechend der veränderten Weltkriegslage verschärfenden Besatzungspolitik. Erst im Herbst 1941 besonders aber im Frühjahr/Sommer 1942 liefen in den Pariser Filmtheatern deutsche propagandistische Kulturfilme an. Bisher hatte sich die Propaganda im Filmbereich weitgehend auf die Wochenschau und deutsche Spielfilme beschränkt.

In den Jahren 1941 bis 1944 stellte die deutsche Filmindustrie im Auftrage des RMVP mehrere anti-sowjetische Kulturfilme her, die zur Propaganda im In- und Ausland eingesetzt wurden ${ }^{607}$. Am 7. September 1941 lief in Paris "Face au bolchevisme" in Sondervorstellungen an. Der Film sollte die antisowjetische Ausstellung "Le bolchevisme contre l'Europe ${ }^{\text {"608, die am }}$ 1. März 1942 eröffnet wurde, vorbereiten. Die Filmtheaterbesitzer zahlten für den Film weder Leihmiete noch mußten sie einen Anteil der Einnahmen an die Verleihfirmen abführen. Angeblich soll der Erfolg ausgezeichnet gewesen sein ${ }^{609}$. „Face au bolchevisme“ war aus deutschem Wochenschaumaterial hergestellt worden 610 . Als sogenannte Vorpropaganda für den Film, der mit 77 Kopien lief, wurden in der besetzten Zone 6000 Plakate, 2860000 Handzettel und 7 Vorspannfilme verbreitet. Die Staffel in Bordeaux verteilte zusätzlich noch 6000 Plakate mehr. Allerdings hatte diese massive Werbung für den Film erst am 4./5. September, also nur wenige Tage vor seinem Start begonnen. Seinen Einsatz bezeichnete das Referat Film als erfolgreich. Es habe keine Störungen gegeben, das Publikum sei auffallend diszipliniert gewesen. Durch die billigen Eintrittspreise, seien alle Bevölkerungsschichten vertreten gewesen, auch solche, die es sich ansonsten nicht leisten konnten, ins Kino zu gehen. Abgesehen von Paris hatten in 11 französischen Städten der besetzten Zone - in Bordeaux, Angers, Nantes, Rennes, Tours, Brest, Vauban, Laval und Le Mans - seit dem 7. September insgesamt 10486 Besucher den Film gesehen ${ }^{611}$. Freilich zeigt die Bemerkung über die Disziplin des Publikums, daß die Besatzer auch negative Reaktionen des Publikums erwarteten; demnach war ein Kulturfilm schon erfolgreich, wenn das Publikum sich nicht regte und ohne Störungen zusah. Weiterhin heißt es zur Rezeption des Filmes: „Insbesondere verfehlten die Aufnahmen von den So-

Beide Filme wurden in Frankreich jedoch während der dreißiger Jahre gezeigt. Siehe dazu Kapitel II. 1. dieser Arbeit.

607 DREWNIAK, Der deutsche Film, S. 352-356.

$608 \mathrm{Zu}$ der Ausstellung siehe RossignOL, Histoire de la Propagande, S. 275-281; THALMANN, La Mise au pas, S. $238 \mathrm{f}$.

609 BA-MA, RW35 223, Prop.Abt., Ref.Film, Tätigkeitsbericht, 5. 9.-12. 9. 1941.

610 BA-MA, RW4 219, MBF, Prop.Abt., Lagebericht, 16. 8.-31. 8. 1941.

611 BA-MA, RW35 223, Prop.Abt., Ref.Film, Tätigkeitsbericht, 5. 9.-12. 9. 1941. 
wjet-Greueln nicht ihre Wirkung. Überall wurde am Schluß der Vorstellung ostentativ Beifall gespendet"612. Nach Meinung des Referats wäre die Wirkung des Filmes stärker gewesen, wenn er mehr unveröffentlichtes Material und mehr Szenen zur „kulturzersetzenden Wirkung des Bolschewismus“613 wie „Kirchenschändung und Kinderelend“ gezeigt hätte. In der zweiten Woche lief „Face au bolchevisme" unter anderem auch in Biarritz und La Rochelle an; insgesamt verzeichnete der Film bis Mitte September 20157 Besucher, was das Referat als gutes Ergebnis bezeichnete. Trotzdem übte das Referat auch Kritik. Es war der Meinung, in Zukunft dürften ähnliche Filme nicht nur aus aneinandergereihten Ausschnitten aus der Wochenschau bestehen, sondern müßten unbedingt unveröffentlichtes Material enthalten, was auf den Werbeplakaten anzukündigen wäre. Zudem sollte der Mangel an geographischen Kenntnissen bei den Franzosen von den Herstellern mit bedacht werden ${ }^{614}$. Eine Woche später meldete das Referat, nach wie vor sei das Interesse des Publikums an dem Film groß; in Paris hatten ihn bisher 14000 Personen gesehen, hinzu kamen 13025 Besucher in der französischen Provinz ${ }^{615}$. Im Oktober meldete die Propaganda Staffel Nordost-Dijon 20083 Besucher, die Staffel Nordwest-ST. Germain 24195 Personen ${ }^{616}$. Obgleich das Referat Film zahlreiche Meldungen über den Erfolg des Filmes brachte, kam es betreffend der Terminierung der Vorstellungen am Sonntagmorgen zu dem Schluß, gerade diese Veranstaltungen seien vor allem in kleineren Orten sehr schlecht besucht: „Man muß wissen, daß der Franzose am Sonntag kein Frühaufsteher ist und wenn, daß er dann in die Kirche geht"617. In einem einzelnen Fall soll der Pfarrer der kleinen Gemeinde Laigle in seiner Predigt auf den Film hingewiesen und den Gottesdienst deswegen verschoben haben. Im Allgemeinen zog die Bevölkerung es aber vor, am Sonntagmorgen keine Vorstellungen deutscher Propagandafilme zu besuchen ${ }^{618}$.

Im September 1941 wurde eine Sondervorstellung von „Face au bolchevisme" vor Pétain und mehreren Ministern veranstaltet. Die Propaganda Abteilung berichtete, der Film sei bei Pétain auf „lebhaften Beifall“619 gestoßen, woraufhin dieser den Wunsch geäußert habe, man möge den Film auch im unbesetzten Gebiet verbreiten. Die ACE übernahm den Vertrieb und zeigte den Film in der Folge auch in der ZNO in Sondervorführungen zu ermäßigten Preisen. Er lief - angeblich erfolgreich - beispielsweise in der Gegend von Marseille, in Nizza, Cannes und Avignon ${ }^{620}$. Doch ist es bezeichnend, daß

612 Ibid.

613 Ibid.

614 Ibid. Tätigkeitsbericht, 12. 9.-19. 9. 1941.

615 Ibid. Tätigkeitsbericht, 19. 9.-26. 9. 1941.

616 BA-MA, RW35 224, Prop.Abt., Ref.Film, Tätigkeitsbericht, 17. 10.-24. 10. 1941.

617 Ibid. Tätigkeitsbericht, 10. 10.-17. 10. 1941.

618 Ibid.

619 BA-MA, RW4 220, Prop. Abt., Lagebericht, 16. 10.-23. 10. 1941.

620 BA-MA, RW35 224, Ref. Film., Tätigkeitsberichte, 24. 10.-31. 10. 1941; 5.-12. 12. 1941. 
das Referat Film im Dezember/Januar 1941/42 betreffend seines Einsatzes in der ZNO resümierte, nur wenige Besitzer von Filmtheatern hätten sich geweigert, den Film zu zeigen und es sei nirgends zu Unruhen gekommen ${ }^{621}$. Als Vorbereitung für die erwähnte Anfang März eröffnete anti-bolschewistische Ausstellung liefen in Sondervorführungen auch noch weitere Filme wie „Das Sowjetparadies“ in französischer Synchronisation und „Hitlerjunge Quex“. Zu diesem Zeitpunkt lief „Face au bolchevisme“ immer noch im unbesetzten Gebiet Frankreichs ${ }^{622}$.

Zur Demonstration der angeblichen Stärke des kriegführenden Deutschland setzte die Propaganda Abteilung „Feldzug im Osten“ („Guerre à l'est“) als Kulturfilm vor Wochenschau und Hauptfilm in den französischen Filmtheatern ein ${ }^{623}$. Dieser ursprünglich abendfüllende Kulturfilm war von der deutschen Zensur nur mit Kürzungen und Änderungen freigegeben worden ${ }^{624}$ und lief Anfang Mai 1942 in den Pariser Uraufführungstheatern Le César und Max Linder an. Der Besuch der Vorstellungen war schwach, der Film bekam aber gute Pressekritiken. Das Referat Film resümierte: „Die kriegerischen Ereignisse sind dem Franzosen sehr ferne, er nimmt daran nur wenig teil"625. Schließlich zeigten die Filmtheater "Guerre à l'est" nur noch zu ermäßigten Eintrittspreisen in Sondervorführungen ${ }^{626}$. „Les Arsenaux du Reich" war ein sogenannter Rüstungsfilm, der im Juni 1942 in Pariser Lichtspielhäusern ebenfalls als Kulturfilm zwischen Wochenschau und Hauptfilm anlief. In Paris und Umgebung wurde er in 52, in der Provinz in 34 Filmtheatern gezeigt ${ }^{627}$. Über den Erfolg dieses Filmes in den Pariser Filmtheatern Denfert-Rochereau-Palace und Thêâtre-Montrouge ließ sich das Referat durch sogenannte französische V-Leute berichten:

Diese Kraftausstellung macht Eindruck. Das Publikum folgt der Vorführung ohne Reaktion um nicht zu sagen mit Interesse. [...] Der Film wurde mit Aufmerksamkeit verfolgt, ohne viel Gemurmel, das Publikum hat sich milde für die Vorführung interessiert, keine Reaktion ${ }^{628}$.

Die von den Propaganda Staffeln Nordost, Nordwest und Südwest ausgeschickten V-Männer berichteten, der Film sei zwar lang und eintönig, doch er interessiere das Publikum sehr. Es hieß weiter: „Die Zuschauer sind von der Kraft der deutschen Arbeit, von dieser Material-Schau, dieser einfach unbe-

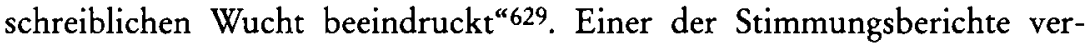
merkte, im Publikum habe sich zeitweise Gemurmel vernehmen lassen, weil

621 BA-MA, RW35 225, Prop.Abt., Ref.Film., Tätigkeitsbericht, 6. 3.-14. 3. 1942.

622 BA-MA, RW4 221, Prop.Abt., Lagebericht, 1. 3.-15. 3. 1942.

623 BA-MA, RW35 225, Prop.Abt., Ref.Film, Tätigkeitsbericht, 18. 4.-25. 4. 1942.

624 BA-MA, RW4 221, Prop.Abt., Lagebericht, 1. 3.-15. 3. 1942.

625 BA-MA, RW35 226, Prop.Abt., Gr.Film, Tätigkeitsbericht, 2. 5.-9. 5. 1942.

626 Ibid., Tätigkeitsbericht, 13.6.-20.6. 1942.

627 Ibid. Tätigkeitsbericht, 10. 7.-17. 7. 1942.

628 Ibid. Tätigkeitsbericht, 13.6.-20. 6. 1942.

629 Ibid. 
einige Besucher dadurch bewußt die Wirkung der Waffenschau hätten mindern wollen. Insgesamt sei der Film aber „trotz seiner Länge und seiner Monotonie" 630 ruhig verfolgt worden. Die Staffel St. Germain berichtete sogar, Informanten hätten ihr mehrfach mitgeteilt, daß nach Ende des Filmes aufgrund seiner Langatmigkeit ein „befreites Aufatmen“631 durch den Zuschauerraum gegangen sei. Im Filmtheater ABC in Dijon wurde der Film sogar bei einer Vorführung ausgepfiffen und das Publikum klatschte Beifall, als das Wort „Ende“ erschien ${ }^{632}$. Das Gros der Zuschauer ließ diesen offensichtlich langweiligen Film gleichsam geduldig über sich ergehen; die gewünschte Wirkung auf das Publikum dürfte er wohl nicht erzielt haben.

Der Kulturfilm „Libre Amérique" („Rund um die Freiheitsstatue“) war aus amerikanischen Wochenschauen zusammengeschnitten worden und stellte mit entsprechendem Kommentar versehen einen in erster Linie antiamerikanischen Propagandafilm dar. Er wurde im Beiprogramm in Paris und in der Provinz im Juni 1942 mit 100 Kopien eingesetzt. Durch entsprechende Montage der Ausschnitte aus Wochenschauen unterschiedlicher Jahrgänge suggerierte der Film beispielsweise mit Szenen zu Streiks und Ausschreitungen der amerikanischen Polizei, die USA würden ihrem demokratischen Anspruch nicht gerecht. Er zeigte ferner Alltagszenen mit Schwarzen sowie „aufrührende Szenen von Negertänzen“633. Abschließend stellte der Film das angeblich voyeuristische Amerika dar, in Form des gefilmten Selbstmords eines jungen Mannes, der sich vor den Augen einer großen Menschenmenge aus dem 30. Stock in den Tod stürzt ${ }^{634}$. Nach Meinung der Propaganda Staffel Dijon soll der Film bei den französischen Zuschauern einen nachhaltigen Eindruck hinterlassen haben. Allerdings vermerkte die Staffel auch, das französische Publikum habe sich offensichtlich über die „Vorführung der Negertänze" 635 in diesem Film gefreut; trotzdem war sie davon überzeugt, die Zuschauer hätten erfolgreich einen negativen Gesamteindruck von Amerika erhalten. Dagegen meinte die Staffel Angers, der Film sei vom Publikum sofort als Propaganda erkannt und nicht für glaubwürdig befunden worden ${ }^{636}$. Die Staffel St. Germain meldete, das französische Publikum sehe ihn als "Lustspielfilm“637; der Sinn des Films bleibe der Mehrzahl der Zuschauer verborgen. Einmal mehr wird hier deutlich, wie problematisch es für die deutschen Dienststellen war, mit einem Propagandafilm die gewünschte Wirkung zu erzeugen. Während die sogenannten Negertänze eigentlich anti-amerikanische Propaganda darstellen sollten, bewirkten sie of-

630 Ibid.

631 BA-MA, RW35 226, Prop.Abt., Ref.Film, Tätigkeitsbericht, 3. 7. 1942.

632 Ibid. Tätigkeitsbericht, 10. 7. 1942.

633 Ibid. Tätigkeitsberichte, 1.6.-6. 6. 1942; 13. 6.--20. 6. 1942.

634 Ibid.

635 BA-MA, RW35 226, Prop.Abt., Ref.Film, Tätigkeitsbericht, 13. 6.-20. 6. 1942.

636 Ibid.

637 BA-MA, RW35 226, Prop.Abt., Ref.Film, Tätigkeitsbericht, 3. 7. 1942. 
fenbar bei dem französischen Publikum das genaue Gegenteil. Die Berichte der deutschen Dienststellen zeigen, daß deutsche Propagandafilme allgemein wenig glaubwürdig auf die französische Bevölkerung wirkten. Während es diesen Propagandafilmen jedoch lediglich an Glaubwürdigkeit mangelte und sie zumindest eine relativ weite Verbreitung fanden, war die Reaktion auf andere Filme noch negativer.

Dies war der Fall bei „Der ewige Jude“ (Fritz Hippler/Eberhard Taubert, 1940), einem abendfüllenden anti-jüdischen „Dokumentarfilm“; dessen Idee und Herstellung stellen entscheidend ein Werk von Goebbels dar. Die Reichskristallnacht am 9. November 1938 hatte nicht nur im Ausland, sondern teilweise auch im Inland Kritik hervorgerufen. Um die Deutschen besser „aufzuklären“, setzte der Propagandaminister diesen Film in Deutschland ein. Nach dem Einmarsch in Polen im September 1939 wurden die Aufnahmen hierzu in polnischen Ghettos gedreht. Die Tagebuchnotizen von Goebbels zeigen, daß er den Film mehrmals umarbeitete und auch Hitler mehrfach Änderungen verlangte, weshalb die Produktion schließlich erst am 28. November 1940 in Deutschland zur Uraufführung kam. Nach Berichten des SD war der Film nicht besonders erfolgreich ${ }^{638}$. Der Einsatz dieses Filmes in Frankreich war schon relativ früh erwogen worden. Im September 1941 suchte die Propaganda Abteilung nach begleitenden Filmen zur Ausstellung „Le Juif et la France“639, die am 5. September im Palais Berlitz eröffnet worden war. Die Gruppe Aktivpropaganda der Propaganda Abteilung schlug „Der ewige Jude“ vor. Deswegen stellte die Informationsabteilung der Botschaft eine verkürzte Fassung des „Ewigen Juden“ her. Diese Fassung wurde mit eigenen Kommentaren versehen und lief im Rahmen der Ausstellung unter dem Titel „Le Péril juif“. Bei der Herstellung dieser Fassung war auch Robert Muzard behilflich gewesen, der selbst einen französischen antijüdischen Film („Les Corrupteurs“) im Auftrag der Botschaft herstellte ${ }^{640}$. Im September 1941 wurde diese Fassung von der Zensur durch die Propaganda Abteilung freigegeben, die in ihrem Bericht betonte, man habe auch Umfang und Art der Synchronisation überprüft. Die Filmprüfstelle kam zu dem Schluß: „Es steht außer Frage, daß der Film im gegenwärtigen Zeitpunkt für Frankreich von außerordentlichem propagandistischen Wert sein dürfte,

${ }^{638} \mathrm{Zu}$ dem Film siehe beispielsweise Yizhak AHREN, Stig HornshoJ-MOLLER, Christoph B. MelChers, „Der Ewige Jude“, Aachen 1990, hier S. 15-30. Moeller, Der Filmminister, S. 241-243.

639 Offizieller Veranstalter war das Institut d'études des questions juives; organisiert war sie jedoch vor allem von Carltheo Zeitschel, der bei der Botschaft mit jüdischen Angelegenheiten befaßt war. Siehe Thalmann, La Mise au pas, S. $238 \mathrm{f}$.

640 PA-AA, 1113, Kult 12 Nr. 4, DBP, Informationsabteilung, Abert, Aufzeichnung für Legationsrat Buscher, Betr.: Filmherstellung, 9. 9. 1942. Im Rahmen der Ausstellung liefen in einzelnen Sondervorstellungen "Le Péril Juif" und "Les Corrupteurs". Laut Thalmann lief in Sondervorstellungen auch "Le Juif Süss" (THALMANN, La Mise au pas,

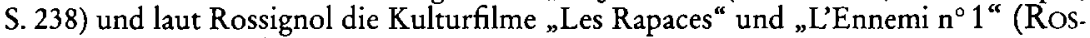
SIGNOL, Histoire de la Propagande, S. 226). 
und daß der Einsatz dieses Filmes möglichst bald erfolgen sollte" ${ }^{\text {"641. Daher }}$ ließ sie den Film unbeschränkt für Frankreich zu und empfahl dessen öffentlichen Einsatz. Laut Will Abert von der Informationsabteilung der Deutschen Botschaft soll „Le Péril Juif“ während der Ausstellung angeblich mit Erfolg gelaufen sein, obgleich er anmerkte, daß der Film für Frankreich "fremde Aspekte des Problems"642 behandelte, was auch die Kurzfassung des Filmes nicht hätte ändern können. Als die Ausstellung „Le Juif et la France" wenig später in Bordeaux und Nancy gezeigt wurde, sollen nach Aberts Angaben dort rund Zehntausend Besucher die Filme „Le Péril juif“ und „Les Corrupteurs" gesehen haben. Zudem hätten politische Gruppen den erstgenannten Film entliehen und bei Vorträgen vorgeführt ${ }^{643}$. Nach Ansicht der Botschaft hatte der Film die Besucher der Ausstellung jedoch nur beeindrucken können, „soweit diese eine gewisse Aufnahmebereitschaft mitbrachten "644. Er hielt ihn für den Einsatz in Filmtheatern für ungeeignet, weil es sich um offene Propaganda handelte.

Tatsächlich zögerten RMVP und Propaganda Abteilung lange, den „Ewigen Juden " in öffentlichen Vorführungen zu zeigen. Während die Propaganda Abteilung den Einsatz des Filmes durch Sondervorstellungen in den Pariser Filmtheatern Mitte Oktober 1941 erwog $^{645}$, kam es hierzu erst im Sommer 1942, kurz vor der Einführung des Judensterns. Hierbei handelte es sich jedoch keineswegs um die von der Botschaft hergestellte Kurzfassung, sondern um eine weitere, von der Tobis vertriebene französisch synchronisierte Auslandsfassung des Filmes ${ }^{646}$. Offenbar hatte die Propaganda Abteilung zeitweise erwogen, die Auslandsfassung mehr auf französische Verhältnisse abzustimmen und französische Filmaufnahmen einzufügen. Schmidtke gab jedoch im Oktober 1941 die Anweisung, die französisch synchronisierte Fassung des Filmes solle ohne Einfügen französischer Dokumente erstellt werden $^{647}$. Im Januar 1942 war die französische Fassung zwar fertig, mußte jedoch noch auf Wunsch des Staffelführers verändert werden. Über den endgültigen Einsatz sollte Schmidtke entscheiden ${ }^{648}$. Geplant war der Einsatz in Sondervorstellungen. Die Filmtheaterbesitzer sollten keine Leihgebühr bezahlen und die Einnahmen aus den Vorstellungen behalten ${ }^{649}$. Erst im Som-

641 BA-MA, RW35 223, Prop.Abt., Ref.Film, Tätigkeitsbericht, 29. 8.-5. 9. 1941.

642 PA-AA, 1113, Kult 12 Nr. 4, DBP, Informationsabteilung, Abert, Aufzeichnung für Legationsrat Buscher, Betr.: Filmherstellung, 9. 9. 1942.

643 Ibid.

644 PA-AA, 1113, Kult 12 Nr. 4, DBP, Lohmann, Vermerk, Betr.: Einflußnahme auf die Filmherstellung durch Informationsstelle und Informationsabteilung, insbesondere Nova-Films, 12. 12. 1942. (Stellungnahme zu einer Notiz Aberts vom 9. 11. 1942)

645 BA-MA, RW35 224, Prop.Abt., Ref.Film, Tätigkeitsbericht, 10. 10.-17. 10. 1941.

646 PA-AA, 1113, Kult 12 Nr. 4, DBP, Informationsabteilung, Abert, Aufzeichnung für Legationsrat Buscher, Betr:: Filmherstellung, 9. 9. 1942.

647 BA-MA, RW 35 224, Prop.Abt., Ref.Film, Tätigkeitsbericht, 24. 10. 1941.

648 Ibid. Tätigkeitsbericht, 2. 1. 1942.

649 Ibid. Tätigkeitsbericht, 24. 10.-31. 10. 1941. 
mer 1942, fast ein Jahr nachdem "Le Péril juif“ erstmalig synchronisiert und für Frankreich zensiert worden war, kam der Film schließlich in die Filmtheater. Er sollte die Einführung des Judensterns in Frankreich im Juni 1942 gleichsam propagandistisch begleiten und die Bevölkerung dahingehend beeinflussen: „Im Zusammenhang mit der Einführung des Judensterns soll in der nächsten Woche der Film ,Der ewige Jude' in Paris im Kino Le César versuchsweise eingesetzt werden. Über den weiteren Einsatz wird je nach Erfolg in diesem Theater entschieden werden"650. Am 3. Juli 1942 lief der Film im Filmtheater Le César an. Obgleich der Eintrittspreis für diesen Film ermäBigt war, war der Besuch des Filmes von Anfang an schwach ${ }^{651}$. Nur kurze Zeit später wurde „Le Péril juif“" dort wieder abgesetzt, weil er laut Referat Film nur mäßigen Erfolg hatte. Statt dessen wurde der Film in dem kleineren und unbekannteren Filmtheater Cameo gezeigt ${ }^{652}$. Auch in Deutschland war „Der ewige Jude“ kein Erfolg gewesen. Dort lief er in zwei unterschiedlichen Fassungen. Das Plakat zu einer Sonderaufführung der NSDAP am 28. November 1940 in Berlin empfahl „empfindsamen Gemütern" 653 den Besuch der Vorstellung mit der gekürzten Fassung. In Paris schrieb die Zeitung Gringoire am 31. Juli 1942:

Höchst befremdend, aber am eindrucksvollsten in diesem Film, ist das grausame Töten der Tiere in den Schlachthäusern durch jüdische Schlächter. Der endlose Todeskampf der Ochsen und Hammel, die dem jüdischen Gesetz entsprechend erstochen werden und beim ekelhaften Gelächter ihrer Henker die letzten Laute ihres gequälten Fleisches von sich geben müssen, das zu sehen ist wahrhaftig eine Tortur ${ }^{654}$.

Interessanterweise fehlten gerade diese Szenen in der gekürzten deutschen Version. Im Anschluß daran wurden in dem Film als angeblicher Kontrast "deutsche Menschen und Bilder deutschen Wesens ${ }^{\text {“ } 655}$ gezeigt. Im Februar/ März 1944 wurde „Der ewige Jude“ ebenso wie "Hitlerjunge Quex“ erneut in Frankreich eingesetzt ${ }^{656}$. Die Resonanz beim französischen Publikum dürfte hier aufgrund der veränderten Kriegslage nun noch schlechter als im Sommer 1942 gewesen sein.

Ebenso wie „Der ewige Jude“ die Einführung des Judensterns hatte vorbereiten sollen, so wurden auch andere Maßnahmen der Besatzungsmacht durch entsprechende Filme flankiert. Die Filme über französische Kriegsge-

650 BA-MA, RW35 226, Prop.Abt., Gr.Film, Tätigkeitsbericht, 6. 6.-12. 6. 1942.

651 Ibid. Tätigkeitsberichte, 13. 6.-20. 6. 1942; 10. 7. 1942.

652 Ibid. Tätigkeitsbericht, 10. 7.-17. 7. 1942; Ibid. 25. 7. - 31. 7. 1942.

653 Zit. n. WULF, Theater und Film, S. 456.

654 Zit. n. der Übersetzung von WULF, Theater und Film, S. 459.

655 Albert BRODBECK, Der ewige Jude - Uraufführung des großen Dokumentarfilms, in: Deutsche Allgemeine Zeitung, 29. 11. 1940, zit. n. WULF, Theater und Film, S. 457 f. Brodbeck schrieb: „Das Entsetzen erregenste Kapitel kommt am Schluß: das grausame, unmenschliche, barbarische Schächten von Schlachttieren (Dieser Abschnitt wird in den Vorstellungen, weil er die Nerven einer zu harten Belastungsprobe aussetzt, nur wahlweise gezeigt.)".

656 BA-MA, RW35 227, Prop.Abt., Filmprüfstelle, Tätigkeitsbericht, 26. 2.-4. 3. 1944. 
fangene in Deutschland gehörten hier zur sogenannten Beruhigungspropaganda, welche die Sorgen und Fragen der Angehörigen in Frankreich aufnehmen und widerlegen sollte. Grundsätzlich gehörte die Frage der französischen Kriegsgefangenen in Deutschland allerdings eher zu den Propagandathemen der Regierung in Vichy 657 . Tatsächlich kam die Anregung, Filme über französische Kriegsgefangene in Frankreich öffentlich zu zeigen, ursprünglich von französischer Seite und stammte nicht von den deutschen Dienststellen. Der französische Regierungsbeauftragte Georges Scapini äußerte sie im November 1940 gegenüber dem damaligen Leiter der Außenstelle der Deutschen Wochenschau in Paris, F. von Kondratovicz. Dieser bat daraufhin seine Vorgesetzten bei der Deutschen Wochenschau in Berlin, ihm entsprechendes Filmmaterial zuzusenden, das er in Form eines kurzen Propagandafilmes im Anhang an die Wochenschau zeigen wollte. Von dort erhielt er nur Material, das keinen Ton enthielt und das in Paris zunächst zu einem stummen Kurzfilm von etwa 350 Metern zusammengeschnitten wurde. Anschließend wurde der Film mit Text versehen und vertont. Der „kriegsblinde" Scapini ließ den Film von Mitarbeitern besichtigen und war, so von Kondratovicz, „entzückt "658 über das Ergebnis. Er wollte dem Film selbst eine kurze Ansprache voranstellen, die „stimmungsmäßig im günstigen Sinne den weiteren Aufbau und die Verständigung " beeinflussen sollte.

So versandte von Kondratovicz am 24. April 1941 Einladungskarten zur ersten Sondervorstellung des Filmes unter dem Titel „Un Stalag quelque part en Allemagne". Die Uraufführung sollte im Beisein Scapinis und 1500 geladenen Kindern französischer Kriegsgefangener stattfinden. Doch noch vor der Vorführung kam es aufgrund der Zulassung des Filmes durch die Zensur der Propaganda Abteilung zu Unstimmigkeiten und Schmidtke verbot schließlich den Film. Er war der Ansicht, der Film würde zu einem großen Skandal führen und bemängelte vor allem solche Aufnahmen, die Kriegsgefangene „bei schwerer Arbeit im Schnee mit bloßen Händen" 659 zeigten. Er wunderte sich, weshalb sich die Hersteller nicht auf die Darstellung der Freizeit in den Lagern beschränkt hatten. Zur eventuellen Reaktion des Publikums im Falle einer Vorführung heißt es: „Es hätte in dem Theater ein unglaubliches Schluchzen und Weinen der Kinder eingesetzt, die ihre Angehörigen in dieser Art Aufnahme als Kriegsgefangene gesehen hätten" ${ }^{660}$. Schmidtke versicherte von Kondratovicz, ihm selbst drehe sich bei diesen

657 Rossignol, Histoire de la Propagande, S. 125-127.

658 BA-MA, RW4 219, DW, Außenstelle Paris, v. Kondratovicz an DW Berlin, Auslandsabteilung, 30. 4. 1941. Zu Scapini siehe auch JÄCKEL, Frankreich, S. 102-104; Scapini hatte als Vorsitzender des Comité France-Allemagne 1937 einmal länger mit Hitler gesprochen und war im September 1940 von Pétain beauftragt worden, wegen der Frage der Kriegsgefangenen mit den deutschen Stellen in Kontakt zu treten.

659 BA-MA, RW4 219, MBF, Prop.Abt., Kommandeur, Schmidtke an OKW/ Wpr Berlin, Betr.: Außenstelle der Deutschen Wochenschau G.m.b.H., 17.6. 1941.

660 Ibid. 
Bildern „das Herz im Leibe" um, wenn er sich an die Stelle der Kinder versetze. Demgegenüber führte von Kondratovicz an, bei der Bearbeitung des Filmes hätten seine französischen Mitarbeiter betont, wie erleichtert sie darüber seien, die Gefangenen nicht hinter Gittern, sondern bei der Arbeit in freier Natur zu sehen ${ }^{661}$. Es ist durchaus denkbar, daß diese Mitarbeiter mit ihrer Aussage, der Anblick der in der freien Natur - im Schnee - arbeitenden Kriegsgefangenen sei beruhigend, ihre deutschen Vorgesetzten absichtlich hinters Licht geführt hatten; vielleicht wollten sie einen Mißerfolg des Filmes provozieren. In jedem Falle war die Einschätzung Schmidtkes, was die voraussehbare Reaktion des Publikums betrifft, hier sicherlich realistischer. Der Streit um den Kriegsgefangenenfilm war abgesehen von solchen inhaltlichen Differenzen auch Teil genereller Unstimmigkeiten zwischen von Kondratovicz und Schmidtke, worauf noch zurückzukommen sein wird. Nach dem Verbot von „Un Stalag quelque part en Allemagne“ notierte das Referat Film in seinem Tätigkeitsbericht, das OKW werde nun neues Filmmaterial zu diesem Thema zur Verfügung stellen; erst dann sollte entschieden werden, ob die Propaganda Abteilung einen Film über französische Kriegsgefangene öffentlich vorführen wolle ${ }^{662}$. Nachdem also die Anregung zu den Filmen über Kriegsgefangene zunächst von französischer Seite gekommen war und der erste Versuch in diese Richtung mit "Un Stalag quelque part en Allemagne“ gescheitert war, wartete die Propaganda Abteilung also auf Material aus Berlin. Von planmäßiger Propaganda kann hier nicht die Rede sein.

Um den Angehörigen der französischen Kriegsgefangenen schließlich doch noch deutlich zu machen, wie angenehm jene angeblich in deutschen Lagern lebten und untergebracht waren, zeigte die Propaganda Abteilung kurz vor der Jahreswende 1941/42 mehrere kurze Kriegsgefangenenfilme in Sondervorstellungen. Die Kulturfilme trugen die vielsagenden Titel „Lagerleben“, „Traumspiel“, „Heimkehr“ und „Schönes Frankreich“. Seit Oktober 1941 bereitete das Referat Film ihren Einsatz vor663. Die vorgeblichen Dokumentarfilme befaßten sich mit dem Leben der Kriegsgefangenen im Lager, bei der Arbeit und vor allem mit ihrer Freizeitgestaltung. „Heimkehr" handelte von den durch „Führererlaß“ vorzeitig entlassenen französischen Weltkriegsteilnehmern. In „Traumspiel“ inszenierten französische kriegsgefangene Offiziere in einem sogenannten Offlag für ihre Mitgefangenen ein Theaterstück; in "Schönes Frankreich" führten in einem "Stalag" französische Kriegsgefangene ein Revue-Theater auf664. Die vier Filme, die zusammen als abendfüllendes Programm im Sonderverleih der Tobis unter dem

661 BA-MA, RW4 219, Schreiben, v. Kondratovicz, Dt. Wochenschau, Außenstelle Paris an Deutsche Wochenschau Berlin, Auslandsabteilung, 30. 4. 1941.

662 BA-MA, RW35 220, Prop.Abt., Ref.Film, Tätigkeitsbericht, 17. 4.-24. 4. 1941.

663 BA-MA, RW35 223, Prop.Abt., Ref.Film, Tätigkeitsberichte, 3. 10.-10. 10. 1941; 31. 10.-7. 11. 1941.

664 BA-MA, RW35 224, Prop.Abt., Ref. Film., Tätigkeitsbericht, 2. 1. 1942. „Traumspiel“ erhielt in den Akten des Ref. Film u.a. den Titel „Lübben“. 
Gesamttitel „Nos Prisonniers de guerre" liefen, hatte das OKW/WPr zur Verfügung gestellt. Den Erlös sollte aus propagandistischen Gründen die französische Organisation zur Betreuung der Kriegsgefangenen erhalten ${ }^{665}$. Zur Werbung wurden gemeinsam mit der Deutschen Botschaft Plakate mit der beinahe fürsorglich anmutenden Aufschrift "Nos Prisonniers" ausgesucht ${ }^{666}$. Scapini hielt eine gefilmte Ansprache, die als Vorwort dem Gesamtfilm vorangestellt wurde667. Am 16. Dezember 1941 wurde „Nos Prisonniers" in Paris uraufgeführt. Die Einladungen an Angehörige von Kriegsgefangenen und offizielle französische Persönlichkeiten erfolgten durch das Büro Scapini ${ }^{668}$. Allerdings kam keiner seiner Mitarbeiter zur Uraufführung und Scapini selbst reiste kurz vorher nach Berlin ${ }^{669}$.

Ende Januar 1942 schrieb das Referat zur Reaktion des Publikums auf den Film, der Erfolg sei dem von deutschen Spitzenfilmen durchaus vergleichbar: „Unter Berücksichtigung der besonderen Aufgabe dieses Filmes und der Abneigung, die Franzosen im allgemeinen gegen Dokumentarfilme haben, ist es also mehr als zufriedenstellend" 670 . Obgleich das Referat einen Erfolg vermeldete, schwingt hier erneut mit, daß die französischen Zuschauer grundsätzlich deutsche Propaganda in Form von Kulturfilmen ablehnten. Der Erfolg von „Nos Prisonniers" bedeutet noch lange nicht, daß das französische Publikum etwa den propagandistischen Aussagen dieser Filme nahestand. Er dürfte eher darauf zurückzuführen sein, daß die Bevölkerung natürlicherweise für jegliche Art von Information über die Kriegsgefangenen empfänglich war, selbst dann, wenn es sich um Propagandafilme handelte. Sicherlich konnten diese Filme jedoch nicht wirklich der Beruhigung der Angehörigen dienen. So meldete die Staffel St. Germain, unter den Besuchern sei die Meinung laut geworden, die Aufnahmen stammten aus einem Musterlager oder seien gestellt. Ein Geschäftsmann aus Orleans soll gesagt haben, „daß eine solche Unterbringung und Sorgfalt für die Kriegsgefangenen weder in Frankreich während dieses Feldzugs, noch in den Gefangenenlagern Deutschlands während des Weltkrieges 1914-18“671 vorhanden gewesen wären. Allerdings sah die Staffel in dieser Aussage einen Einzelfall. Zudem berichtete die Staffel später, der Besuch des Filmes lasse in den Städten besonders nach den Erstaufführungen stark nach, was sie der schlechten Mundpropaganda zuschrieb. Auch bemängelte sie, daß entgegen der Einladungen, die

665 BA-MA, RW4 220, Prop.Abt., Lageberichte, 16. 10.-23. 10. 1941.

666 BA-MA, RW35 224, Prop.Abt., Ref.Film, Tätigkeitsbericht, 7. 11.-14. 11. 1941.

667 Ibid. Tätigkeitsbericht, 17. 10.-24. 10. 1941.

668 BA-MA, RW4 220, Prop.Abt., Lageberichte, 1. 12.-15. 12. 1941.

669 BA-MA, RW35 224, Prop.Abt., Ref.Film., Tätigkeitsbericht, 2. 1. 1942.

670 BA-MA, RW35 225, Prop.Abt., Ref.Film, Tätigkeitsbericht, 24. 1.-31. 1. 1942. Für das Filmtheater Apollo in Bordeaux wurde eine vergleichende Tabelle der Einnahmen von „Nos Prisonniers" und erfolgreicheren deutschen Spielfilmen aufgestellt. Während dieser Film in der ersten Woche 90000 Francs einspielte waren es bei „Bel ami“ 149000, "Ohm Krüger" 121000 und „Operette" 111000 Francs gewesen.

671 BA-MA, RW35 225, Prop.Abt., Ref.Film, Tätigkeitsbericht, 24. 1.-31. 1. 1942. 
zu den festlichen Erstaufführungs-Veranstaltungen an offizielle französische Persönlichkeiten ergangen waren, diese niemals anwesend waren. Insgesamt sollen aber etwa 10 Prozent der Bevölkerung den Film gesehen haben ${ }^{672}$. In jedem Fall war die Propaganda Abteilung der Ansicht, sie habe mit der Verbreitung dieses Filmes eine besondere Leistung vollbracht. Im Januar berichtete das Referat Film von der Vorpropaganda für „Prisonniers de guerre“ in den Staffelgebieten. In der Presse, die sich hier an die Vorgaben der deutschen Dienststellen hielt, sei betont worden, zum ersten Mal werde hier ein Volk über seine Gefangenen noch während der Dauer der Kriegsgefangenschaft unterrichtet. „Der Film beweise die menschliche Behandlung, die den Franzosen in Deutschland zuteil wird. Der Film wirke keineswegs gestellt" ${ }^{\text {"673. }}$. Bis Anfang Oktober 1942 wurden Scapini aus dem Erlös der Vorführungen dieses Filmes für den Unterstützungsfonds rund 1380360 Francs übergeben ${ }^{674}$. Später kamen noch etwa 1401150 Francs $^{675}$ sowie 1602 Francs $^{676}$ hinzu.

Auch im unbesetzten Gebiet wurde „Nos Prisonniers“ gezeigt. Zur Erstaufführung in Vichy erschien am 25. Dezember 1941, also am ersten Weihnachtsfeiertag, Pétain persönlich mit etlichen Regierungsmitgliedern ${ }^{677}$. Bei dieser Vorstellung brachte das Publikum während einiger Szenen, unter anderem bei einer zweiten Rede Scapinis in dem Film, seine Ablehnung offen zum Ausdruck. Deswegen fragte das französische Informationsministerium bei der Zweigstelle der Deutschen Botschaft in Vichy an, ob der Film nicht für die unbesetzte Zone um die betreffenden Szenen, nicht aber die Rede Scapinis, gekürzt werden könne. Bei den Szenen handelte es sich unter anderem um Sequenzen im Friseursalon (45 Sekunden) und um die Vorführung der Revue (24 Minuten) ${ }^{678}$. Doch Schleier gab der Zweigstelle Vichy zur Antwort, alle deutschen Dienststellen seien sich darüber einig, daß eine Kürzung von "Prisonniers" strikt abzulehnen sei ${ }^{679}$. Die ungeschminkten Reaktionen des Publikums im unbesetzten Gebiet zeigen, wie offensichtlich, plump und wirkungslos die Propaganda dieser Filme in den Augen der Franzosen war.

Ein weiteres Thema deutscher Filmpropaganda, das mit dem der Kriegsgefangenen zum Teil eng verbunden war, war der französische Arbeitseinsatz in Deutschland. Beide Themen trafen freilich generell bei der Bevölkerung nicht gerade auf Zustimmung. Seit Beginn der Okkupation rekrutierte die Besatzungsmacht Franzosen für die Arbeit in Deutschland. Doch der Bedarf

672 Ibid. Tätigkeitsbericht, 30. 1.-6. 2. 1942.

673 BA-MA, RW4, 221, MBF, Prop.Abt., Lageberichte, 1. 1.-15. 1. 1942, 16. 1.1942.

674 BA-MA, RW35 227, Prop.Abt.,Gr.Film, Tätigkeitsbericht, 4. 10.-10. 10. 1942.

675 Ibid. Tätigkeitsbericht, 25. 10.-31. 10. 1942.

676 Ibid. Tätigkeitsbericht, 26. 12. 1942-2. 1. 1943.

677 BA-MA, RW35 224, Prop.Abt., Ref. Film, Tätigkeitsbericht, 2. 1. 1942.

678 PA-AA, 1217, Kult 12 Nr. 4 I, Zweigstelle der Deutschen Botschaft in Vichy, Struve an Lierau, DBP, 16. 1. 1942.

679 Ibid. DBP, Schleier an Zweigstelle der Deutschen Botschaft in Vichy, 20. 1. 1942. 
an sogenannten Freiwilligen stieg und im Juni 1942 ließ sich die französische Regierung auf einen Handel mit der Besatzungsmacht ein. Sie tauschte eine bestimmte Anzahl an sogenannten freiwilligen Arbeitern gegen eine Anzahl freigelassener französischer Kriegsgefangener ein. Die Arbeiter „lösten“ die Kriegsgefangenen gleichsam „ab“; deswegen lief diese Aktion unter dem Begriff La Relève. Dies änderte sich mit der Einführung des Service du travail obligatoire (STO) den die Vichy-Regierung mit dem Gesetz vom 16. Februar 1943 festlegte, weil die deutsche Seite mehr und mehr Arbeitskräfte einforderte. Vor allem seit dem Frühjahr/Sommer des Jahres 1942 wurden nun verstärkt französische Arbeiter zum STO in Deutschland zwangsverpflichtet ${ }^{680}$. Entsprechende Kulturfilme sollten die Akzeptanz solcher Maßnahmen unterstützen und die Bevölkerung vom Sinn des Arbeitseinsatzes in Deutschland überzeugen.

Im Juni 1942 forderte Major Schmidtke beim RMVP Filmmaterial zur Werbung französischer Arbeitskräfte an. Insbesondere bat er um die schnellstmögliche Lieferung von Filmen folgender Art:

Filme, die die Schönheit der deutschen Landschaft aufzeigen und den Franzosen vor Augen führen, daß auch Deutschland ein schönes Land ist. [...] Nicht in Betracht kommen solche Kulturfilme, in denen auf dem Hintergrund oder im Rahmen der schönen Landschaft die Erziehungsarbeit am deutschen Volk z.B. BDM und HJ etc. vorgeführt wird ${ }^{681}$.

Demnach sollten die Filme ein schönes Deutschland, nicht aber ein offensichtlich nationalsozialistisches Land zeigen, weil dies in Schmidtkes Augen bei den französischen Zuschauer eher abschreckend gewirkt hätte. Ende Juli 1942 wurden daraufhin die Filme „La Beauté du travail“, „La Main dans la main" sowie "Freude und Schönheit" in Sondervorstellungen gezeigt ${ }^{682}$. Abgesehen von der Vorführung solcher allgemein mit einem positiven Bild Deutschlands werbenden Kulturfilme, versuchte sich das Referat auch an der Herstellung eines eigenen Filmes zur Anwerbung französischer Arbeitskräfte. Es plante dieses Filmprojekt bereits seit Januar 1942. Ein abendfüllender Kulturfilm sollte den Einsatz französischer Arbeitskräfte in Deutschland in entsprechend positiver Weise darstellen. Die NSDAP sandte Diedrich eine genauere Planung dieses Filmes zu. Die Gruppe Aktivpropaganda sollte die Produktion betreuen; die Mitarbeit von französischen Filmregisseuren, Drehbuchautoren, Kameraleuten und Komponisten war geplant. Das Referat Film machte hierfür Vorschläge, betonte jedoch, es könne sich für die Qualifikation der französischen Kräfte nicht verbürgen. Außerdem seien die Franzosen in der Herstellung von Propagandafilmen generell zu unerfahren. Es schlug der NSDAP mehrere Personen vor: Robert Muzard, der bereits an der Herstellung von "Les Corrupteurs" beteiligt gewesen war, Georges

680 JÄCKEL, Frankreich, S. 223 f.

681 BA-MA, RW35 226, Prop.Abt., Gr.Film, Tätigkeitsbericht, 1. 6.-6. 6. 1942.

682 Ibid. Tätigkeitsbericht, 25. 7.-31. 7. 1942. 
Fronvall, Journalist vom „Paris Soir", sowie Thiriet, der schon für „Nos Prisonniers" die passende Musik verfaßt hatte. Alle drei waren aus der Kriegsgefangenschaft entlassen worden ${ }^{683}$. Offenbar ließ die Herstellung des Filmes auf sich warten, denn im Juni 1942 forderte Schmidtke das RMVP auf, besagten Film aufgrund seiner "kriegswichtigen Bedeutung ${ }^{\text {} 684}$ dringend herzustellen. Wieder betonte er, die Mitarbeiter müßten Franzosen sein, „damit französische Mentalität und die verschiedenartigen werbepsychologischen Gesichtspunkte ihren Niederschlag finden"685. Schließlich übernahm die Deutsche Film AG in München die Herstellung des Filmes. Im September 1942 waren die Vorbereitungen dazu erst soweit gediehen, daß diese einige Mitarbeiter, darunter den Produktionschef Arno Funke, nach Paris entsandte, um dort mit der Botschaft, Alfred Greven, der Filmprüfstelle und der Gruppe Aktivpropaganda der Propaganda Abteilung zu verhandeln. Die Aufnahmen des Filmes, die in Frankreich spielten, sollte die Continental drehen ${ }^{686}$. Im Oktober 1942 sandte die Informationsabteilung des AA an die Deutsche Botschaft in Abschrift ein Schreiben der Deutschen Film AG an das RMVP und bat die Deutsche Botschaft um Stellungnahme ${ }^{687}$.

Nach dem Brief der Münchner Firma hatte Goebbels persönlich die Herstellung des Filmes genehmigt. Der Drehbuchautor Robert Perrier war auf Anraten Muzards mit dem Manuskript beauftragt worden und in Paris war das Drehbuch mit Vertretern der Deutschen Botschaft und der Propaganda Abteilung abgesprochen worden. Alle Beteiligten, so der Brief, hätten sich bisher zustimmend geäußert und auf eine schnelle Herstellung des Filmes gedrängt. Zur Zeit würden noch einige Richtlinien von Autor Perrier zusammen mit dem deutsch sprechenden Regisseur Rust, ebenfalls von Muzard empfohlen, in das Drehbuch mit eingearbeitet ${ }^{688}$. Es kam jedoch erst einmal zu Unstimmigkeiten mit Greven, dessen Continental zunächst die in Paris spielenden Anfangs- und Schlußszenen hatte drehen sollen. Nach seiner Rückkehr von einem Aufenthalt aus Berlin weigerte sich Greven, die bereits mit seinem Stellvertreter Bauermeister abgeschlossenen Verträge einzuhalten, angeblich weil die Devisenunterlagen nicht vorlägen. Grundsätzlich aber erklärte er, diese Verträge ließen sich nicht mit den Richtlinien, die er vom Reichsfilmintendanten erhalten habe, vereinbaren. Die Deutsche Film AG beschloß, das Projekt nun in Zusammenarbeit mit Muzard zu verwirklichen, „der sich außergewöhnlich deutschfreundlich und aktiv" 689 zeigte. Sie bat

683 BA-MA, RW35 224, Prop.Abt., Ref.Film, Tätigkeitsbericht, 2. 1. 1942.

684 BA-MA, RW35 226, Prop.Abt., Gr.Film, Tätigkeitsbericht, 1. 6.-6. 6. 1942.

685 Ibid.

686 PA-AA, 1114, Kult 12 Nr. 4e, DBP, Knothe an Bran, AA, 24. 9. 1942.

687 PA-AA, 1218, Kult 12 Nr. 4 II, AA an DBP, Betr.: Film zur Werbung französischer Facharbeiter "La Relève“, 12. 10. 1942.

${ }^{688}$ Ibid. Deutsche Film A.G., Herstellungs- und Verwertungs- Gesellschaft m.b.H. München an RMVP, Herrn Lahs, Abschrift, Betr: Film zur Werbung frz. Facharbeiter, "La Relève“, 28. 9. 1942.

689 Ibid. 
nun das RMVP um Stellungnahme, ob gegen Muzard und Rust Bedenken bestünden. Die Zeit dränge insbesondere deswegen, weil in den nächsten Wochen in Frankreich eine verstärkte Propaganda zur Arbeiteranwerbung laufen sollte, für die der Film wichtig sein werde ${ }^{690}$. Die Stellungnahme der Botschaft war positiv, mahnte aber zur Eile, wenn der Film überhaupt noch seinen Zweck erfüllen solle 691 . Offenbar lag aber erst im Dezember 1942 das fertige Drehbuch vor, von dem Greven eine deutsche Übersetzung an die Deutsche Botschaft schickte692. Der Film hieß „La Relève“, im deutschen Titel „Die von der Ablöse“, Robert Perrier und der Regisseur Serge Griboff wurden als Autoren genannt ${ }^{693}$.

Laut Drehbuch nahm der Film die negative Haltung der französischen Bevölkerung zum Arbeitseinsatz in Deutschland auf, freilich nur um diese angeblichen Vorurteile anschließend gründlich zu widerlegen. So trifft zu Beginn des Drehbuches der französische Arbeiter Paul kurz vor seiner freiwilligen Abreise nach Deutschland Freunde in einer Kneipe des Viertels Bastille, damals ein typisches Arbeiterviertel. Seine Freunde halten ihn für verrückt. In Deutschland müsse er sicherlich nur schwer arbeiten, außerdem habe man von Rückkehrern gehört, es gebe nichts zu essen und Wanzen im Strohsack und ansonsten sei das Leben dort wie in einem Zuchthaus. Doch Paul beteuert, er sei gerade neugierig auf dieses Zuchthaus und überhaupt, werde er seiner Frau zu Hause Geld schicken können ${ }^{694}$. Dieses Argument, die französischen Arbeiter könnten in Deutschland Geld verdienen und dies anschließend nach Hause schicken, findet sich häufig in der deutschen Propaganda zum Arbeitseinsat ${ }^{695}$. Anschließend sieht das Drehbuch eine ausführliche Schilderung von Pauls Aufenthalt in Deutschland vor; zu Beginn unternimmt er demnach zusammen mit zwei französischen Kollegen eine Besichtigungstour durch mehrere deutsche Fabriken, in denen Franzosen arbeiten und besucht die Wohnheime der französischen Arbeiter. Die Kollegen, die Paul begleiten, sind laut Drehbuch beide schon auf Urlaub in Frankreich gewesen, aber dennoch wieder nach Deutschland zurückgekehrt. Dies soll laut Drehbuch als der beste Beweis für das so angenehme Leben in Deutschland gelten. Ferner sieht es für die Besichtigungstour Pauls ungezwungene, wie es heißt, "nicht gestellte" 696 Szenen vor, die vom wunderbaren Leben der fran-

690 Ibid.

691 PA-AA, 1218, Kult 12 Nr. 4 II, Durchdruck, DBP an AA, Betr.: Anwerbung frz. Facharbeiter/Film "La Relève“, Bezug: Erlaß vom 12.10. 1942 Inf. K III 4348/42, 28. 10.1942.

692 PA-AA, 1143a, Kult. 12 Nr. 4, Continental-Films an Lohmann, DBP, Kulturabt., Betr.: Film „La Relève“, 24. 12. 1942.

693 Ibid. „Die von der Ablöse“-Verfilmte Reportage über die französischen Arbeiter in Deutschland, Autor: Robert Perrier, Decoupage: Robert Perrier und Serge Griboff, ohne Datum (etwa Dezember 1942).

694 Ibid.

695 Rossignol, Histoire de la Propagande, S. 185-193.

696 PA-AA, 1143a, Kult. 12 Nr. 4, „Die von der Ablöse“-Verfilmte Reportage über die 
zösischen Arbeiter in Deutschland zeugen. Die Antworten der während der Tour befragten Arbeiter gibt das Manuskript ebenfalls vor. Diese sind durchweg zufrieden mit ihrer Arbeit, verdienen sehr viel und einer gibt an, durch seinen Arbeitseinsatz, sei sein Vater aus deutscher Kriegsgefangenschaft entlassen worden. Die Szenen in dem Schlafsaal eines französischen Wohnheimes bzw. Männerlagers sehen geradezu eine Idylle vor: Männer beim Kartenoder Würfelspiel, ein Schuster und ein Frisör bei der Arbeit; ein Arbeiter zeichnet bunte Ansichtskarten mit Sätzen wie „Dein Männchen, der Dich nicht vergißt"697, „Aus den Augen dem Herzen nahe“ und „Für meine Nenette, ihr Loulou"; anschließend sind Großaufnahmen der Spielkarten vorgesehen.

Abgesehen von dem positiven Bild, das hier vom Arbeitseinsatz in Deutschland vermittelt werden sollte, war der Film zugleich wohl als Anleitung gedacht, wie die französischen Arbeitskräfte sich verhalten sollten, um den Aufenthalt in Deutschland angenehm gestalten zu können: Sie sollten fleißig und reinlich sein. Dies wird besonders in den Sequenzen deutlich, die für die Darstellung eines französischen Frauenlagers bei Telefunken in Berlin vorgesehen waren. Zunächst sieht das Drehbuch Szenen in einer deutlich reinlichen, mit Blumen und dem Portrait Pétains geschmückten Stube mit jungen zufriedenen Frauen, die gerade gemeinsam Eis essen, vor. Als Kontrast folgt ein dreckiges Zimmer, in dem eine unzufriedene Französin weinend sitzt, weil die anderen sie beschuldigen, eine Diebin zu sein. Sie klagt über Wanzen. Der Sprecher des Filmes kommentiert an dieser Stelle, die Französinnen, die schlecht arbeiteten und unreinlich seien, würden sich über die Zustände des Lebens in Deutschland am meisten beschweren: „Dabei sind diese jungen Mädchen leider nur Erziehungsprodukte der Volks-

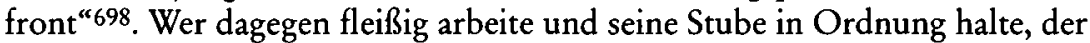
könne nicht anders als glücklich über seine Arbeit in Deutschland sein. Daraufhin folgen ausführliche Szenen zur Freizeit, die den Aufenthalt in Deutschland eher als eine Erholung erscheinen lassen; darunter sind auch Szenen mit französischen Arbeitern, die bei einer Berliner Familie untergebracht sind und dort genußvoll Bratkartoffeln essen. Die letzten Sequenzen des Filmes sollen an den Beginn anknüpfen: Paul kehrt nach sechs Monaten Arbeit in Deutschland nach Paris zurück, um sich in der gleichen Kneipe nahe der Bastille wieder mit seinen Freunden zu treffen. Triumphierend tritt er den überraschten Freunden gesund und wohlgenährt gegenüber und verkündet, nun habe er genügend Geld, um diese einzuladen. Der Film sollte enden mit den Worten: „Nun denn, jetzt ist die Reihe an mir. Wirt! Drei Schnäpse"699.

französischen Arbeiter in Deutschland, Autor: Robert Perrier, Decoupage: Robert Perrier und Serge Griboff, ohne Datum (etwa Dezember 1942).

697 Ibid.

698 Ibid.

699 Ibid. 
In den Akten der Deutschen Botschaft ist ein weiteres Drehbuch zu einer Reportage von Jacques Morval mit dem Titel „Dienst an Europa“ zum Arbeitseinsatz in Deutschland zu finden, das in weiten Teilen identisch mit der Vorlage zu „La Relève“ ist ${ }^{700}$. Allerdings basiert der Aufbau von „Dienst an Europa “ auf dem Grundgedanken, die deutschen Soldaten würden an der Ostfront für den Frieden Europas ihr Leben hingeben. Deswegen sei es notwendig, daß die französischen Arbeiter diesen Kampf durch ihre Arbeit in Deutschland unterstützen, sich für ein gemeinsames freies Europa einsetzten. Es ist sehr wahrscheinlich, daß gerade dieser Aspekt allein auf Wunsch der deutschen Dienststellen in das Drehbuch eingearbeitet worden war, da es sich hier um eine deutsche Konzeption der Propaganda für den Arbeitseinsatz handelte, wie beispielsweise die Plakatpropaganda zeigt. Während die französische Propaganda der Vichy-Regierung eher Frankreich in den Vordergrund stellte, argumentierte die deutsche mit dem Aspekt des vom Bolschewismus zu befreienden Europa ${ }^{701}$. Gleich zu Beginn sieht das Drehbuch Szenen vor, in denen ein deutscher Arbeiter an die Ostfront geht und ein französischer Arbeiter seinen Platz an der Maschine in einer deutschen $\mathrm{Fa}_{\mathrm{a}}$ brik einnimmt. Es folgen Bilder vom Krieg an der Ostfront, während der Sprecher kommentiert: „Deutschland führt einen heroischen Kampf, um Europa vor dem Bolschewismus zu retten. Seine Söhne geben ihr Blut auf den Schlachtfeldern. Frankreich, welches mitarbeiten will an dem Aufbau des neuen Europa, schickt seine Jugend nach Deutschland nicht um zu kämpfen, sondern um zu arbeiten"702. Die in Deutschland arbeitenden Franzosen preist der Kommentar als „Soldaten des neuen Europa“. Anschließend folgen wie in "La Relève" Darstellungen des wunderbaren Arbeitslebens in Deutschland. Die Regieanweisung für den Rundgang im Werk des Deutschen Verlags in Berlin lautet so: „Jeder ist gut gelaunt. Ein Witz hier und da, wenn sich die Kamera von einem Arbeitsplatz zum anderen bewegt. Dann die Garderobe, die Toiletten, die Brausebäder, die Kantine an dem Ufer der Spree“703. Währenddessen spricht der Kommentar: „Die neuzeitlichen Einrichtungen dieses Werkes, der Komfort, der den Arbeitern gegeben wird, ist die Verwirklichung des Sozialismus"704. Daraufhin folgen laut Regieanweisung in schneller Folge Bilder der französischen Arbeiter bei der Benutzung der gesamten sozialen Einrichtungen, um diese dann zu kontrastieren mit den Elendsvierteln der Arbeiter im „bolschewistischen Russland“ und dem Krieg an der Ostfront ${ }^{705}$.

700 PA-AA, 1143a, Kult. 12 Nr. 4, Dienst an Europa, Reportage von Jacques Morval, Übersetzung, ohne Datum (etwa 1943).

701 RossignOL, Histoire de la Propagande, S. 189-191.

702 PA-AA, 1143a, Kult. 12 Nr. 4, „Dienst an Europa“, Reportage von Jacques Morval, Übersetzung, ohne Datum (etwa 1943).

703 Ibid.

704 Ibid.

705 Ibid. 
Bran hielt dieses Filmprojekt zum Arbeitseinsatz insgesamt für zu umständlich. Seiner Ansicht nach sollten eher kurze Filme und Wochenschauberichte die Bevölkerung möglichst schnell und einfach über den Verbleib und die Lebensumstände ihrer Angehörigen in Deutschland aufklären. Der Regisseur Griboff und Schriftleiter Montarron sollten nach Berlin reisen, um Änderungen an dem Buch unter anderem mit einem Vertreter der DAF und dem AA zu besprechen ${ }^{706}$. Neben DAF und AA war auch Günter Kaufmann, Leiter des Amtes Filmproduktion der Reichspropagandaleitung der NSDAP an der Herstellung eines solchen Filmes interessiert ${ }^{707}$. Allerdings dachte auch Kaufmann hierbei sicherlich weniger an ein Drehbuch wie „Dienst an Europa“. Kaufmann war im Mai 1943 nach Paris gereist. Er hatte mit der Gruppe Aktivpropaganda der Propaganda Abteilung vereinbart, daß der Film unter Obhut und nach den Richtlinien des MBF, im Einvernehmen mit Knothe von der Deutschen Botschaft geschrieben werden solle. Es sollte ein Beiprogramm-Film von etwa 3-400 m werden; Montarron und Griboff sollten zur Durchführung des Auftrags nach Deutschland kommen. Die Continental sollte den Film herstellen. Die Gruppe Aktivpropaganda versprach, französische Schriftsteller ausfindig zu machen, „die das Thema des Arbeitseinsatzes in Deutschland von der rein menschlichen Seite im Sinne einer Spielfilmhandlung "708 ausarbeiten könnten. Der Film sollte einfach nur das angenehme Leben der französischen Arbeiter in Deutschland zeigen. Hierbei legte Kaufmann großen Wert auf eine französische Regieführung, um das Thema aus dem Publikum aus französischer Perspektive vorzuführen ${ }^{709}$. Im August 1943 heißt es in einem Bericht der Botschaft an das AA, der Regisseur Griboff und Schriftleiter Montarron seien zur Vorbereitung des Filmes „Arbeitseinsatz im Reich“ in Berlin gewesen ${ }^{710}$.

Inwiefern genau die obigen Drehbücher jemals realisiert wurden, konnte nicht ermittelt werden. Allerdings stellte die französische Firma Nova Films unter der Leitung von Muzard 1943 mit deutscher Unterstützung zwei Filme her, die für den Arbeitseinsatz warben. „Travailleurs de France en Allemagne“ schildert ähnlich wie das Drehbuch zu „La Relève“ das schöne Leben der französischen Arbeitskräfte in Deutschland; es ist denkbar, daß das obige Drehbuch hier als Grundlage gedient hatte. Der Film lief im Frühjahr 1944 in den französischen Filmtheatern an und sollte die französischen Arbeiter dazu animieren, nach Deutschland zu gehen. „Permissionaires n'oubliez pas“

706 PA-AA, 1143a, Kult. 12 Nr. 4, AA, Bran an Leis, AA, Betr.: Französischer Facharbeiter-Film, "Dienst an Europa“, Berlin 11. 5. 1943.

707 Ibid. DBP, Knothe an Bran, AA, Betr.: Französischer Facharbeiterfilm, „Dienst an Europa“, 22. 5. 1943.

708 Ibid. NSDAP, Reichspropagandaleitung, Amt Filmproduktion, Kaufmann an Gruppe Aktivpropaganda, Prop.Abt., 10. 5. 1943.

709 Ibid.

710 Ibid. DBP an AA, Telegramm, 1. 8. 1943. 
richtete sich an die Arbeiter, die in Frankreich nur auf Urlaub waren und wieder nach Deutschland zurückkehren sollten ${ }^{711}$.

Die Themen der Kulturfilme konnte das Publikum in französischen Filmtheatern auch in der Wochenschau wiederfinden. Im folgenden soll auf die Inhalte der dort verfolgten Propaganda allerdings nicht detailliert eingegangen werden, da dies den Rahmen der Arbeit sprengen würde. Im Vordergrund der Ausführungen zur Wochenschau steht vor allem ihre Aufnahme durch das französische Publikum ${ }^{712}$. Vor dem Kriege hatte es im Bereich der französischen Wochenschauen drei französische und zwei amerikanische Filmfirmen gegeben: France-Actualités Gaumont, Eclair Journal, Pathé Journal, Fox Movietone und Actualités Paramount. Mit der Besetzung Frankreichs mußten diese ihre Aktivitäten einstellen. Zu Beginn der Okkupation vertrieb zunächst die ACE eine französische Version der Deutschen Wochenschau, deren Vorführung ab Mai 1941 obligatorisch wurde. Im Falle der Weigerung, diese zu zeigen, konnte das betreffende Filmtheater geschlossen werden. Doch diese Maßnahme war nicht so erfolgreich wie die Besatzer gehofft hatten ${ }^{713}$.

Bei der Vorführung der Wochenschau wurden oft Proteste und laute Zwischenrufe unter den Zuschauern beobachtet. Obgleich sie zwangsweise zwischen Kulturfilm und Hauptfilm plaziert wurde, erschienen die Besucher oft erst später, um die Wochenschau absichtlich zu verpassen. Es kam sogar vor, daß Zuschauer den Raum ostentativ verließen und erst zum Spielfilm wiederkehrten. Letzteres hatte kurzzeitig zur Folge, daß das Verlassen der Filmtheater für die Dauer der Wochenschau verboten wurde. Auch versuchte die Besatzungsmacht durch Erhellung der Zuschauerräume, Plakatanschläge und Drohungen an die Filmtheaterbesitzer, den negativen Reaktionen des Publikums entgegenzuwirken ${ }^{714}$. Diese Maßnahmen blieben nicht ohne Wirkung. In einem Bericht vom Mai 1941 zur Tagung der Filmreferenten der Staffeln bei der Propaganda Abteilung heißt es, bei der Vorführung der Wochenschau seien in der letzten Zeit „bis auf geringfügige Einzelfälle“ keine Kundgebungen oder Demonstrationen mehr beobachtet worden und deshalb könne auf diese Maßnahmen nun verzichtet werden ${ }^{715}$. Seit Ende Mai 1941 zeigten die Filmtheater die Wochenschau daraufhin wieder in verdun-

711 BeRTIN-MAghit, Le Cinéma sous l'Occupation, S. 138.

712 Zur Wochenschau in Frankreich siehe grundlegend BERTIN-MAGHIT, Le Cinéma sous l'Occupation, S. 106-119; Thalmann, La Mise au pas, S. 192-194; GARÇON, The Film Propaganda, S. 170-175.

713 BA-MA, RW35 221, Prop.Abt., Ref.Film, Tätigkeitsbericht, 15. 5,-21. 5. 1941; Thalmann, La Mise au pas, S. 192.

714 ThalmanN, La Mise au pas, S. 193. Zu solchen Gegenmaßnahmen siehe auch BAMA, RW35 221, Prop.Abt., Ref.Film, Tätigkeitsbericht, 8. 5.-14. 5. 1941.

715 BA-MA, RW35 221, Prop.Abt., Ref.Film, Tätigkeitsbericht, 8. 5.-14. 5. 1941; Ausführungen zu einer Tagung der Filmreferenten der Propaganda Staffeln bei der Propaganda Abteilung am 14. 5. 1941. 
kelten Räumen ${ }^{716}$. Langfristig suchte die Besatzungsmacht jedoch nach einer anderen Lösung dieses Problemes. Zudem waren Versuche, die Deutsche Wochenschau im unbesetzten Gebiet zu vertreiben, gescheitert ${ }^{717}$. Eine deutsch-französische Wochenschau sollte schließlich für mehr Akzeptanz beim französischen Publikum sorgen.

Im November 1941 unterzeichnete die Vichy-Regierung ein deutsch-französisches Wochenschauabkommen. Dieses sicherte einer noch nicht benannten französischen Firma mit deutscher Beteiligung für die Dauer von 15 Jahren die Exklusivrechte für die Herausgabe der Wochenschau im besetzten und unbesetzten Gebiet zu. Diesem Unternehmen sollte die Deutsche Wochenschau $\mathrm{GmbH}$ sämtliches Filmmaterial zur Vefügung stellen, das für eine französische Wochenschau benötigt würde ${ }^{718}$. Am 4. Mai 1942 wurde mit dem Unternehmen France-Actualités die deutsch-französische Wochenschau gegründet. Präsident des Vorstandes war Henri Clerc, Vizepräsident Wilhelm Knothe, der Sachverständige des RMVP bei der Deutschen Botschaft. Insgesamt bestand der Vorstand aus drei französischen und zwei deutschen Mitgliedern. Bei der Gründung von France-Actualités war der Anteil an deutschem und französischem Kapital $60 \mathrm{zu} 40$ Prozent, was sich nach Ablauf eines Jahres änderte. Der französische Anteil betrug nunmehr 60 Prozent $^{719}$. Kurz vor Unterzeichnung des Wochenschauabkommens schrieb das Referat Film im Oktober 1941:

Aus taktischen, psychologischen und propagandistischen Gründen ist vorgesehen, den nächsten Ausgaben der Wochenschau einen stärkeren deutschen Charakter zu geben, um mit dem Start der neuen, dann französischen Wochenschau auf der Grundlage deutsch-französischer Gemeinschaftsarbeit das besondere Gepräge der neuen Wochenschau in Erscheinung treten lassen zu können ${ }^{720}$.

Durch diesen Trick sollte der neuen französischen Wochenschau eine größere Akzeptanz verliehen werden. Mehr als die Hälfte des Filmmaterials von France-Actualités stammte allerdings von Propagandakompanien der Wehrmacht und bestand zum großen Teil aus Berichten zum Kriegsgeschehen. Die Besatzer wollten damit in Frankreich die eigene militärische Stärke demonstrieren. Ferner war die Dauer der neuen Wochenschau länger, als es die französischen Actualités vor dem Kriege gewesen waren ${ }^{721}$. All diese Faktoren trugen nicht gerade dazu bei, daß das Publikum die Wochenschau besser akzeptierte. In den Akten des Referats läßt sich kurz nach der Einführung von

716 Ibid. Tätigkeitsbericht, 22. 5.-28. 5. 1941.

717 Garçon, The Film Propaganda, S. 170 f.

$718 \mathrm{AN}, \mathrm{F} 60 / 1480-2$, Convention entre le gouvernement allemand et le gouvernement français concernant la création d'une société française d'actualités cinématographiques à participation allemande, 18.8. 1941; zu dem Abkommen siehe auch BA-MA, RW35 224, Prop.Abt., Ref.Film, Tätigkeitsbericht, 10.10.-17. 10. 1941 und 24. 10.-31. 10. 1941.

719 Bertin-Maghit, Le Cinéma sous l'Occupation, S. 107.

720 BA-MA, RW35 224, Prop.Abt., Ref.Film, Tätigkeitsbericht, 24. 10.-31. 10. 1941.

721 Garçon, The Film Propaganda, S. 171. 
France-Actualités dennoch ein positiver Bericht zur Aufnahme der neuen Wochenschau durch das Publikum finden. Angeblich sollen die Zuschauer ein starkes Interesse gezeigt haben: „Es zeigt sich immer wieder, daß die Wochenschau mit guten und eindrucksvollen Filmberichten aus dem Osten ein hervorragendes Propagandamittel ist. Sehr oft bedauern die Zuschauer, daß die Wochenschau schon zu Ende ist" ${ }^{\text {"722 }}$. Es sei propagandistisch notwendig, möglichst viele Berichte aus den Kriegsgebieten in der Wochenschau zu zeigen. Angeblich riefen demnach Berichte neutraler Art, wie Reportagen aus Spanien, kein Interesse beim französischen Publikum hervor. Diese übertriebene Einschätzung verdeutlicht eher die Wunschvorstellungen des Referats, denn es ist kaum denkbar, daß die Zuschauer sich tatsächlich bedauernd über das Ende der Wochenschau äußerten. Vermutlich hat sich das Publikum für die ersten Ausgaben von France-Actualités aus Neugierde interessiert. Diese Haltung der Zuschauer hielt jedoch nicht lange an, denn schon wenig später häuften sich Berichte über negative Reaktionen. Anfang Juni 1942 meldete die Propaganda Staffel Dijon, es sei in zwei Fällen zu Störungen der Wochenschau gekommen. In Troyes habe eine Frau in einer Szene, in der mehrmals Hitler erschien, „encore lui“ gerufen:

Bei dem folgenden Bild, das den Geburtstagsgruß deutscher Kinder an den Führer zeigte, rief sie laut: "Il les endormit“. Dann bemerkte sie bei einem Bild Lavals und seiner Mitarbeiter „O, cette bande de vaches“. Die Frau, welche Mutter von fünf Kindern ist und deren Mann Kriegsgefangener ist, wurde von der Feldgendarmerie abgeführt und zu zwei Monaten Gefängnis verurteilt ${ }^{723}$.

Vor allem nach der Kriegswende im Winter 1942 wurde die Reaktion des Publikums auf die Wochenschau immer negativer. Anfang März 1943 wird gesagt, das französische Publikum kritisiere nun zunehmend die Monotonie der Wochenschau, vor allem „die immer wiederholte Darstellung abgeschossener Tanks und Flugzeuge, das Abfeuern von Geschützen, den Marsch der Gefangenen "724. Im neu besetzten südfranzösischen Gebiet lief die Wochenschau deswegen fast überall nur bei halbverdunkeltem Saal. Die Zuschauer scheuten keine Zwischenrufe wie "genug“ oder in ironischem Ton „die Deutschen siegen immer". Weiter heißt es: „Vermißt werden gemäß der Mentalität der Franzosen Episoden humoristischer Art aus dem Soldatenleben"725. Angesichts der für die Deutschen verschlechterten Lage an der Ostfront bezeichneten die Zuschauer die Kriegsdarstellungen der Wochenschau als Propaganda. Ein Jahr später, im März 1944, klagte die Filmprüfstelle darüber, wegen der kriegsbedingten schwierigen Transportlage erreiche die Wochenschau die entsprechenden Filmtheater oft zu spät. Die Folge sei, daß etliche Lichtspielhäuser völlig veraltete Wochenschauen zeigten ${ }^{726}$. Im April

722 BA-MA, RW35 226, Prop.Abt., Gr.Film, Tätigkeitsbericht, 15. 5.-23. 5. 1942.

723 Ibid. Tätigkeitsbericht, 1.6.-6.61942.

724 BA-MA, RW35 227, Prop.Abt., Filmprüfstelle, Tätigkeitsbericht, 27. 2.-6. 3. 1943.

725 Ibid.

726 AN, AJ40 1001, Prop.Abt., Filmprüfstelle, Tätigkeitsbericht, 4. 3.-10. 3. 1944. 
1944 notierte die Filmprüfstelle, bei Ansprachen französischer Staatsmänner seien Störungen durch auffälliges Husten beobachtet worden. Ferner wurde teilweise in den Filmtheatern die Reihenfolge Kulturfilm, Wochenschau und Spielfilm nicht mehr eingehalten. Auch erschienen die Zuschauer häufig erst zum Hauptfilm ${ }^{727}$. Anfang Juni meldeten die Staffeln aus der Provinz zunehmend bewaffnete Angriffe der Résistance auf Filmtheater bei Vorführungen der Wochenschau. Widerstandskämpfer sollen laut Filmprüfstelle das Publikum zur Anhörung ihrer Reden gezwungen haben: „In einem Falle wird aus Neuilly s/Marne berichtet, daß die Theaterbesucher auf die Rede eines jungen Maquis mit Lachen und Zurufen geantwortet haben, wie: ,Vas apprendre ta leçon' - ,Vas chercher ton bibron'“728. Dieser Versuch, die Anschläge auf Filmtheater als lächerlichen Kinderkram darzustellen, konnte freilich nicht verbergen, daß Vorführungen der Wochenschau immer mehr als kompletter Mißerfolg anzusehen waren. Gerade seit Ende des Jahres 1942 klafften die siegesgewissen Filmberichte von der Lage an der Ostfront und die Realität immer mehr auseinander. Weder die französische Version der Deutschen Wochenschau zu Beginn der Besatzungszeit noch die spätere France-Actualités können somit als erfolgreich bezeichnet werden.

Entsprechend dieser Folge von Mißerfolgen zunächst der Deutschen Wochenschau und anschließend der von den Besatzern dominierten deutschfranzösischen France-Actualités wechselten auch die Leiter der Außenstelle der Deutschen Wochenschau in Paris, die mit France-Actualités eng zusammenarbeitete, relativ häufig. Erster Leiter war seit September 1940 der oben erwähnte von Kondratovicz. Die Besetzung gerade dieses Postens war nicht einfach; kurz vor seiner von Goebbels verfügten Abberufung im Sommer 1941 betonte die Deutsche Wochenschau in Berlin: „Wir erinnern daran, daß nach langem Suchen und nach unendlichen Schwierigkeiten in der Person des Herrn von Kondratovicz [...] endlich jemand gefunden wurde, der einigermaßen für den schwierigen Pariser Posten geeignet erschien"729. Die Wochenschau betonte, daß alle Beteiligten sich darüber im klaren waren, daß gerade die in Paris gestellten Aufgaben „äußerst diffizil“ sein würden. Doch auch mit diesem Schreiben konnte sie die Abberufung des Leiters nicht mehr verhindern, da Goebbels diese längst verfügt hatte. Offenbar war das Verhältnis zwischen von Kondratovicz, der Propaganda Abteilung und Greven von Beginn an schwierig. Von Kondratovicz hatte sich schließlich beim $\mathrm{OKW} / \mathrm{WPr}$ in einem Schreiben über die mangelnde Unterstützung seiner Arbeit durch die Propaganda Abteilung beschwert sowie etliche Funktionsträger der Abteilung angegriffen und kritisiert. Zudem hatte er gemutmaßt, die Kollegen von der Propaganda Abteilung seien durch die Animosität, die zwischen ihm und Greven bestehe, beeinflußt worden und hätten ihn inner-

727 Ibid. Tätigkeitsbericht, 26. 3.-1. 4. 1944.

728 Ibid. Tätigkeitsbericht, 27. 5.-3 .6. 1944.

729 BA-MA, RW4 219, Deutsche Wochenschau GmbH an Hippler, RMVP, 27. 5. 1941. 
halb der Pariser Dienststellen isoliert. Gegen diese Vorwürfe verteidigte sich Schmidtke in einem wutentbrannten Beschwerdebrief an das OKW/WPr. Er erklärte von Kondratovicz für inkompetent und betonte, jener spreche so schlecht Französisch, daß er seinen französischen Mitarbeitern und Kameramännern seit Beginn seiner Tätigkeit in Paris ausgeliefert gewesen sei ${ }^{730}$. Schmidtke trug seine Position Goebbels persönlich vor, der von Kondratovicz seines Postens enthob und ihn nach Berlin abberief ${ }^{31}$. Im Juni 1941 traf als neuer Leiter der Pariser Außenstelle der Deutschen Wochenschau Heinz Beller in Paris ein ${ }^{732}$. Doch auch dieser blieb nicht sehr lange. Sein Nachfolger von Weyrauch wurde schließlich gegen Ende der Besatzung ebenfalls kritisiert. So bat Schmidtke das RMVP im November 1943, nun auch von Weyrauch abzuberufen, weil dieser den Anforderungen des Postens nicht mehr gewachsen sei. Bei der Zensur der Wochenschau bemerke die Propaganda Abteilung immer wieder, die nichtssagende Ausarbeitung derselben. Weyrauch fehle es an Initiative und er lasse sich von den Franzosen überfahren ${ }^{733}$. Diesen Schritt hatte Schmidtke jedoch nicht mit Knothe von der Deutschen Botschaft abgestimmt; vor allem Greven hatte ihn bei seiner Beschwerde unterstützt. Knothe versuchte zwar von Weyrauchs Abberufung zu verhindern, bemerkte aber auch, dieser sei in letzter Zeit phlegmatisch geworden und habe es an Initiative mangeln lassen ${ }^{734}$.

Weyrauch war im Januar 1944 immer noch in seinem Amt, wie aus einem Schreiben Henri Clercs an Knothe hervorgeht. Clerc beschwerte sich bei der Botschaft über negative Presse zu France-Actualités, welche die deutsche Zensur nicht verhindert hatte. Die Artikel kritisierten die filmische Darstellung Marcel Déats während der Rede auf einer anti-bolschewistischen Großveranstaltung im Velodrome d'Hiver im Dezember 1943735. Angeblich waren die Sequenzen schlecht geschnitten und ließen Déat so lächerlich erscheinen, daß etliche Zuschauer lachten. Zudem behauptete der Autor, FranceActualités sabotiere die Kriegsbilder von der Ostfront und stelle diese nicht genügend heraus. Da auch einige Propaganda Staffeln berichteten, daß die Zuschauer diese Sequenz in der Wochenschau lächerlich fänden, schlug Clerc vor, den Bericht herauszuschneiden. Vor allem war er aber darüber enttäuscht, daß die deutsche Zensur eine Diffamierung der France-Actualités in

730 Ibid. MBF, Prop.Abt., Kommandeur, Schmidtke an OKW/ Wpr Berlin, Betr.: Außenstelle der Deutschen Wochenschau GmbH, 17.6. 1941.

731 Ibid. MBF, Prop.Abt., Schmidtke an OKW/WPr, Eilt, Meldung Nr. f 741, 12.6. 1941.

732 BA-MA, RW35 221, Prop.Abt., Ref.Film, Tätigkeitsbericht, 12. 6.-18. 6. 1941.

733 PA-AA, 1113, Kult 12 Nr. 4, RMVP, Fries an Knothe, Betr.: Außenstelle Paris der Deutschen Wochenschau, 28. 12.1943.

734 Ibid. Knothe an Fries, RMVP, 5. 1. 1944.

735 Marcel Déats Rassemblement national populaire (RNP) bildete in Opposition zur Vichy-Regierung eine „faschistische Linksfront“. Das RNP schloß sich im Sommer 1941 mit Jacques Doriots Parti populaire français zusammen und rief $1944 \mathrm{zu}$ einem anti-bolschewistischen Kreuzug in Europa auf. 
der Presse zugelassen hatte, zumal er mit den deutschen Dienststellen zusammenarbeitete. Clerc betonte zudem, die France-Actualités habe die Bilder von der Ostfront bisher immer in vollem Einverständnis mit von Weyrauch und der deutschen Zensur ausgewählt ${ }^{736}$. Zwei Wochen zuvor hatte sich Clerc in einem Brief an Regierungschef Laval gegen die Benutzung der Szenen zu Déat ausgesprochen. Seine Kameramänner hätten während der Veranstaltung vor allem die Menschenmengen und weniger die Redner gefilmt; diese habe ein Kameramann eher zufällig aufgenommen, allerdings ohne Sinn und Zusammenhang. Deshalb wollte Clerc sie nicht benutzen. Ferner übte er in seinem Brief an Laval generell Kritik an der ihm offenbar von dieser Seite aufgezwungenen Art des Beitrags über diese Veranstaltung. Die propagandistische Intention war seiner Ansicht nach zu offensichtlich. Nach Clercs Ansicht war diese Propaganda nicht vorsichtig genug, denn immerhin müsse man bedenken, daß die Zuschauer in den Filmtheatern zur Zeit gezwungen würden, die Wochenschau zu sehen; angesichts der Ansammlung von Menschen, seien negative Reaktionen wahrscheinlich. Auch er glaube an die $\mathrm{Zu}-$ kunft Frankreichs in einem "neuen Europa“, aber er wolle die Bevölkerung auf andere Weise davon überzeugen und nicht mit übertrieben wirkender Propaganda. Zudem sei ihm am Vortag während einer Besprechung mit Schmidtke ein propagandistisch schlechter Filmbeitrag über „Attentate von Terroristen" für die Wochenschau vom 6. Januar 1944 aufgezwungen worden. Clerc betonte, er wolle in Zukunft den Posten des Präsidenten der France-Actualités niederlegen, falls ihm nicht mehr Unabhängigkeit zugesprochen würde. Andernfalls sei es besser, aus France-Actualités ein Staatsorgan zu machen, daß die Vorgaben der französischen Regierung und der deutschen Besatzungsmacht einfach ausführe ${ }^{737}$. Am 6. Januar 1944 übernahm Philippe Henriot das Secrétariat d'État à l'Information und veranlaßte eine Umorganisation der France-Actualités. Ganz im Gegensatz zu Clerc war er der Ansicht, die propagandistischen Möglichkeiten der Wochenschau seien bisher nicht genügend ausgeschöpft worden. Im März 1944 enthebt er Clerc seines Postens ${ }^{738}$. Sowohl auf deutscher als auch auf französischer Seite waren sich die Beteiligten uneinig darüber, wie die von der deutsch-französischen Wochenschau betriebene Propaganda auszusehen hatte. Ursache hierfür war nicht zuletzt auch deren offensichtlicher Mißerfolg.

Der propagandistische Einsatz deutscher Filme folgte in Frankreich keinem deutlich umrissenen Plan. Er setzte sowohl im Bereich der Spielfilme als auch bei den Kulturfilmen erst allmählich im Verlaufe des Jahres 1941 ein und wurde gemäß der allgemein verfolgten Besatzungspolitik seit 1942 verstärkt.

736 PA-AA, 1113, Kult 12 Nr. 4, France-Actualités, Henri Clerc an Knothe, DBP, 8. 1. 1944; zur Pressekritik siehe ibid. Le Pilori, Le sabotage continue, 8. 1. 1944; ibid. Révolution nationale, Les spectacles, toujours les mêmes, France Actualités ou le sabotage continue, 8. 1. 1944.

737 PA-AA, 1113, Kult 12 Nr. 4, Henri Clerc an Laval, Kopie, 23. 12. 1943.

738 BERTIN-MAGHIT, Le Cinéma sous l'Occupation, S. 118. 
Hierbei zeigten die Dienststellen in Paris, vor allem die Propaganda Abteilung, eine weit größere Initiative als deren Vorgesetzte in Berlin. Auch über die Inhalte der Kulturfilme waren sich sowohl die Propaganda Abteilung als auch das RMVP nicht im klaren. Propagandistische Spielfilme wurden zudem nur wenig und mit Vorsicht eingesetzt. Rückblickend läßt sich bei der verfolgten Filmpropaganda in Frankreich eine manifeste Unbeholfenheit ausmachen, wie etwa der Streit um die sogenannten Kriegsgefangenenfilme oder die Gestaltung der France-Actualités zeigen. Die Unsicherheit darüber, wie und in welcher Form in Frankreich deutsche Propagandafilme einzusetzen waren, hing auch hier eng mit der Angst vor den Reaktionen des französischen Publikums zusammen. Trotz der zum Teil so positiven offiziellen deutschen Schilderungen über die angebliche Wirkung der deutschen Propagandafilme auf die Zuschauer, war das Publikum offenbar ausgesprochen kritisch. Dagegen zeigen etwa Drehbücher zu einigen Kulturfilmprojekten ebenso wie die Berichte der Dienststellen selbst, wie naiv und plump - zumindest rückblickend gesehen - die deutsche Propaganda zum großen Teil gestaltet war.

\subsection{Französische Propagandafilme unter deutschem Einflu $\beta$ - das Beispiel der Nova-Films}

Nicht nur die Besatzungsmacht, sondern auch die Vichy-Regierung sah im Film grundsätzlich ein Propagandainstrument ${ }^{739}$. Wie war die Haltung der deutschen Dienststellen bezüglich der Herstellung französischer Propagandafilme? Grundsätzlich standen die Besatzer diesen Aktivitäten zwar nicht gänzlich ablehnend gegenüber, allerdings sprach der durch die kriegsbedingten Umstände zunehmende Mangel an Rohfilm in den Augen der Besatzungsmacht gegen französische Propagandafilme. So fragte beispielsweise am 3. November 1942 - kurz vor der Besetzung ganz Frankreichs - der COIC bei der Deutschen Botschaft an, ob das Film-Magazin „La France en Marche" auch im unbesetzten Gebiet vertrieben werden dürfe. Dieses Instrument der Vichy-Propaganda wurde seit 1940 in der unbesetzten Zone von Verdet-Kléber hergestellt. René de Chambrun, der Rechtsanwalt des COIC, bat darum, dieses Magazin der nationalen Propaganda während der Vorstellungen anstelle des vorgesehenen Kulturfilms bringen zu dürfen. Hinsichtlich der Länge eignete sich das Magazin hierzu. Es sollte laut Lohmann im Rahmen der gesamten Kontingente für Propagandafilme berücksichtigt

739 BerTin-MaghIT, Le Cinéma sous l'Occupation, S. 136-141; überblickshaft zur Propaganda der Vichy-Regierung siehe bei Rossignol, Histoire de la Propagande, S. 9-48, sowie ab S. 77 zu den einzelnen Themen dieser Propaganda: Der Mythos Pétains, die Révolution nationale, Frankreich im "neuen Europa“, STO in Deutschland; zu den Themen gehörten ferner anti-bolschewistische, anti-jüdische und gegen Freimaurer gerichtete Propaganda, anti-englische und anti-amerikanische Propaganda. 
werden ${ }^{740}$. Die Botschaft konstatierte zwar, daß sie dieses Magazin nicht verbieten könne, aber dennoch dessen Vertrieb wegen des Mangels an Rohfilm in Grenzen zu halten beabsichtige ${ }^{741}$. Die deutschen Dienststellen waren deswegen gegenüber der französischen Produktion von Propagandafilmen skeptisch eingestellt. Sie zogen es grundsätzlich vor, eigene Filmpropaganda zu betreiben, wobei eine Kooperation mit der französischen Seite - wie im Falle der Wochenschau - als Tarnung dienen konnte, um die vermeintliche Wirkung der deutschen Propaganda auf das französische Publikum zu erhöhen. Wie die Filmprojekte "La Relève“ und „Dienst an Europa“ zeigen, wollten die Besatzer sich französischer Kräfte allenfalls bedienen, damit diese die deutsche Propaganda in die französische Mentalität transponierten.

Eine der wenigen französischen Firmen, die im Auftrag der deutschen Dienststellen französische Propagandafilme herstellten, war die Nova-Films unter der Leitung von Robert Muzard. Sie produzierte den anti-freimauerischen Film „Forces occultes“ (1942), eine propagandistische Sketch-Serie „Monsieur Girouette“, Filme über den Einsatz französischer Arbeiter in Deutschland wie „Travailleurs de France en Allemagne“ (1943), „Permissionaires, n'oubliez pas“ (1943) sowie Filme mit prodeutscher Kriegspropaganda wie "Douzes Heures d'Angoisse" (1944) und "Le Vrai Combat" $(1944)^{742}$. Zunächst planten jedoch weder AA und RMVP noch die Dienststellen in Paris die Herstellung französischer Filme im Dienste deutscher Propaganda. Die Initiative hierzu ergriffen im Herbst 1941 Will Abert von der Informationsabteilung der Botschaft und Robert Muzard ${ }^{73}$. Muzards Werdegang wies bis dahin bereits einen ausgeprägten Bezug zu Deutschland auf. Er hatte seit 1932 in Berlin Germanistik studiert, arbeitete ab $1935 \mathrm{zu}-$ nächst als Statist bei der Ufa, später unter anderem auch als Regisseur in Prag und Budapest. Bei der Ufa hatte er offenbar Diedrich und einige französische Schauspieler kennengelernt ${ }^{74}$. Zudem arbeitete Muzard vor dem Krieg nicht nur im Filmbereich, sondern auch beim Internationalen Zentralbüro Freude und Arbeit in Berlin als Referent für Frankreich und Veranstalter des soge-

740 PA-AA, 1143b, Kult 12 Nr. 4, COIC, René de Chambrun an Lohmann, DBP, 3. 11. 1942; die Länge des Magazins wird mit 3000 Metern angegeben.

741 Ibid. DBP, Lohmann, Vermerk für Knothe, Greven, Derichsweiler, Betr.: Französische Propagandafilme, 6. 11. 1942; Anlage, Herstellung und Verbreitung von Kulturfilmen, die einen propagandistischen Zweck haben.

742 Eine weitere französische Produktionsfirma die französische Propagandafilme im Auftrag der deutschen Dienststellen aber auch der Vichy-Regierung herstellte war die BUSDAC. Im Auftrag der Propaganda Abteilung stellte sie die Filme „Résistance“ und "Patriotisme" her; zum letzteren siehe AN, AJ40 1001-1, Prop.Abt., Filmprüfstelle, Tätigkeitsbericht, 26. 2.-4. 3. 1944. Im Februar 1944 produzierte die BUSDAC außerdem den Propagandafilm „Français souvenez-vous" und anschließend "Fait d'arme“. Siehe BERTIN-MAGHIT, Le Cinéma sous l'Occupation, S. 141.

${ }^{743}$ PA-AA, 1113, Kult 12 Nr. 4, DBP, W. Abert, Aufzeichnung für Buscher, Betr.: Filmherstellung, 9. 9. 1942; Abert berichtet darin rückblickend über die Anfänge dieser Kooperation.

744 BERTIN-MAghit, Le Cinéma sous l'Occupation, S. $137 \mathrm{f}$. 
nannten deutsch-französischen Volkstumsgruppenaustausches gearbeitet ${ }^{745}$. Dort lernte er Hibbelen, den damaligen Geschäftsführer der Zeitschrift des Zentralbüros, kennen. 1939 kehrte er nach Frankreich zurück und geriet im Juni 1940 in deutsche Kriegsgefangenschaft, aus der er auf persönliche Intervention von Abetz Anfang 1941 wieder entlassen wurde. Bei seiner Rückkehr nach Paris traf er Hibbelen als Mitarbeiter der Botschaft wieder, der ihm die Leitung der im Besitz der Botschaft befindlichen Filmzeitschrift CinéMondial vermittelte. Gemeinsam mit Abert erarbeitete Muzard schließlich einen Plan zum Aufbau der deutschen Filmpropaganda in Frankreich, weil so Muzard - in dem Bereich bis zu diesem Zeitpunkt nur wenig von den deutschen Dienststellen unternommen worden war ${ }^{746}$.

Abert betonte, er habe diese Initiative gemeinsam mit Muzard im Herbst 1941 vor allem deswegen ergriffen, weil seit Beginn der Besatzung zu wenig Filme mit deutscher Propaganda in Frankreich gezeigt worden waren. Abgesehen von "Ohm Krüger" und „Jud Süß" habe sich die deutsche Filmpropaganda auf die Wochenschauberichte zum Kriegsgeschehen beschränkt. Er kritisierte, daß die deutschen Dienststellen nicht darüber hinaus versucht hätten, „aktuelle politische Themen in Form von Kulturfilmen oder kurzen Spielfilmen zu beleben "747. Diese Kritik richtete sich in erster Linie gegen die Arbeit der Propaganda Abteilung. Deren Versäumnis war seiner Ansicht nach um so schwerwiegender, als "gerade die schaulustige französische Bevölkerung" im Hinblick auf eine Beeinflussung sehr zugänglich sei. Zudem habe gerade der Film in der französischen Propaganda vor dem Krieg in Frankreich neben Presse und Rundfunk eine große Rolle gespielt. Als die Propaganda Abteilung für die Ausstellung "Le Juif et la France“ nach Begleitfilmen suchte, hatte Abert zu diesem Zweck eine Kurzfassung des „Ewigen Juden " herstellen lassen. Zudem schlug er vor, einen französischen Film zu produzieren, der sich mit dem ,verderblichen jüdischen Einfluß “748 auf die französische Jugend befaßte. Die Botschaft hatte diesen Vorschlag der Propaganda Abteilung unterbreitet. Diedrich und Schmidtke waren jedoch der Meinung, daß ein solcher Film allein von der Propaganda Abteilung hergestellt werden sollte, im Einvernehmen mit der Abteilung Film im RMVP und der Deutschen Botschaft. Die Botschaft sollte deswegen einen konkreten Vorschlag für den Film vorlegen ${ }^{74}$. Diese gab jedoch den etwa halbstündigen anti-jüdischen Film „Les Corrupteurs“ (1941) ohne Einverständnis der Propaganda Abteilung bei Muzard in Auftrag. Dieser konnte daraufhin den Film nur unter Schwierigkeiten produzieren, weil die Propaganda Abteilung zunächst die Genehmigung für Rohfilm verweigerte. Muzard wurde angewie-

745 PA-AA, 1113, Kult 12 Nr. 4, Muzard, Bericht für Abetz, 24. 1. 1944.

746 Ibid.

747 Ibid. DBP, Abert, Aufzeichnung für Buscher, Betr.: Filmherstellung, 9. 9. 1942.

748 Ibid.

749 BA-MA, RW35 224, Prop.Abt., Ref.Film, Tätigkeitsbericht, 10. 10.-17. 10. 1941. 
sen, sich den benötigten Rohfilm auf dem Schwarzmarkt zu besorgen $750 . \mathrm{Zu}$ dem verzögerte die Propaganda Abteilung den Einsatz des fertigen Films. Am 11. Dezember gab die Zensur der Staffel „Les Corrupteurs" schließlich für Vorstellungen im Rahmen der anti-jüdischen Ausstellung frei. Abert notierte dazu: „Er konnte daher nur einen Monat laufen, aber sein Erfolg war beträchtlich, trotz des damals schon schwächeren Besuchs der Ausstellung “751.

Das Referat Film teilte dem RMVP mit, daß der anti-jüdische Film „Les Corrupteurs" am 11. Dezember $1941 \mathrm{im}$ Rahmen der Ausstellung „Le Juif et la France" gelaufen war. Sie schickte den Film in Kopie nach Berlin und wollte wissen, ob sie diesen auch im normalen Filmprogramm einsetzen solle ${ }^{752}$. Greven hielt „Les Corrupteurs" für den Einsatz in Frankreich für ungeeignet, doch das RMVP gab ihn für den Vertrieb in ganz Frankreich frei ${ }^{753}$. Im Juli 1942 zeigte Muzard ihn seinem ehemaligen Chef, dem Leiter der DAF, Robert Ley, anläßlich eines Besuches in Paris. Dieser war davon angetan und "Les Corrupteurs" erhielt in Berlin ein deutsches Zensurvisum ${ }^{754}$. Obgleich Greven den Film für schlecht hielt, mußte die Continental ihn anschließend für den Vertrieb außerhalb der Ausstellung ankaufen. Die Continental koppelte ihn dabei an die eigene erfolgreiche Produktion "Les inconnus dans la maison", um eine größtmögliche Verbreitung zu erreichen ${ }^{755}$. Laut Abert sollen die Reaktionen des Publikums gut gewesen sein und angeblich sollen die Zuschauer sogar in der Pause vor dem Hauptfilm über die Judenfrage diskutiert haben ${ }^{756}$. Diese Einschätzung ist freilich weit übertrieben, wofür auch die Ansicht anderer Zeitgenossen über den Film spricht. Lohmann, ein ehemaliger Mitarbeiter der Propaganda Abteilung, der nun für die Botschaft arbeitete, war wie Greven der Meinung, daß der Film schlecht sei. In "Les Corrupteurs" gebe es zwar eine durchgehende Spielhandlung und der Autor habe sich durchaus um eine versteckte Propaganda bemüht. Der Film sei aber so plump gemacht, daß auch weniger intelligente Zuschauer die Absicht bemerken müßten. Muzard habe vor allem den Schlußteil sehr lang gestaltet, was die Wirkung des Beginns, der keineswegs so schlecht sei, gänzlich aufhebe. Lohmann hielt die Machart des Filmes und dessen Propaganda nicht für französisch, sondern für „typisch deutsch“. Seiner Ansicht nach setzte der Film eine Entwicklung voraus, die in Deutsch-

750 PA-AA, 1113, Kult 12 Nr. 4, Muzard, Bericht für Abetz, 24. 1. 1944.

751 Ibid. DBP, Abert, Aufzeichnung für Buscher, Betr.: Filmherstellung, 9. 9. 1942.

752 BA-MA, RW35 224, Ref.Film, Tätigkeitsbericht, 19. 12. 1941.

753 PA-AA, 1217, Kult 12 Nr. 4 I, DBP, Buscher, Aufzeichnung für Geheimrat Rahn, 13. 2. 1942.

754 PA-AA, 1113, Kult 12 Nr. 4, Muzard, Bericht für Abetz, 24. 1. 1944; BA-MA, RW35 226, Prop.Abt., Ref. Film, Tätigkeitsbericht, 10. 7. 1942.

755 PA-AA, 1217, Kult 12 Nr 4 I, Continental an ACE, Doppel, Betr.: Beiprogrammfilme, 4. 8. 1942.

756 PA-AA, 1113, Kult 12 Nr. 4, DBP, Abert, Aufzeichnung für Buscher, Betr.: Filmherstellung, 9.9.1942. 
land seit 1933 im Gange sei, in Frankreich aber nicht einmal begonnen habe, womit er die anti-jüdische Propaganda meinte. Lohmann führte das ,typisch Deutsche “ des Filmes auf den langjährigen Aufenthalt Muzards in Deutschland zurück:

Die deutsche Entwicklung dürte ihn als jungen begeisterungsfähigen Menschen sehr stark beeinflußt haben. So schön das im Einzelfall ist, so ist unserem propagandistischen Ziel damit nicht gedient, denn wir wollen das französische Volk gewinnen, und das können wir nur mit französischen Mitteln, auf die es anspricht ${ }^{757}$.

In den Vorstellungen Lohmanns war Muzard nach einem zu langen Aufenthalt in Deutschland nicht mehr zu einer auf die französische Mentalität abgestimmten Propaganda fähig. Zudem hatte auch Abert entscheidenden Einfluß auf die Herstellung des Filmes genommen ${ }^{758}$.

Muzard übernahm anschließend im Januar 1942 die Produktionsfirma Nova-Films mit dem Einverständnis der Informationsabteilung der Botschaft. Finanziell war die Botschaft an der Firma durch den Strohmann Oberst Alfred Bocher, Chargé de Mission der Groupe Collaboration, beteiligt ${ }^{759}$. Robert Muzard, André Briand und Alfred Bocher waren zu je einem Drittel an der Firma beteiligt, deren Zweck die Produktion von Dokumentar- und Propagandafilmen sowie die französische Synchronisation ausländischer Filme war ${ }^{760}$. Die Propaganda Abteilung war abgesehen von der Gruppe Aktivpropaganda zunächst gegen die Gründung der Nova, weil ihrer Ansicht nach die Beteiligung an französischen Filmfirmen und die Herstellung von Propagandafilmen nicht in die Kompetenzen der Botschaft fielen ${ }^{761}$. Nach Muzards Darstellung versuchte dieser in der Folge, auch die Propaganda Abteilung von der Notwendigkeit seiner Firma zu überzeugen, was ihm bei Diedrich angeblich bald darauf gelang ${ }^{762}$. Im Mai und Juni 1942 drehte Muzard unter dem Titel „Monsieur Girouette“ eine Serie von sechs Kurzfilmen ${ }^{763}$. Diese jeweils drei- bis vierminütigen Sketch-Filme zeigten die französischen Filmtheater Mitte Juli 1942 im Anhang an die Deutsche

757 Ibid. DBP, Lohmann, Vermerk, Betr.: Einflußnahme auf die Filmherstellung durch Informationsabteilung, insbesondere Nova-Film, 12. 12. 1942 (Stellungnahme zu einer Notiz Aberts vom 9. 11.1942).

758 PA-AA, 1205, Kult 1, W. Abert, Bericht über meine propagandistische Tätigkeit vom 1. Juli 1940 - 31. Dezember 1941, Dezember 1941. Abert nennt hier als Tätigkeiten die Idee und Planung dieses Filmes sowie die Herstellungsleitung.

759 PA-AA, 1113, Kult 12 Nr. 4, Muzard, Bericht für Abetz, 24. 1. 1944. Ursprünglich war die Nova-Films am 11. September 1941 laut Bertin-Maghit von den Brüdern Babikian als Produktionsfirma von Spiel- und Dokumentarfilmen gegründet worden, siehe BERTIN-MAGHIT, Le Cinéma sous l'Occupation, S. 138.

760 PA-AA, 1113, Kult 12 Nr. 4, Gründungsvertrag der Nova-Films, Kopie, 7. 1. 1942. 761 Ibid. RMVP, Ministerialrat Dr. Fries, Vermerk, Abschrift an RR Wieland in Abt. Ausland, 31. 3. 1943.

762 Ibid. Muzard, Bericht für Abetz, 24. 1. 1944.

763 Ibid. 
Wochenschau, weil sich für sie ansonsten kein Verleih finden ließ ${ }^{764}$. Laut Lohmann hatte Muzard für „Monsieur Girouette" die in Deutschland sehr populären „Tran und Helle"-Filme zum Vorbild genommen. In diesen Kurzfilmen behandelten 1939/40 die rheinischen Komiker Ludwig Schmitz und Jupp Hussels allwöchentlich im Anschluß an die Wochenschau aktuelle Themen („Hamsterfragen“, „englische Flugblätter"), wobei der eine vom anderen seine aufklärende, sprich propagandistische, Lektion lernte ${ }^{765}$. Die Girouette-Filme beruhten allerdings nicht auf einer Idee Muzards, sondern stammten ursprünglich aus der Feder Aberts. Dieser hatte im April 1941 in Le Vrai de Vrai, einer politisch-satirischen Einlage der Zeitung Paris Toujours, sogenannte satirische Sketche kreiert, die ebenfalls den Titel „Monsieur Girouette" trugen. In einem Bericht über seine Propagandatätigkeit gibt Abert an, im November 1941 habe er die Leitung und Herstellung von drei "Girouette"-Filmsketchen übernommen ${ }^{766}$. Die "Girouette "-Filme waren nach Ansicht Lohmanns vollständig mißlungen. Neben technischen Mängeln sollen sie propagandistisch so offensichtlich knallig gewesen sein, daß sich das französische Publikum erstaunt nach ihrem Sinn und Zweck gefragt habe. Die Themen der Filme hätten niemanden interessiert und seien schlecht präsentiert worden. Im Falle einer Fortsetzung der Serie sollten laut Lohmann bei der Stoffwahl unbedingt andere Franzosen gefragt werden ${ }^{767}$. Muzard selbst war von der komischen und gleichzeitig propagandistischen Wirkung der Filme überzeugt. Er betonte, bei „Une pirouette de Monsieur Girouette" sogar Lachen im Publikum festgestellt zu haben ${ }^{768}$. Abert, der ebenfalls ein positives Bild der Reaktion der Zuschauer zeichnete, konstatierte allerdings ähnlich wie Lohmann, das Publikum sei zunächst erstaunt gewesen und hätte die Filme nicht so recht verstanden. Angeblich sollen die $\mathrm{Zu}-$ schauer die propagandistische Tendenz schließlich erkannt haben und den Film trotzdem positiv aufgenommen haben. In einigen Kinos habe man sogar Beifall geklatscht. Als jedoch die Deutsche Wochenschau durch die FranceActualités ersetzt wurde, stellte die Nova die Produktion der Sketch-Filme erst einmal $\operatorname{ein}^{769}$.

764 BA-MA, RW35 226, Prop.Abt., Gr.Film, Tätigkeitsbericht, 10. 7.-17. 7. 1942.

765 PA-AA, 1113, Kult 12 Nr. 4, DBP, Lohmann, Kulturabteilung, Vermerk, Betr.: Einflußnahme auf die Filmherstellung durch Informationsabteilung, insbesondere Nova Film, 12. 12. 1942. (Stellungnahme zu einer Notiz Aberts vom 9.11. 1942); zu den „Tran und Helle“ Filmen siehe DREWNIAK, Der deutsche Film, S. 48f.

766 PA-AA, 1205, Kult 1, W. Abert, Bericht über meine propagandistische Tätigkeit vom 1. Juli 1940 - 31. Dezember 1941, Dezember 1941.

767 PA-AA, 1113, Kult 12 Nr. 4, DBP, Lohmann, Vermerk, Betr.: Einflußnahme auf die Filmherstellung durch Informationsabteilung, insbesondere Nova Film, 12. 12. 1942. (Stellungnahme zu einer Notiz Aberts vom 9.11. 1942)

768 PA-AA, 1217, Kult 12 Nr. 4 I, Muzard, Bericht an Buscher, 17. 7. 1942.

769 PA-AA, 1113, Kult 12 Nr. 4, DBP, Abert, Aufzeichnung für Buscher, Betr.: Filmherstellung, 9. 9.1942. 
Die Deutsche Botschaft hatte über den in ihrem Besitz befindlichen französischen Verlag Le Pont zur Produktion der Girouette-Filme mehrere Kredite bewilligt. Diese benutze sie anschließend, um Muzard unter Druck zu setzen. Er sollte der Botschaft eine mehrheitliche Beteiligung an der Nova einräumen. Bei der Gründung der Nova hatte vor allem die Propaganda Abteilung dagegen protestiert. Als jedoch nach der Einigung zwischen AA und RMVP der Bereich der Kulturpropaganda in den Kompetenzbereich der Botschaft überging, hatte diese sich entschlossen, die Anteilsmehrheit an der Nova heimlich über den Verlag Le Pont zu erlangen ${ }^{770}$. Muzard bestand allerdings auf der relativen Unabhängigkeit der Firma. Zudem gab Muzard an, das französische Informationsministerium könne im Falle der mehrheitlichen Beteiligung von Le Pont an der Nova Verdacht schöpfen. Wenn er als Strohmann gelte, wäre dies der Arbeit der Nova keineswegs förderlich. Abschließend betonte er gegenüber der Informationsabteilung der Botschaft, Abetz und Schleier könnten persönlich bestätigen, daß er gleich nach der Machtergreifung ein Vorkämpfer für die deutsch-französische Verständigung gewesen sei ${ }^{771}$. In der Diskussion um die Übernahme der Nova durch die Botschaft war sich auch die deutsche Seite weiterhin nicht einig, obgleich zu diesem Zeitpunkt die Kompetenzen für Kulturpropaganda bereits allein bei der Botschaft lagen. Hier zeigte sich einmal mehr, welche Rolle der Konkurrenzstreit der deutschen Dienststellen auch nach seiner Beilegung noch spielte und wie wenig loyal mitunter die ehemaligen Mitarbeiter der Propaganda Abteilung jetzt ihrem neuen Arbeitgeber gegenüber waren. Der mit Filmfragen befaßte Lohmann vertrat als Mitarbeiter der Botschaft die Ansicht, es dürfe nicht zu ihren Aufgaben gehören, in Frankreich mit einer eigenen Firma Propagandafilme herzustellen. Für eine Produktion von Propagandafilmen, die der politischen Linie der Botschaft entsprächen, seien andere Möglichkeiten als die einer eigenen Produktionsfirma besser. Seiner Meinung nach sollten die Filme in Deutschland hergestellt und anschließend französisch synchronisiert werden. Eine andere Möglichkeit sah er darin, daß das AA oder die Botschaft die Continental mit der Produktion solcher Filme beauftragten. Die Botschaft sollte auch weiterhin die Nova mit der Herstellung von Propagandafilmen betrauen, ohne diese jedoch zu besitzen. Lohmann forderte eine klare Trennung der Kompetenzen, da ansonsten die Frage der ungeklärten Zuständigkeiten kein Ende nähme. Dies habe bisher zu „einer gegenseitigen Bekämpfung der deutschen Dienststellen untereinander

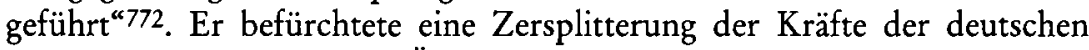
Dienststellen im Falle einer Übernahme der Firma durch die Deutsche Botschaft. Laut Lohmann waren abgesehen von der Continental folgende deut-

770 Ibid. DBP, Lohmann, Notiz für Generalkonsul Knothe, 14. 8. 1942.

771 Ibid. Muzard an Buscher, DBP, 15. 8. 1942; Muzard sträubte sich mehrfach gegen die Mehrheitsbeteiligung der Botschaft; siehe Ibid. DBP, Lohmann, Vermerk, Betr: Nova Film /Verstärkung des deutschen Einflusses, 10. 10.1942.

772 Ibid. DBP, Lohmann, Notiz für Generalkonsul Knothe, 14. 8. 1942. 
sche Stellen mit Filmangelegenheiten beschäftigt, erteilten Produktionsaufträge oder führten Filmprojekte durch: die Filmprüfstelle, die Gruppe Aktivpropaganda der Propaganda Abteilung und die Informationsabteilung der Deutschen Botschaft. Letztere verfolgte diese Aktivitäten über die NovaFilms, die Agence Havas, die Diffusions Modernes und die Société d'applications cinématographiques ${ }^{773}$. Darüber hinaus war die Agence Havas bestrebt, im Filmbereich Fuß zu fassen, indem sie im Spielfilmbereich versuche, Aktien des Gaumont Konzerns zu erwerben, der wiederum dem Unternehmen Publicis verbunden sei. Mit deutscher Unterstützung werde die, so Lohmann, in Frankreich beliebte Verflechtung zwischen Film, Radio, Presse wieder belebt, die der MBF mit Mühe innerhalb von zwei Jahren zerstört hatte. Die Verflechtung war nach Lohmanns Ansicht selbst für Eingeweihte nicht mehr zu überblicken und drohte der deutschen Seite über den Kopf zu wach$\operatorname{sen}^{774}$. Laut Lohmann sprach vor allem aber auch die schlechte Qualität und der geringe Absatz der durch die Nova hergestellten Filme gegen eine Anteilserhöhung. Er konstatierte: „Hätte die Nova-Film einen Film hergestellt, der das Publikum packt, so wäre er ihr nach meiner festen Überzeugung aus der Hand gerissen worden, auch wenn er noch so tendenziös wäre"775. Lohmann verhielt sich auch in einem weiteren Punkt illoyal gegenüber der Botschaft. Er berichtete in dieser Angelegenheit direkt der Abteilung Film im RMVP ohne dabei den Dienstweg über das AA einzuhalten. Das RMVP vertrat die gleiche Ansicht wie Lohmann, und zwar daß „die Beteiligung an französischen Filmfirmen Sache der unter der Führung des Propagandamini-

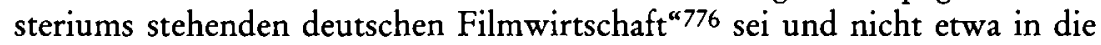
Kompetenzen des AA falle. Offenbar konnte die Botschaft in der Folge keine Mehrheitsbeteiligung an der Nova erhalten, da sie dieser zusammen mit anderen Dienststellen auch weiterhin lediglich Aufträge für die Herstellung von Propagandafilmen erteilte.

Im September/Oktober 1942 realisierte die Nova den abendfüllenden antifreimaurerischen und auch anti-jüdischen Film „Forces occultes“. Dies geschah im Auftrag der Deutschen Botschaft, der Propaganda Abteilung sowie der Sipo-SD ${ }^{777}$. Während die Propaganda Abteilung vorher der Nova gegenüber eher skeptisch eingestellt war, so wandelte sich dies mit der Herstellung dieses Filmes. Sie beteiligte sich nicht nur finanziell an dem Film, sondern nahm offenbar auch inhaltlichen Einfluß. Im Dezember 1942 prüfte das Re-

773 Ibid. DBP, Lohmann, Kulturabteilung, Vermerk, Betr.: Nova Film /Verstärkung des deutschen Einflusses, 10. 10. 1942.

774 Ibid.

775 PA-AA, 1113, Kult 12 Nr. 4, DBP, Lohmann, Vermerk, Betr.: Einflußnahme auf die Filmherstellung durch Informationsabteilung, insbesondere Nova Film, 12. 12. 1942 (Stellungnahme zu einer Notiz Aberts vom 9.11. 1942).

776 Ibid. RMVP, Fries, Vermerk, Abschrift an Wieland in Abt. Ausland, 31. 3. 1943.

777 PA-AA, 1218, Kult 12 Nr. 4 II, Muzard an Lohmann, DBP, Betr.: Propagandistischer Film „Forces occultes“, 28. 8. 1942. 
ferat Film „Forces occultes“. Es bemerkte, obgleich der Film grundsätzlich gelungen sei, müßten noch einige Änderungen und Ergänzungen eingefügt werden. Die endgültige Fassung sollte im Januar auf den Champs-Elysées anlaufen. Zusätzlich zu der abendfüllenden Fassung des Filmes sollte die Nova noch eine kürzere Fassung von 7-800 Metern herstellen; diese sollte im Beiprogramm laufen 778 . Ebenso wie "Les Corrupteurs" war der vorgeblich dokumentarische Film auf der Grundlage eines Spielfilm-Drehbuches entstanden und wurde von Schauspielern gespielt. Im gleichen Maße wie das Ansehen der Nova in den Augen der deutschen Dienststellen stieg, machte sie sich auf französischer Seite mehr und mehr Feinde. Muzard beklagte sich gegenüber Abetz, innerhalb der gaullistisch eingestellten Filmkreise werde versucht, seine Firma zu sabotieren. Die Filmtheater hätten „Forces occultes" nur auf Druck der Propaganda Abteilung aufgeführt ${ }^{779}$. Der Film startete im März 1943 im Filmtheater Champs-Elysées. Er war abgesehen von der gekürzten Fassung im Beiprogramm auch noch für andere Pariser Filmtheater vorgesehen ${ }^{780}$. Das Champs-Elysées setzte den Film im April 1943 nach vier Wochen Laufzeit ab. Er lief im übrigen in Paris und in der Provinz angeblich mit überdurchschnittlichem Erfolg 781 . Laut Muzard soll er angeblich erfolgreich gewesen sein: „Trotz der eindeutigen propagandistischen Note des Films standen die Zuschauer wochenlang Schlange um sich den Film anzusehen"782. Wenig später lud das RMVP Muzard nach Berlin ein, der dort den Film Goebbels persönlich vorführte. Der Propagandaminister lobte „Forces occultes“ und beauftragte Muzard, weitere Projekte auszuarbeiten. Zudem beschloß das RMVP, den anti-freimaurerischen Film in ganz Europa einzusetzen ${ }^{783}$.

Im Frühjahr 1943 fuhr Kaufmann, Leiter des Amtes Filmproduktion der Berliner Reichsleitung der NSDAP, nach Paris, um in dieser Angelegenheit mit Muzard zu sprechen. Goebbels hatte in der Morgenkonferenz vom 9. Mai 1943 die Anweisung erteilt, die antisemitische Propaganda in Europa zu verstärken. Nach Ansicht Kaufmanns sollte Muzard deswegen besonders schnell eine europäische Fassung von „Forces occultes" erstellen. Die inhaltliche Einflußnahme war hier relativ groß, denn Kaufmann sprach in Paris mit Muzard und Regisseur Paul Riche genau ab, um welche Szenen die französische Fassung zu ergänzen wäre. Sie mußten noch gedreht werden und sollten deutlich machen, welchen Einfluß die Freimaurerei in Frankreich in staatli-

778 BA-MA, RW35 227, Prop.Abt., Filmprüfstelle, Tätigkeitsbericht, 19. 12.-26. 12. 1942. Laut Bertin-Maghit soll Muzard aus "Forces occultes“ die in „nationaler Hinsicht" schockierendsten Szenen herausgeschnitten haben, und ihn so von $1600 \mathrm{~m}$ um 750m gekürzt haben, BERTIN-MAGHIT, Le Cinéma sous l'Occupation, S. 136-141.

779 PA-AA, 1113, Kult 12 Nr. 4, Robert Muzard, Bericht für Abetz, 24. 1. 1944.

780 BA-MA, RW 35 227, Prop.Abt., Filmprüfstelle, Tätigkeitsbericht, 6. 2.-13. 2. 1943.

781 Ibid. Tätigkeitsbericht, 3. 4.-10. 4. 1943.

782 PA-AA, 1113, Kult 12 Nr. 4, Muzard, Bericht für Abetz, 24. 1. 1944.

783 Ibid. 
chen und wirtschaftlichen Positionen gehabt und wie diese den Krieg mit Deutschland heraufbeschworen habe. Wieviel Vertrauen die deutsche Seite in die Arbeit der Nova setzte, zeigt sich darin, daß Kaufmann für die Dreharbeiten bereits grünes Licht gegeben hatte, noch bevor ihm das neue Drehbuch zugeschickt wurde. In seinem Brief an Knothe betonte er: „Herr Muzard und Herr Riche haben meine Wünsche völlig verstanden"784. Absichtlich plante die Nova für die europäische Fassung von „Forces occultes" keine Synchronisation, sondern nur eine Untertitelung in der jeweiligen Landessprache. Die deutsche Seite legte besonderen Wert darauf, dem Publikum das Gefühl zu vermitteln, es handele sich hier um eine rein französische Produktion und nicht um deutsche Propaganda. Kaufmann bat Knothe, er möge Muzard zu einer beschleunigten Fertigstellung der Fassung anhalten, da Goebbels persönlich daran sehr interessiert sei ${ }^{785}$. Anschließend gab der Propagandaminister ausdrücklich seine Zustimmung zum Einsatz des Filmes in Europa $^{786}$. Seine Fertigstellung war für Mitte Juli 1943 vorgesehen ${ }^{787}$. Es gibt keine Hinweise darauf, daß der Film auch tatsächlich europaweit eingesetzt wurde. Muzard selbst versuchte noch im Mai/Juni 1944 die französische Fassung nach Spanien zu verkaufen ${ }^{788}$. Er fand dort letztlich aber keine Verleihfirma für den Film ${ }^{789}$.

Die Nova klagte in der Folge trotz der Anerkennung ihrer Arbeit durch den Propagandaminister persönlich über finanzielle Schwierigkeiten, weil die Propagandafilme keine kommerziellen Erfolge darstellten. Deswegen genehmigte die Propaganda Abteilung Muzard 1943 die Herstellung eines unterhaltenden Spielfilms. Doch auch die Finanzierung dieses Projektes war relativ problematisch. Muzard berichtete, die französischen Produzenten hätten ihm bekundet, die Nova-Films habe sich durch die Herstellung der Propagandafilme eindeutig auf die Seite der Kollaborateure gestellt. Nach einem anglo-amerikanischen Sieg werde sie mit Sicherheit aufgelöst und Muzard erschossen. Trotzdem gelang es ihm, mit Pathé ein Abkommen zu treffen und den Spielfilm „Tornavara“ herzustellen ${ }^{790}$. In der Abteilung Film im RMVP wurde stark kritisiert, daß Muzard zum Teil mit deutschen finanziellen Mitteln diesen Spielfilm herstellen konnte, da hierfür in erster Linie die Continental Films zuständig sein sollte. Zudem, so Fries, hätte „Tornavara“ keiner-

784 PA-AA, 1143a, Kult. 12 Nr. 4, NSDAP, Reichspropagandaleitung, Amt Filmproduktion, Gebietsführer Kaufmann an Knothe, 10. 5. 1943.

785 Ibid.

786 PA-AA, 1143a, Kult. 12 Nr. 4, NSDAP, Reichspropagandaleitung, Kaufmann, an Knothe DBP, Berlin 4. 6. 1943.

787 Ibid. Knothe an Kaufmann, Amt Filmproduktion, Reichspropagandaleitung, NSDAP, 22. 6. 1943.

788 ANP, AJ40 1001-1, Prop.Abt., Filmprüfstelle, Tätigkeitsbericht, 8. 4.-15. 4. 1944; PA-AA, 1113, Kult 12 Nr. 4, Nova-Films, Muzard an Gast, 10. 6. 1944.

789 BA-KO, R109 III/8, Protokoll Nr. 36/44 über die Auslandsbeiratssitzung der deutschen Filmwirtschaft am Freitag, dem 21. Juli 1944, 2. 8. 1944.

790 PA-AA, 1113 Kult 12 Nr. 4, Muzard, Bericht für Abetz, 24. 1. 1944. 
lei kulturpolitischen oder propagandistischen Sinn ${ }^{791}$. Im Herbst 1943 ließ die Propaganda Abteilung Muzards zweites Spielfilmprojekt zu, für dessen Realisierung dann letztlich nicht genügend Mittel vorhanden waren ${ }^{792} . \mathrm{Mu}-$ zard hatte sich mit diesem Projekt erneut direkt an die deutschen Dienststellen gewandt, mit der Bitte, man möge für ihn beim zuständigen französischen COIC Fürsprache halten, damit das Projekt genehmigt würde. Um eine Finanzierung durch die Botschaft zu erreichen, versuchte er offenbar, diese mit einer anti-englischen Tendenz des Spielfilmes zu ködern. „La Belle marseillaise" spiele während der Französischen Revolution 1800-1803. Unter anderem waren Mordanschläge auf Bonaparte thematisiert und in einer der Szenen sollte der englische Premierminister William Pitt die Verschwörung gegen Bonaparte einleiten. Die Botschaft und die Filmprüfstelle waren jedoch der Ansicht, die anti-englische Tendenz müsse den gesamten Film durchziehen ${ }^{793}$. Muzard konnte das Filmprojekt nicht realisieren und produzierte stattdessen 1944 noch den Spielfilm „L'Enfant de l'amour" von Jean Stelli794.

Immer wieder wandte sich Muzard 1943 und 1944 an die deutschen Dienststellen mit der Bitte um finanzielle Unterstützung. So plante er im Herbst 1943 den Kauf einer eigenen Verleihfirma und bat zunächst die Propaganda Abteilung, sich daran finanziell zu beteiligen. Diese war jedoch der Ansicht, Muzard schiebe seine Propagandadienste zur Erreichung kommerzieller Zwecke vor, zumal er bisher viel Unterstützung sowie Vergünstigungen erhalten hatte. Da sie außerdem die Qualität der von der Nova hergestellten Propagandafilme wenig schätzte, sollte Muzard nicht weiter unterstützt werden 795 . Wenig später trat dieser vergeblich mit der gleichen Bitte an die Botschaft heran und verwies auf "gemeinsame propagandistische Filmpläne"796. Schließlich wandte er sich im Januar 1944 an Abetz persönlich, um ihn von einer finanziellen Unterstützung zu überzeugen. Er zeichnete in seinem Schreiben die Entstehungsgeschichte sowie sämtliche Aktivitäten der Nova nach und betonte, welches Engagement er bisher in Zusammenarbeit mit der Botschaft in der Herstellung von Propagandafilmen gezeigt habe sogar im Streit gegen die Propaganda Abteilung. Zur Zeit stelle er kleinere Filme im Auftrag der Propaganda Abteilung her. Der Informationsabteilung der Botschaft habe er ein Kurzfilmprojekt eingereicht, das die „Terroristen“ negativ darstellt und die französische Miliz verherrlicht. Muzard meinte abschließend: „Es ist bedauernswert, daß die Deutsche Botschaft sich an der Herstellung von aufklärenden Filmen nicht mehr beteiligt, zumal sie auf die-

791 Ibid. RMVP, Fries, Vermerk, Abschrift an Abt. Ausland, 31. 3. 1943.

792 Ibid. Muzard, Bericht für Abetz, 24. 1. 1944.

793 PA-AA, 1143b, Kult 12 Nr. 4, Muzard an Lohmann, DBP, 3. 2. 1943; ibid.

Prop.Abt., Derichsweiler an Lohmann, DBP, 5. 3. 1943.

794 BerTin-Maghit, Le Cinéma sous l'Occupation, S. 139.

795 PA-AA, 1113, Kult 12 Nr. 4, Prop.Abt., Derichsweiler an Knothe, DBP, 9. 11. 1943.

796 Ibid. Muzard, Aktennotiz für Knothe, 28. 11. 1943. 
sem Gebiet Pionierarbeit geleistet hat "797. Muzard versuchte also, den Konkurrenzkampf der deutschen Dienststellen für die eigenen Zwecke zu instrumentalisieren. Auf seinen Brief hin empfing ihn zwar die Botschaft zu einem Gespräch ${ }^{798}$, doch erhielt er letztlich keinerlei Unterstützung für den Kauf einer Verleihfirma. Abert versuchte dennoch weiter, Muzard zu unterstützen, weil er den Einfluß der Deutschen Botschaft auf die Herstellung französischer Propagandafilme unbedingt beibehalten wollte. Als die Propaganda Abteilung mehrere Filme bei der Nova in Auftrag gab, schlug er vor, die Botschaft solle sich mit 50 Prozent an den Herstellungskosten beteiligen, um das Terrain nicht der konkurrierenden Dienststelle zu überlassen ${ }^{799}$.

Andere Initiativen zur Beauftragung der Nova kamen sogar aus Berlin. Da Goebbels den Film „Forces occultes“ gelobt hatte, schickte Kaufmann von der Reichsleitung der NSDAP der Deutschen Botschaft in Paris im Juni 1943 ein deutsches Film-Manuskript mit dem Titel „Andrés Weg“. Sie sollte prüfen lassen, ob sich dieser französische Propagandafilm durch die Nova oder die Continental Films realisieren ließe ${ }^{800}$. Den Anlaß für den Stoff lieferten die russischen Freiwilligen, die an der Atlantik-Küste in Frankreich neben den Deutschen eingesetzt waren. Die englische Presse hatte sich darüber mokiert. Kaufmann wollte dieses Thema absichtlich in einem französischen Film behandeln ${ }^{801}$. Muzard sollte einen Kurzfilm über den Stoff machen, den ein französischer Drehbuchautor entsprechend der Mentalität der Bevölkerung ausarbeiten sollte ${ }^{802}$. Die Geschichte von „Andrés Weg“ spielte 1943 im Milieu französischer Bürgerfamilien. In einer kleinen Stadt in der Bretagne wird bei Andrés Familie der deutsche Hauptmann Dittmar mit seinem russischen Burschen, einem Freiwilligen, einquartiert. Beide sollen den deutschen Atlantikwall verteidigen. Angesichts der Feindschaft zwischen Deutschen und Russen wundert sich Andrés Vater darüber. Der Medizinstudent André kehrt aus Paris zurück. Er hat dort erlebt, wie seine Freundin bei einer Bombardierung durch die Engländer getötet wurde, wobei sie kurz vor ihrem Tod André noch von Erschießungen polnischer Offiziere in Katyn durch Rußland erzählt. André ist angesichts des Todes der Freundin entschlossen, in die

797 Ibid. Robert Muzard, Bericht für Abetz, 24. 1. 1944.

798 Ibid.

799 PA-AA, 1143a, Kult 12 Nr. 4, DBP, Abert, Aufzeichnung für Dr. von Kutzschenbach, Betr.: Herstellung von Propagandafilmen, 1943; laut dieser Planung sollte die Nova im Verlauf des Jahres 1944 zwei anti-amerikanische Filme herstellen: "Ce que l'oncle Sam ne dit pas" mit einer Länge von 450 Metern und einem Herstellungspreis von 490050 Francs sowie „Au pays des possibilités illimitées“, 350 Meter lang und mit Herstellungskosten von 423500 Francs.

800 Ibid. NSDAP, Reichspropagandaleitung, Amt Filmproduktion, Kaufmann an Knothe, DBP, 4. 6. 1943.

801 Ibid.

802 PA-AA, 1143a, Kult 12 Nr. 4, NSDAP, Reichspropagandaleitung, Amt Filmproduktion, Kaufmann an Muzard, 4. 6. 1943; die Länge des Films sollte 400 Meter betragen. 
Legion der Freiwilligen einzutreten, um an der Seite der Deutschen an der Ostfront zu kämpfen. Sein Vater ist dagegen und versucht vergeblich, ihn davon abzuhalten. Darüber hinaus streitet er sich mit seiner Tochter Françoise, die den deutschen Hauptmann, der bei ihnen einquartiert ist, „hübsch und gebildet ${ }^{\star 803}$ findet und ihn besonders freundlich grüßt. Sie rechtfertigt sich ihrem Vater gegenüber mit der Begründung, die Deutschen seien Helden und schützten Europa. Abschließend betont André gegenüber seinen Eltern, die wollen, daß er sein Examen macht: „Für Eure Zukunft gehe ich nach dem Osten" 804 . Muzard war ebenso wie Greven wenig beeindruckt von diesem Drehbuch. Es enthielt zuviel Stoff für einen Kurzfilm. Die Geschichte fand er zu naiv behandelt, Andrés Bekehrung und Verhalten, sein Eintritt in die Legion der Freiwilligen wirkten zu unwahrscheinlich ${ }^{805}$. Knothe teilte Kaufmann mit, sowohl Greven als auch Muzard hätten das Drehbuch als „grobe Holzhammerpropaganda " 806 bezeichnet, die bei der allgemeinen Stimmung in Frankreich eher das Gegenteil dessen hervorrufen würde, was beabsichtigt sei. Das Projekt wurde nicht verwirklicht.

Im Frühjahr 1944 drehte die Nova ihre beiden letzten Propagandafilme, diesmal im Auftrag der Deutschen Botschaft. „Le Vrai combat“ war ein Film, der für die französische Miliz und gegen die Résistance Partei nahm. „Douze heures d'angoisse" richtete sich gegen die kommunistische Résistance. Noch zu diesem Zeitpunkt, kurz vor Ende der Besatzung, wurde der Streit zwischen den Dienststellen noch deutlich. Am 10. Juni 1944 vermerkte Abert, die Aufnahmen für die genannten Filme seien zu zwei Dritteln fertig. Allerdings habe Reinelt von der Propaganda Abteilung bisher die fehlenden 2000 Meter Negativfilm mit dem Hinweis auf den Mangel an Rohfilm verweigert. Laut Reinelt war nicht mehr Rohfilm erhältlich. Abert setzte sich dafür ein, Rohfilm aus dem Restbestand der Agfa Paris zu entnehmen und anschlieBend in Berlin Ersatz dafür anzufordern ${ }^{807}$. Der Film sollte 350 Meter lang sein. Laut Drehbuch von Serge Gambier handelte "Le Vrai combat" von zwei Brüdern, Paul (23) und François (17). In den ersten Szenen ist Paul unterschiedlicher Propaganda ausgesetzt: Radio Paris und Radio Alger. Weder die Miliz noch die Résistance erwecken allerdings sein Interesse, er ist neutral. Dann wird sein Bruder François - schlafend im Wohnzimmer zu Hause - von sogenannten jüdischen Terroristen ermordet, die eigentlich seinen Vater treffen wollten. Aus Rache tritt Paul in die Miliz ein. Dort aber sagt man

${ }^{803}$ Ibid. Ohne Datum und Verfasser, Andrés Weg, Film-Drehbuch, 1943.

804 Ibid.

805 Ibid. Muzard an Knothe, DBP, Betr.: Unsere Stellungnahme zum Film „Andrés Weg", 19.6. 1943.

806 Ibid. DBP, Knothe an Kaufmann, Amt Filmproduktion, Reichspropagandaleitung, NSDAP, 22. 6. 1943.

807 PA-AA, 1113, Kult 12 Nr. 4, DBP, Abert, Aufzeichnung für Gast, Betr.: Herstellung der Propagandafilme „Douze Heures d'Angoisse“ (Heures Rouges) und „Le vrai Combat", 10.6. 1944. 
ihm, er dürfe keinen persönlichen Rachefeldzug führen. Er solle bis zuletzt die schlechte Kraft bekämpfen, die unter dem Deckmantel der ausländischen Propaganda aus dem Mord ein idealisiertes Verbrechen gemacht habe: „Paul devra réaliser cet idéal, sans lequel la Milice ne saurait l'accepter dans ses rangs " 808 . Der Kampf in der Miliz sollte demnach als besonders ehrenvoll dargestellt werden. Das Drehbuch zu "Douzes heures d'angoisse“ von Jacques de Sibarre und Pierre Gerau sah folgende Rahmenhandlung vor: Ein Bankangestellter aus einem kleinen französischen Ort hat einen Alptraum, in dem Kommunisten, die alle Polizisten und den Priester umbringen, den Ort besetzen. Es herrscht eine Atmosphäre von Angst bis der Bankangestellte wieder aus seinem Traum erwacht ${ }^{809}$. Beide Filme liefen erst kurz vor der $\mathrm{Li}$ bération in den französischen Filmtheatern an; sie dürften damit keinerlei propagandistische Wirkung auf das französische Publikum gehabt haben.

Muzard war sich offenbar bewußt, daß er im Fall eines Sieges der Alliierten in Frankreich für seine propagandistischen Aktivitäten zur Rechenschaft gezogen würde. Im Frühjahr 1944 bemühte er sich darum, „Forces occultes“ sowie "Tornavara" nach Spanien zu exportieren. Gleichzeitig reiste er nach Spanien, um dort eine eigene Filmproduktions- und Vertriebsfirma aufzubauen, was ihm letztlich nicht gelang ${ }^{810}$. Die geplante Filiale der französischen Nova-Films hätte deutsche und französische Spitzenfilme nach Spanien einführen und Propagandafilme herstellen sollen. Der Botschaft gegenüber betonte Muzard noch am 10. Juni 1944, gerade jetzt müßten Spanien und Deutschland mehr denn je zusammenhalten, „um das altüberlieferte europäische Kulturerbe von der Barbarei und dem Weltjudentum zu retten"811. Nach der Okkupation belegte das CRIE Muzard und seine Mitarbeiter mit schweren Strafen. Jean Marquès-Rivière, Drehbuchautor von „Forces occultes“ wurde am 17. Januar 1947 in Abwesenheit zum Tode verurteilt und Jean Mamy, der Regisseur des Filmes, wurde am 29. März 1949 in Montrouge hingerichtet. Robert Muzard verurteilte das CRIE am 25. November $1945 \mathrm{zu}$ drei Jahren $\mathrm{Haft}^{812}$.

Laut Bertin-Maghit hatte Muzard ursprünglich nur unpolitische, kommerzielle Spielfilme drehen wollen, wurde jedoch von den Deutschen gezwungen, Propagandafilme herzustellen ${ }^{813}$. Obgleich die kommerziellen Motive Muzards sicherlich auch eine Rolle spielten, haben die vorangegangenen Ausführungen gezeigt, daß seine Aktivität im besetzten Paris differenzierter zu sehen ist. Den Anstoß zur Herstellung „französischer" Propagandafilme im Dienste deutscher Propaganda gaben nicht die deutschen Dienst-

808 Ibid. „Le vrai combat", Scenario original de Serge Gambier, 350m. (Juni 1944)

${ }^{809}$ Ibid. „Heures rouges“, Scenario original de Jaques Sibarre et Pierre Geran, $400 \mathrm{~m}$. (Juni 1944); der Film in einem zweiten Titel auch „Heures Rouges“.

810 Ibid. DBP an AA, Bericht Muzards über Spanienreise, 19.6. 1944.

811 Ibid. Muzard an Gast, 10.6. 1944.

812 BertiN-Maghit, Le Cinéma sous l'Occupation, S. 223.

813 Ibid. S. $137 f$. 
stellen. Diese Aktivitäten gingen deutlich auf eine gemeinsame Idee von $\mathrm{Mu}-$ zard und Abert zurück. Letzterer war zwar Mitarbeiter der Botschaft, doch hatte diese Initiative einen eher persönlichen Charakter. Muzards Motivation hierzu ist zudem in engem Zusammenhang mit seinem langen Aufenthalt im nationalsozialistischen Deutschland zu sehen. Nach der Initiative von $\mathrm{Mu}-$ zard und Abert waren auch bei der Herstellung französischer Propagandafilme - ähnlich wie bei den Theatergastspielen - die Kompetenzstreitigkeiten der deutschen Dienststellen für deren Aktivitäten ausschlaggebend, was bis 1944 andauerte. Dabei beurteilten einzelne deutsche Funktionsträger die Produktionen Muzards sehr kritisch, obgleich seine Arbeit punktuell sogar durch Goebbels persönlich Anerkennung erfuhr. Muzards Filme galten zum Teil als zu deutsch, als unzureichend an die französische Mentalität angepaßt. Zwar versuchte Muzard auch mit der Produktion von Spielfilmen kommerzielle Ziele zu verfolgen, doch war er zu diesem Zeitpunkt schon zu sehr auf die finanziell wenig einträgliche Herstellung von Propagandafilmen festgelegt und damit innerhalb der französischen Filmbranche für andere Aktivitäten gleichsam diskreditiert.

\subsection{Deutsche Filmpolitik und französische Filmexportfrage}

Langfristig verfolgte die deutsche Besatzungsmacht mit Hilfe der Kulturpropaganda das Ziel der Errichtung einer „kulturellen Hegemonie“ in Europa. Dies war in Frankreich eng verbunden mit der Verhinderung französischen Kulturexports, um die französische kulturelle Ausstrahlungskraft zu verringern bzw. zu zerstören. Bei der Haltung der Besatzer gegenüber dem Export französischer Kulturgüter muß grundlegend zwischen dem Reich als importierendem Ausland und anderen Gebieten unterschieden werden, die von den Deutschen besetzt, annektiert, mit ihnen verbündet oder neutral waren. Aus innenpolitischen Gründen wurde in Deutschland der Import französischer Kultur am strengsten gehandhabt. Die deutschen Filmtheater zeigten nur sehr wenige französische Filme, wobei es sich hier vor allem um Produktionen der Continental handelte ${ }^{814}$. Im Vordergrund der folgenden Ausführungen soll daher vor allem die Frage des französischen Filmexports außerhalb Deutschlands stehen. Diese stand in engem Zusammenhang mit der deutschen Filmexportpolitik. Im Vergleich zum Theater, wo das Verbot des Kulturexports in Bezug auf französische Gastspielreisen von RMVP und Propaganda Abteilung sehr strikt gehandhabt wurde ${ }^{815}$, behandelte die Be-

$814 \mathrm{Zu}$ französischen Filmen in Deutschland siehe DREWNIAK, Der deutsche Film, S. 838-840. In deutschen Filmtheatern waren laut Drewniak außer den Produktionen der Continental ferner auch die Filme „Liebe im Süden" von Fernandel mit Carlo Rim, „Mademoiselle Bonaparte“ von Maurice Tourneur und „Le Dernier atout" (1942) von Jacques Becker zu sehen.

815 AN, AJ40 1001-7, Prop.St., Gr.Kult.Th., von Heyden Linden, Aktennotiz über die Besprechungen am 19., 20. und 21. 3. 1942 in Berlin mit Schlösser, Lang, Bollert, 28. 3. 
satzungsmacht den Export französischer Filme vergleichsweise flexibel. Die Anzahl der exportierten Filme war allerdings relativ gering. Vertrieben wurden sie hauptsächlich in Belgien und der Schweiz. Vor allem Produktionen der Continental gelangten auch nach Holland, Deutschland und in die Tschechoslowakei. Vierzig Filme wurden nach Italien exportiert, darunter waren 12 Produktionen der Continental ${ }^{816}$. Es ist auf den ersten Blick erstaunlich, $\mathrm{daß}$ der Export französischer Filme in zumindest geringem Maße erlaubt war, während das RMVP entschieden gegen französische Theatergastspiele im Ausland und auch generell gegen französischen Kulturexport war. Immerhin bildete der Film in den Augen der Nationalsozialisten gegenüber dem Theater ein weit wichtigeres Instrument deutscher Kulturpropaganda. Wie sahen nun die deutschen Bestimmungen zum französischen Filmexport aus und aus welchen Gründen wurde hier die Verhinderung französischen Kulturexports im Vergleich zum Theater weniger strikt gehandhabt? Welche Rolle war ferner dem französischen Film im "neuen Europa“ nach den Vorstellungen der Besatzungsmacht zugedacht?

Im Zuge der Wiederaufnahme der französischen Filmproduktion im März/April des Jahres $1941^{817}$ drängten die französischen Produzenten und Berufsorganisationen auf die Klärung der Frage eines französischen Filmexports. Im Unterschied zu Theatergastspielen, deren Finanzierung sehr aufwendig sein konnte, war generell im Bereich des Filmes ein Export für die Produzenten notwendig, wenn sich ein Film amortisieren sollte. Innerhalb der französischen Filmproduktion bestand also ein wesentliches finanzielles Interesse an der Ausfuhr von Filmen ${ }^{818}$. In einem Bericht an das RMVP vertrat das Referat Film im Januar 1941 den Standpunkt, Paris müsse als bedeutender Standort für den Filmexport in Europa zugunsten der deutschen Filminteressen erhalten bleiben ${ }^{819}$. Im März reiste Referatsleiter Diedrich mit Koegl, dem Leiter der Filmprüfstelle, nach Berlin, um die Frage des Exports französischer Filme mit dem RMVP zu besprechen. Das Referat be-

1942. Dort heißt es, Gastspiele französischer Ensembles in Deutschland seien noch nicht erwünscht, man rechne aber in weiter Ferne mit einer Lockerung in dieser Angelegenheit. $\mathrm{Zu}$ den Initiativen für französische Gastspiele siehe AN, AJ40 1002-2, Prop.St., Gr.Kult., Schreiben von Lucht an Lang, RMVP, Betr.: Gastspielaustausch, 12. 11. 1941; in der Anlage schickte Lucht drei vom RMVP angeforderte Listen nach Berlin: Eine Aufstellung von französischen Künstlern aus den Bereichen Musik und Theater, die für Gastspiele im Reich in Frage kamen. Trotzdem kam es dort nicht zu Gastspielen französischer Theatertruppen vor deutschem Publikum. Eine Ausnahme bildeten französische Gastspiele zur sogenannten Betreuung französischer Kriegsgefangener und Zwangsarbeiter in Deutschland.

816 BERTIN-Maghit, Le Cinéma sous l'Occupation, S. 106.

817 CCDR, L'Emprise (Cinéma), S. 22; in der Z.N.O. hatte die Filmproduktion bereits im Dezember 1940 wieder begonnen.

818 BERTIN-MAGHIT, Le Cinéma sous l'Occupation, S. 103. Siehe dazu auch BA-MA, RW35 221, Prop.Abt., Ref.Film, Tätigkeitsbericht, 1.5.-7.51941.

819 PA-AA, 1125b, Kult 12 Nr. 4, Prop.Abt., Ref.Film, Untergruppe Filmexport, Bericht, 28. 5. 1941. 
tonte, diese müsse recht bald und in jedem Fall noch während der Anwesenheit der deutschen Besatzungsmacht in Frankreich geklärt werden ${ }^{820}$. Zunächst wurde beschlossen, eine Untergruppe Filmexport beim Referat Film sowie eine zivile Exportstelle für die Bearbeitung der kaufmännischen und organisatorischen Fragen einzurichten ${ }^{821}$. Im April 1941 entstand diese Stelle vorläufig bei der Continental. Oberstleutnant Koegl übernahm die Leitung dieser Exportstelle und der Gruppe Filmexport beim Referat Film ${ }^{822}$. Doch eine Lösung der Frage des Filmexports war damit noch lange nicht in Sicht. Anfang Mai 1941 war laut Referat Film eine Klärung nur ,nach Eintreffen der großen Richtlinien aus Berlin" 823 möglich. Die französischen Filmorganisationen drängten auf einen Filmexport. Das Referat erhielt fortwährend neue Anträge, weil die französischen Produzenten sicher gehen wollten, ihre Filme auch im Ausland vertreiben und somit deren Finanzierung absichern zu können. Die Produktion von Filmen ohne eine endgültige Regelung dieser Frage bedeutete ein Risiko. Diedrich hatte deshalb zunächst vereinbart, französische Produktionen vorläufig für den deutschen Weltvertrieb anzukaufen. Koegl sollte die Abmachung dem RMVP während einer Dienstreise nach Berlin jedoch erst noch vortragen" 824 . Das Referat Film setzte sich vor allem deswegen für den französischen Filmexport ein, weil es ein weiteres Ziel deutscher Kulturpolitik gefährdet sah: die Aufrechterhaltung des französischen Kulturlebens und damit auch der französischen Filmproduktion. Außerdem zeigte diese vorläufige Vereinbarung bereits, daß ein Filmexport im Falle einer Zustimmung durch das RMVP vor allem über deutsche Firmen laufen sollte. Aus Berlin kehrte Koegl allerdings lediglich mit der Nachricht zurück, das Referat solle die Exportstelle bei der Continental noch nicht einrichten, sondern damit bis zu einer endgültigen Entscheidung aus Berlin warten. Währenddessen trafen bei der vorläufigen Exportstelle vermehrt Anfragen nach französischen Filmen aus dem Ausland, besonders aus Spanien und Italien, ein. Ihre Ausfuhr war jedoch wiederholt vom RMVP verboten worden $^{825}$. Ende Mai 1941 boten französische Produktionsfirmen der Continental dreißig Filme aus der Vorkriegszeit zum Kauf für den Export an, zum Teil

820 BA-MA, RW35 220, Prop.Abt., Ref.Film, Tätigkeitsbericht, 27. 3.-3. 4. 1941.

821 Ibid.

822 Ibid. Tätigkeitsbericht, 3. 4.-10. 4. 1941.

823 PA-AA, 1125b, Kult 12 Nr. 4, Prop.Abt., Ref.Film, Untergruppe Filmexport, Bericht, 28. 5. 1941.

824 Ba-MA, RW35 221, Tätigkeitsbericht, 1. 5.-7. 5. 1941.

825 Ibid. Tätigkeitsbericht, 8. 5.-14. 5. 1941; 22. 5.-28. 5. 1941; 2. 7.-9. 7. 1941. Laut Ehrlich soll schon im Mai 1941 der Export von zehn französischen Filmen aus der Vorkriegszeit nach Spanien genehmigt worden sein, um dort den Einfluß amerikanischer Filme zu vermindern. Sie schreibt, die Filmprüfstelle (Referat Film) habe sich zu dieser Zeit entschlossen, einen Filmexport nur nach Holland und Belgien zuzulassen, und die Ausfuhr nach Spanien habe eine Ausnahme dargestellt (EHRLICH, Cinema of Paradox, S. 151). Die vorliegenden Berichte des Referats Film deuten allerdings nicht darauf hin, daß dort solche Entscheidungen zu jenem Zeitpunkt getroffen wurden. 
nur für einzelne Länder. Auch bei neueren französischen Produktionen bestanden Angebote: „Außer den bereits fertiggestellten Filmen wurde auch von 5 Unternehmungen freiwillig die herzustellende Produktion des Jahres 1941 angeboten, wobei in 2 Fällen Exportvorschüsse angefordert werden"826. Diese Produzenten wollten durch den Verkauf der Exportrechte ihre Filmproduktionen zum Teil vorfinanzieren. Eine Wiederbelebung der französischen Filmproduktion hing also mit einem möglichen Filmexport eng zusammen und ein gut funktionierendes kulturelles Leben war immerhin ein wesentliches Ziel der Besatzer. Das langfristige Ziel einer Verringerung der kulturellen Ausstrahlungskraft Frankreichs war aber nur schwer mit einer Ausfuhr französischer Filme zu vereinbaren. Die zögerliche Haltung des RMVP in dieser Frage war wohl auch in dem Gegensatz beider Ziele begründet. Ferner ist hier anzumerken, daß auf seiten der Continental zusätzlich ein finanzielles Interesse an einem Export ihrer französischen Filme bestand.

Nach einem Aufenthalt Grevens in Berlin genehmigten RMVP und Cautio Anfang Juni 1941 erst einmal die Einrichtung einer Filmexportstelle bei der Continental. Diese erhielt den Auftrag, ihre eigenen Filme zu exportieren und Filme der sogenannten freien französischen Produktion ${ }^{827}$ für den Export anzukaufen. Die dazu nötigen finanziellen Mittel hatte Max Winkler zugesagt. Ebenfalls festgelegt wurden die Aufgaben der Untergruppe Filmexport beim Referat Film. Dazu gehörten die "Überwachung des gesamten Filmexportes aus Paris, Herstellung der Verbindung mit sämtlichen staatlichen Stellen des Reiches, Frankreichs und aller anderen Staaten, um die Möglichkeiten des Exportes zu untersuchen, die bestehenden Verordnungen kennenzulernen und die Devisenfragen zu regeln" 828 . Der Abteilung Filmexport bei der Continental sollte die geschäftliche Durchführung des Filmexports obliegen. Durch den Ankauf französischer Filme sollte hier zunächst ein sogenannter Exportstock entstehen. Grundsätzlich hatte das RMVP nun eine Entscheidung für den französischen Filmexport getroffen. Es fehlte aber eine konkrete Regelung der Frage, in welchem Umfang französische Filme in welche Länder exportiert werden durften. Das RMVP beauftragte Greven, er solle hierfür von Paris aus Vorschläge machen. Unklar waren sich die Besatzer vor allem darüber, ob abgesehen von der Continental auch eine andere französische Stelle Filme exportieren dürfe oder nicht ${ }^{829}$. Mitte Juni sandte Schmidtke über die Attaché-Abteilung des OKW mehrere Schreiben an die deutschen Gesandtschaften in verschiedenen Ländern. Um den französischen Filmexport voranzutreiben, bat er diese um Informationen über die Möglichkeiten der Einfuhr französischer Filme in die jeweiligen Länder und betonte, die Propaganda Abteilung habe beim Referat Film eine Untergruppe

826 BA-MA, RW35 221, Prop.Abt., Ref.Film, Tätigkeitsbericht, 22. 5.-28. 5. 1941.

827 Gemeint waren hier alle französischen Filme, die nicht von der Continental produziert wurden.

828 BA-MA, RW35 221, Prop.Abt., Ref.Film, Tätigkeitsbericht, 29. 5.-4. 6. 1941.

829 Ibid. 
Filmexport eingerichtet ${ }^{830}$. Schmidtke hatte durch die ungewöhnliche Wahl dieses Postweges hinter dem Rücken des AA agieren wollen und scheiterte damit, weil die Abteilung im OKW die Briefe an das AA weiterleitete. Unterstaatssekretär Martin Luther war empört und ließ Abetz über einen Mitarbeiter ausrichten, die Weiterleitung von Schmidtkes Briefen an die Gesandtschaften habe naturgemäß nicht stattgefunden ${ }^{831}$. In einem Brief an das OKW/WPr betonte Luther, der Export französischer Filme falle nicht in das Arbeitsgebiet der Propaganda Abteilung, sondern gehöre „als eine Angelegenheit der deutschen Auslandspropaganda zur ausschließlichen Zuständigkeit des Auswärtigen Amtes"832. Der Export französischer Filme berührte hier also auch die Kompetenzstreitigkeiten der deutschen Dienststellen, wobei Luther in diesem Fall vor allem über die versuchte Umgehung des Dienstweges durch Schmidtke besonders verärgert war.

Mitte Juli 1941 reisten Diedrich und Greven nach Berlin um die Filmexportfrage für Europa und die überseeischen Länder im RMVP zu besprechen. Anwesend waren unter anderem Oberregierungsrat Dr. Fries von der Abteilung Film des RMVP und Dr. Schwarz von der Reichsfilmkammer in Berlin. In einem Bericht des Referats Film heißt es, der in dieser Besprechung ausgearbeitete Entwurf zur Regelung eines französischen Filmexports müsse noch Goebbels vorgelegt werden. Erst nach dessen Stellungnahme wolle das RMVP die endgültigen Exportrichtlinien an das Referat Film senden ${ }^{833}$. Die Continental sollte demnach weiterhin Exportrechte für die guten exportgeeigneten französischen Filme ankaufen und sie zusammen mit den eigenen

830 PA-AA, 1125b, Kult 12 Nr. 4, Prop.Abt., Ref.Film, Schmidtke, An die deutsche Gesandtschaft Stockholm, 19.6. 1941; ibid. AA, Luther an Oberst von Wedel, OKW/ WPr, 16. 7. 1941; aus dem Schreiben Luthers geht hervor, daß Schmidkes Briefe neben Stockholm an die Gesandtschaften Helsinki, Preßburg, Budapest, Bern, Madrid, Lissabon, Tirana und Ankara gehen sollten.

831 PA-AA, 1125b, Kult 12 Nr. 4, AA, Krümmer, Mitteilung für Abetz, 23. 7. 1941.

832 Ibid. AA, Luther an Oberst von Wedel, OKW/WPr, 16. 7. 1941.

833 BA-MA, RW35 222, Tätigkeitsbericht, 25. 7.-31.7. 1941; die anderen Teilnehmer waren: von Eicke (Paris, Contintental-Films), Sdf. (Z) Reinelt (Fachbearbeiter für Ein- und Ausfuhr von Filmen beim Referat Film der Propaganda Abteilung Frankreich), Oberregierungsrat Knothe (Reichsbeauftragter für das Filmwesen auf dem Balkan), Oberregierungsrat Faber (Reichsbeauftragter für das Filmwesen in Italien), Sdf. van Daalen (Brüssel, Referat Film, Prop.Abt. Belgien), von Tiedemann (Den Haag, Reichsbeauftragter beim Reichskommissar für die Niederlande), von Theobald (Berlin, Auslandsabteilung der UFA), Dr. Wünzig (Den Haag, UFA-Vertretung in den Niederlanden). Siehe dazu auch EHRLICH, Cinema of Paradox, S. 150 f.; sie schreibt, diese Besprechung habe in Paris stattgefunden. Laut BERTIN-MAGHIT, Le Cinéma sous l'Occupation, S. 104, der sich auf die Ausführungen Ehrlichs bezieht, hat Goebbels an dieser Besprechung sogar teilgenommen; die vorliegenden Quellen zeigen jedoch, daß Goebbels nicht anwesend war und diese Besprechung in Berlin stattfand. Ferner gehen Ehrlich und Bertin-Maghit in ihren Ausführungen nicht darauf ein, daß es sich hier um einen Entwurf zu einer Regelung des Filmexports gehandelt hat. Goebbels stimmte diesem in einer leicht modifizierten Form erst im November $1941 \mathrm{zu}$, worauf noch näher einzugehen sein wird. 
Produktionen ausführen: „Die Continentalfilm vergibt die Rechte an ihren eigenen wie an den von ihr erworbenen französischen Filmen (im folgenden kurz ,unsere' französischen Filme) grundsätzlich an die deutschen Filmfirmen mit eigenen Auslandsfilialen für die Länder, in denen Filialen unterhalten werden" 834 . Ferner sollte nur der Kunde französische Filme erhalten, der deutsche Filme bereits in ausreichendem Umfang bezogen hatte. Außerdem wurde festgelegt, die Auslandsfilialen müßten generell mehr deutsche als französische Filme vertreiben. Die deutsche Seite fürchtete also deutlich eine mögliche Konkurrenz durch den französischen Film, was das RMVP durch eine entsprechende Exportregelung zu verhindern suchte. Der Export französischer Filme sollte vor allem nach folgenden Grundsätzen geschehen:

Im übrigen erfolgt der Einsatz unserer französischen Filme unter dem Gesichtspunkt der Ergänzung unseres (vorläufig zahlenmäßig noch unzureichenden) deutschen Filmangebots, der Selbstversorgung der europäischen Filmmärkte, der Verdrängung der Amerikaner und - in einzelnen Gebieten - der Vorspannwirkung des französischen Films ${ }^{835}$.

Der Vertrieb deutscher Produktionen sollte durch das gleichzeitige Angebot französischer Filme erleichtert werden, weil letztere sich besonders in einigen Ländern größerer Beliebtheit erfreuten. In Frankreich und Belgien wurde diese Verkaufspraxis von den deutschen Anbietern auch schon in der Vorkriegszeit praktiziert ${ }^{836}$. Französische Filme sollten also generell nur insoweit exportiert werden als dies einer deutschen Filmpolitik in Europa nützlich war. Man wollte sie demnach zur Verdrängung des amerikanischen Films und zur Versorgung der europäischen Märkte einsetzen. Seit Kriegsbeginn war eine verminderte Einfuhr von Filmen aus überseeischen Gebieten zu verzeichnen. Die Filmproduktion in den europäischen Ländern war zurückgegangen und der deutsche Film, der nicht zuletzt durch die militärischen Siege des Reiches auf den Märkten im besetzten und verbündeten Ausland einen wesentlichen Platz einnahm, konnte dort bald den Bedarf nicht mehr decken ${ }^{837}$.

834 BA-MA, RW35 222, Prop.Abt., Ref. Film, Tätigkeitsbericht, 8. 8.-15. 8. 1941; RMVP, Niederschrift vom 29. 7. 1941 über die am 16. Juli 1941 im Reichspropagandaministerium in der Frage des Exports französischer Filme stattgefundene Besprechung (Abschrift).

835 Ibid. In einem Großteil der Exportländer wie Holland, dem flämischen Teil Belgiens, der deutsch- und italienischsprachigen Schweiz, Slowakei, Ungarn, Kroatien, Rumänien, Bulgarien, Griechenland, Türkei, Serbien, Montenegro, „Protektorat Böhmen und Mähren", "Generalgouvernement für die besetzten polnischen Gebiete“, Dänemark, Norwegen, Schweden und Finnland sollten die französischen Filme entweder in deutscher oder italienischer Synchronisation gezeigt werden. Ausnahmen bildeten Spanien, Portugal, Amerika und sonstige überseeische Gebiete sowie die französischen Kolonien, wo sie im Original laufen konnten.

836 Siehe Kapitel I. 1. dieser Arbeit.

837 DREWNIAK, Der deutsche Film, S. 689-694. 
Für eine konkrete Regelung des Filmexports war dieser Entwurf, der noch nicht einmal Goebbels vorgelegt worden war, allerdings noch $\mathrm{zu}$ allgemein gehalten. Eine Lösung des Problems ließ weiter auf sich warten. Zwei Monate später fuhr Diedrich vom 26. September bis zum 1. Oktober 1941 nach Berlin und beschwerte sich dort bei der Abteilung Film des RMVP, man benötige nun endlich klare Richtlinien, die auch die Zustimmung von Goebbels hätten. Diedrich war der Ansicht, die in dem oben genannten Entwurf dargelegten allgemeinen Richtlinien müßten ausgebaut und vervollständigt werden, damit das Referat Film sich über seine Arbeit im klaren sein könne. Ferner sei es notwendig, daß auch den französischen Produzenten endlich mitgeteilt werde, ob, wohin und in welchem Umfang sie ihre Filme exportieren könnten. Anstatt der gewünschten deutlichen Richtlinien erhielt Diedrich von der Abteilung Film in Berlin den Auftrag, er solle selbst zusammen mit Greven einen Vorschlag ausarbeiten, der die Grundlage für endgültige Richtlinien des RMVP bilden könnte ${ }^{838}$. In einem Schreiben vom 20. Oktober 1941 an das RMVP beschwerte sich schließlich die Propaganda Abteilung, unter den gegebenen Umständen könne bei den Pariser Dienststellen kein Vorschlag für eine Exportregelung ausgearbeitet werden. Voraussetzung für die Klärung dieser Frage sei, „die genaueste Kenntnis der Absichten und Pläne über die Rolle, die der franz.[ösische] Film in der Zukunft in Europa und darüber hinaus in der ganzen Welt spielen soll.“839. Dies sei eine politische Frage, die nur von Berlin aus entschieden werden könne, worum die Propaganda Abteilung dringend bitte. Das RMVP müsse entscheiden, wie groß der Anteil französischer Filme an den europäischen Märkten und am Weltmarkt sein dürfe. $\mathrm{Da}$ die Herstellung französischer Filme auf vollen Touren liefe, benötige man dringend grundsätzliche Entscheidungen aus Berlin, auf deren Grundlage erst die Ausarbeitung eigener Vorschläge möglich werde.

Im November 1941, etwa sieben Monate nachdem das Referat Film die Frage des französischen Filmexports aufgeworfen hatte, sandte das RMVP endlich von Goebbels genehmigte Exportrichtlinien nach Paris. Sie entsprachen in ihren Grundzügen dem bereits dargestellten Entwurf vom 16. Juli 1941. Vorab wird allerdings betont, die Propaganda Abteilung müsse den Export französischer Filme verhindern, sofern diese in der besetzten Zone hergestellt und außerhalb der Continental produziert und vertrieben wurden. Zudem versuche die Propaganda Abteilung den Export der Filme, die nicht von der Continental erworben wurden und im unbesetzten Gebiet hergestellten waren, durch deren Verbot im besetzten Gebiet zu unterdrücken ${ }^{840}$. Der Export französischer Filme sollte ausschließlich über die deutsche Con-

838 BA-MA, RW35 223, Prop.Abt., Ref.Film, Tätigkeitsbericht, 3. 10.-10. 10. 1941.

839 Schreiben der Prop. Abt., an das RMVP vom 20. 10. 1941, in: BA-MA, RW35 224, Prop.Abt., Ref.Film, Tätigkeitsbericht, 17. 10.-24. 10. 1941.

840 BA-MA, RW35 224, Prop.Abt., Ref.Film, Tätigkeitsbericht, 14. 11.-21. 11. 1941; siehe Anlage Lb, Richtlinien für den Export französischer Filme. 
tinental und damit allein unter deutscher Kontrolle geschehen. Im Unterschied zu dem Entwurf vom 16. Juli 1941 war ein Angebot französischer Filme in Holland und Serbien erst vorgesehen, falls das dortige Filmangebot nicht ausreichen würde; nach Montenegro und in das sogenannte Generalgouvernement für die besetzten polnischen Gebiete sollten überhaupt keine französischen Filme gelangen. Als Exportgebiete blieben Belgien, die Schweiz, die Slowakei, Ungarn, Kroatien, Rumänien, Bulgarien, Griechenland, die Türkei, das „Protektorat Böhmen und Mähren“, Dänemark, Norwegen, Schweden, Finnland, Italien, Spanien, Portugal, USA und die französischen Kolonien. Die in diesen Richtlinien formulierten Grundsätze eines Einsatzes französischer Filme innerhalb der deutschen Filmpolitik in Europa wurden so nicht in die Praxis umgesetzt; immerhin wurden in der Folge nur wenige französische Filme exportiert und dies erst seit Beginn des Jahres 1942. Etwa 30 Produktionen der Continental und nur einige wenige Filme der französischen Produktion wurden zum Großteil in die Schweiz und nach Belgien ausgeführt ${ }^{841}$.

Ein Grund hierfür war vermutlich die in Frankreich zunehmende Knappheit an Rohfilm, der für Filmkopien und somit für einen Filmexport notwendig war. Ein Großteil der französischen Rohfilmproduktion gelangte in den Jahren 1942/43 nach Deutschland, wo die Rohfilmindustrie mehr und mehr mit der Produktion von Waffen beschäftigt war ${ }^{842}$. Ferner ist denkbar, daß im Zuge der sich verändernden Weltkriegslage das deutsche Interesse an einem französischen Filmexport, der beim RMVP von Beginn an offenbar nicht sehr groß war, weiter sank; primär war für die Besatzer aus propagandistischen und ökonomischen Gründen ein deutscher Filmexport wichtig. Grundsätzlich sah die Besatzungsmacht außerdem die wieder erstarkende französische Filmindustrie als einen Konkurrenten. Hierfür spricht auch die Haltung von Goebbels gegenüber der Arbeit der Continental, die seiner Ansicht nach aufhören sollte, zu gute französische Filme herstellen ${ }^{843}$. Zum Ende des Jahres 1942 wurden die Exportbestimmungen verschärft. In den Richtlinien vom 1. November 1942 heißt es: „Im Generalgouvernement, in den besetzten sowjetischen Gebieten, in den Niederlanden, Norwegen und Jugoslawien sollen bis auf weiteres keine französischen Filme angeboten

841 CCDR, L'Emprise (Cinéma), S. 23. Zum Beginn des Filmexports unter deutscher Besatzung siehe BA-MA, RW35 225, Prop.Abt., Gr.Film, Tätigkeitsbericht, 13. 2.20. 2. 1942. Dort heißt es: „Der Lieferungsbeginn der Continental-Films hat wie im letzten Tätigkeitsbericht bereits erwähnt, begonnen durch die Ausfuhr von 20 französischen Filmen (11 Contintal-Filme und 9 weitere freie französische Filme) nach Finnland.

842 Zur Frage der Ausfuhr französischen Rohfilms nach Deutschland siehe beispielsweise: BA-MA, RW35 223, Prop. Abt., Ref.Film, Tätgikeitsbericht, 22. 8.-29. 8. 1941; RW35 224, 7. 11.-14. 11. 1941; RW35 225, 24. 4.-2. 5. 1942; RW35 226, 1. 6.-6. 6. 1942; 6. 6.-12. 6. 1942; 13. 6. -20.6. 1942.

${ }^{843}$ Siehe Kapitel II. 1.2. dieser Arbeit. 
werden. " 844 . Allerdings gab es im Mai/Juni 1943 sogar Verhandlungen zwischen Greven und Galey zur Gründung einer gemeinsamen deutsch-französischen Exportgesellschaft ${ }^{845}$. Das Projekt wurde jedoch nicht verwirklicht, weil die Forderungen der französischen Seite von den Besatzern als unannehmbar angesehen wurden. Die Filmprüfstelle hatte zur geplanten Gründung dieser Gesellschaft vermerkt, diese sei wirtschaftlich und vor allem auch kulturpolitisch als beachtliche Leistung zu sehen. Sie bedeute eine Vorbereitung der deutsch-französischen Zusammenarbeit im Filmbereich ${ }^{846}$. Daß eine deutsch-französische Zusammenarbeit im Bereich des Filmes tatsächlich für die Zukunft von den Besatzern angestrebt wurde, ist fraglich, denn langfristiges Ziel war die Errichtung einer "kulturellen Hegemonie“ Deutschlands. Dies mußte aber nicht unbedingt bedeuten, daß von deutscher Seite langfristig die französische Filmindustrie völlig zerstört werden sollte.

Im Zusammenhang mit den deutschen Vorstellungen zu einem französischen Filmexport stellt sich die Frage, welche Rolle dem französischen Film in einem von Deutschland kulturell dominierten „Europa neuer Ordnung“ für die Zukunft zugedacht war. Dies ist nicht eindeutig zu klären; das Referat Film hatte beim RMVP mehrfach um Bestimmungen gebeten, die diese Rolle definieren sollten. Die oben genannten angeblich endgültigen Exportrichtlinien vom November 1941 enthielten hierzu keine deutliche Position. Im Bereich des französischen Filmexports legte man sich in der deutschen Kulturpolitik ebensowenig fest wie in der allgemeinen Besatzungspolitik, wenn es um die zukünftige Stellung Frankreichs im „neuen Europa“ ging. In der Sekundärliteratur sind die genannten Exportbestimmungen bisher als Beleg dafür gesehen worden, daß nach den Plänen der Besatzungsmacht der französische Film in eine deutsche Filmpolitik in Europa auch langfristig eingebunden werden sollte. Auf lange Sicht war diesem demnach eine relativ große Bedeutung im "neuen Europa“ sozusagen als Partner für den deutschen Film im Kampf gegen den amerikanischen Film zugedach ${ }^{847}$. Hierbei ist allerdings nicht die Entstehungsgeschichte der Richtlinien berücksichtigt worden. Sie zeigt, daß das RMVP, welches die Filmexportfrage sehr zögerlich behandelte, sich offenbar keineswegs darüber im klaren war, welche Rolle dem französischen Film innerhalb des "neuen Europa“ zukommen sollte. Erst als der Filmexport aufgrund der Wiederbelebung der französischen Filmproduktion notwendig wurde, war man bereit, zugunsten dieses kurzfristigen Zieles den Grundsatz der Verhinderung französischen Kulturexports zurückzustel$\operatorname{len}^{848}$. Die daraufhin ausgearbeiteten Exportrichtlinien sahen zwar eine Aus-

844 Zit. n. DREWNIAK, Der deutsche Film, S. 732.

845 Siehe dazu BERTIN-MAGHIT, Le Cinéma sous l'Occupation, S. 104-106.

846 BA-MA, RW35 227, Prop.Abt., Filmprüfstelle, Tätigkeitsbericht, 22. 5.-29. 5. 1943.

847 Ehrlich, Cinema of Paradox, S. 150f.; BERTIN-MAGHIT, Le Cinéma sous l'Occupation, S. 104.

848 Davon ausgenommen waren allerdings die Continental-Filme, deren Export nicht 
fuhr französischer Filme im Rahmen der deutschen Filmpolitik in Europa vor, doch sind sie nie in die Praxis umgesetzt worden. Exportiert wurden vorwiegend Produktionen der Continental, weil hier auch deutsche ökonomische Interessen eine Rolle spielten. Das RMVP vertrat letztlich eine relativ vorsichtige Haltung gegenüber einer Ausfuhr französischer Filme. Vermutlich wurde hier von deutscher Seite der französische Film, der schon in den Jahren vor dem Kriege für den deutschen Film eine Konkurrenz dargestellt hatte, immer noch gefürchtet. Hierfür spricht auch die Tatsache, daß Frankreich nicht Mitglied der von Goebbels im Juli 1941 wieder gegründeten IFK, der Internationalen Filmkammer ${ }^{849}$, werden sollte. Ein späterer Beitritt war anfangs zwar geplant, wurde jedoch nie verwirklicht. Im Februar 1942 meinte das Referat Film hierzu, aus verschiedensten Gründen erscheine ein Beitritt Frankreichs als noch nicht notwendig. Ohne dies näher zu erläutern, wird in dem Bericht pauschal eine „Wahrung deutscher Interessen" 850 als Motiv genannt. Zur Bedeutung der IFK hat Drewniak unter anderem konstatiert, dass die IFK im Dritten Reich ein wesentliches Instrument im Kampf gegen die Konkurrenz des amerikanischen Films darstellte 851 . Wenn dem französischen Film also tatsächlich eine wichtige Rolle innerhalb dieses Konkurrenzkampfes zugedacht war, dann hätten die Besatzer Frankreich immerhin zu einem Beitritt bewegen müssen.

Offiziell verpflichteten sich die Mitgliedstaaten auf der Gründungstagung der IFK vom 16. bis 21. Juli 1941 dazu, „in gemeinsamer Aufbauarbeit mit den nationalen Filmwirtschaften der internationalen Neuordnung und der Völkerverständigung zu dienen " 852 . Ferner sollte durch diese Organisation auch die Produktion und Verbreitung von Filmen verhindert werden, welche die Beziehungen zwischen den Mitgliedern der Kammer stören könnten. Goebbels Intention zur Gründung der IFK war freilich vor allem die Schaffung eines Instruments zur Kontrolle über die europäischen Filmwirtschaften $^{853}$. In seiner Rede auf der Gründungstagung betonte der Propagandaminister, Europa müsse sich vom amerikanischen Film gänzlich unabhängig

in Frage stand; diese sollten von Anfang an einem besseren Absatz deutscher Filme im Ausland dienen.

${ }^{849}$ Zur IFK siehe DrewniaK, Der deutsche Film, S. 799-802. Die IFK war erstmals 1935 gegründet worden. Laut Drewniak gehörte sie zu den Institutionen mit deren Hilfe Goebbels versuchte, das kulturelle Leben des "neuen Europa" von Deutschland abhängig zu machen. Zur Gründungstagung der IFK vom 16.7.-21. 7. 1941 in Berlin siehe BA-MA, RW35 222, Prop.Abt., Ref.Film, Tätigkeitsbericht, 25. 7.-1. 8. 1941. Diedrich war anläßlich der Neugründung nach Berlin gefahren. Mitglieder der IFK waren neben Deutschland Belgien, Bulgarien, Dänemark, Finnland, Holland, Italien, Kroatien, Norwegen, Rumänien, Slowakei, Spanien, Schweden, Türkei, Ungarn, Böhmen und Mähren.

850 BA-MA, RW35 225, Prop.Abt., Gr.Film, Tätigkeitsbericht, 13. 2.-20. 2.1942.

851 DREWNIAK, Der deutsche Film, S. 801.

852 BA-MA, RW35 222, Prop.Abt., Ref.Film, Tätigkeitsbericht, 25. 7.-31. 7. 1941.

853 Ibid. 
machen. Ferner ging er auch auf die sogenannte Toleranz Deutschlands gegenüber den anderen Filmindustrien Europas ein:

Deutschland liege nichts ferner als die Absicht, das Filmschaffen kleinerer Länder zu unterdrücken, selbst wolle es seinen Ehrgeiz dareinsetzen, nicht so sehr in der Zahl wie in der Qualität der Filme zu glänzen, daneben bleibe mehr als genug Spielraum und Betätigungsfeld für alle anderen filmschaffenden Völker in Europa ${ }^{854}$.

Carl Froelich, Präsident der Reichsfilmkammer und Vizepräsident der IFK, betonte in seiner Rede, jeder qualitativ gute Film trage zur Völkerverständigung bei und müsse deshalb immer auch ein nationaler Film sein. Ebenso meinte Karl Melzer, Vizepräsident der Reichsfilmkammer und Generalsekretär der IFK, in seiner Rede, die Filmproduktion in Europa müsse national gebunden sein, denn nur die konsequente nationale Betonung eines Filmes mache jenen stark und interessant ${ }^{855}$. Auch gegenüber dem französischen Film wurde eine vorgeblich tolerante Haltung Deutschlands propagiert. Dies konnte durchaus glaubhaft erscheinen, da die Besatzer für eine Wiederaufnahme der französischen Filmproduktion eintraten - allerdings erst nachdem sich die deutsche Continental in Paris eine bevorzugte Stellung innerhalb der Filmproduktion gesichert hatte. In einem Artikel der Deutsch-französischen Monatshefte vom Mai 1942 wies C.F. Jäckisch auf den zukünftigen Ehrenplatz der französischen Filmproduktion im "neuen Europa“ hin: "C'est ainsi qu'une nouvelle production française est en train de se créer [...] une production consciente de sa tâche française et européenne qui prendra avec le temps une place d'honneur dans la production cinématographique de l'Europe entière" 856 . In diesem Sinne war man auch auf französischer Seite der Ansicht, dem französischen Film sei in einem „Europa neuer Ordnung" eine angemessene Rolle zugedacht. Raoul Ploquin, Leiter des COIC, schrieb ebenfalls im Mai 1942 in einem Artikel der Deutsch-französischen Monatshefte, es sei wichtig heute für die Zukunft zu arbeiten. Der französische Film werde seinen Platz, den niemand ihm streitig machen werde, im "neuen Europa" einnehmen ${ }^{857}$. Ploquin meint in seinen Ausführungen ferner, die französische Filmindustrie werde an dem Aufbau dieser Zukunft mit der Herstellung von Werken mitarbeiten, die „ein wahres Bild des französischen Geistes und des französischen Lebens" 858 vermitteln könnten. Es ist allerdings fraglich, inwieweit solche Werke tatsächlich in den Augen der Besatzer erwünscht waren.

Laut Ehrlich und Bertin-Maghit, soll auf deutscher Seite ein großes Interesse an der Produktion qualitativ guter französischer Filme bestanden haben,

854 Ibid.

855 Ibid.

856 C.F. JÄCKISCH, Le cinéma allemand et la collaboration européenne, in: DFMH 5 (1942) S. 162 (Ein Sonderheft zum Thema Film).

857 Raoul Ploquin, Der französische Film im neuen Europa, in: DFMH 5 (1942) S. 148 .

858 Ibid. S. 150. 
weil jenen im Kampf gegen den amerikanischen Film eine erhebliche Bedeutung beigemessen worden sei. Zusätzlich hätten die Besatzer die französische Filmproduktion aufgrund ökonomischer und propagandistischer Interessen gefördert. Deutschland habe in die französische Filmindustrie investiert und der Weltöffentlichkeit sollte aus Prestigegründen demonstriert werden, daß in Frankreich unter deutscher Besatzung qualitativ gute Filme hergestellt würden ${ }^{859}$. Ehrlich konstatiert ferner: „Finally, there is the long range view of France as an integral part of the ,new Europe', whose production would glorify not merely France, but the new order as a whole ${ }^{\prime 860}$. Sie betont, die Zensurberichte der Filmprüfstelle enthielten künstlerisch-qualitative Beurteilungen der geprüften Werke und Empfehlungen exportgeeigneter Filme. Darin sieht sie einen Beleg dafür, daß gemäß der deutschen Vorstellungen die französische Filmproduktion ihre gute Reputation aus der Vorkriegszeit behalten sollte ${ }^{861}$. Die künstlerischen Beurteilungen in den Zensurberichten können nicht als Beleg für ein deutsches Interesse an einer qualitativ hochwertigen französischen Filmproduktion angesehen werden. In den Ausführungen zur Zensur ist bereits dargelegt worden, daß bei der Zulassung der Filme für das Inland keine künstlerische Zensur ausgeübt wurde. Die Zensoren nahmen nicht im Sinne einer qualitativ hochwertigen französischen Produktion Einfluß. Die Zensurberichte, die als Information für das RMVP gedacht waren, enthielten durchaus neben politischen auch künstlerische Beurteilungen der Filme. Durch Empfehlungen von exportgeeigneten Filmen kam in diesen Berichten lediglich eine qualitative Zensur für die Zulassung zum Export zum Ausdruck ${ }^{862}$. Dies war sicherlich vor allem darin begründet, daß die Besatzer verhindern wollten, im Ausland könne der Eindruck entstehen, im besetzten Frankreich würden lediglich schlechte Filme hergestellt. Aus Prestigegründen sollte dem Ausland gezeigt werden, daß unter deutscher Besatzung durchaus die Produktion guter Filme möglich sei. Zudem wäre die

859 EHRLICH, Cinema of Paradox, S. 143-153.

860 Ibid. S. 148.

861 Ibid. S. 152. Ein weiterer Beleg ist in ihren Augen die Tatsache, daß man sich darum bemühte, französische Schauspieler und Regisseure, die nach Amerika emigriert waren oder sich in der ZNO befanden, zur Rückkehr zu bewegen. Für diese Bemühungen der Besatzer gibt es allerdings auch andere Gründe. Die Emigranten wirkten häufig in sogenannten amerikanischen Hetzfilmen gegen das Deutsche Reich mit und betrieben auf diese Weise „Feindpropaganda“. Ferner wollten die Besatzer die französische Filmproduktion in Paris konzentrieren, wobei die Rückkehr bekannter Stars in das besetzte Frankreich als wesentliche Hilfe angesehen wurde.

862 Bertin-Maghit, der die Argumentation von Ehrlich übernommen hat, ist sogar zu dem Schluß gekommen, die Besatzer hätten generell die Zensur nicht nur nach politischen Kriterien ausgeübt: „[...] la commission de censure allemande est soucieuse de morale et surtout d'esthétique “ (BERTIN-MAGHIT, Le Cinéma sous l'Occupation, S. 95 f.). Er konstatiert ferner zur Rolle des französischen Films im „neuen Europa“: "Du côté allemand, il faut défendre la production d'un cinéma européen dans lequel le cinéma français est le seul capable de concurrencer le cinéma anglo-saxon" (Ibid, S. 103). 
Funktion als Zugpferd für deutsche Filme mit qualitativ schlechten französischen Filmen geringer gewesen. Trotzdem kann daraus nicht geschlossen werden, die Besatzer hätten ein Interesse an qualitativ guten französischen Filmen gehabt, um diese zu exportieren.

In einer Beurteilung des Filmes „Une Vie de chien“ (1941) von Maurice Cammage, der im unbesetzten Gebiet hergestellt worden war, schrieb die Filmprüfstelle beispielsweise, dem Film fehle es an gutem Geschmack. Man sei deshalb in Sorge, er könne trotz des bestehenden Ausfuhrverbotes ins Ausland gelangen und dort die Ansicht hervorrufen, unter der Kontrolle deutscher Besatzungsbehörden sei eine Produktion besserer Filme nicht möglich, da im Ausland schwer zu unterscheiden sei, ob der Film in der besetzten oder unbesetzten Zone gedreht wurde ${ }^{863}$. Als exportgeeignet bezeichneten die Zensoren besonders Komödien. Dies war der Fall bei „Bolero“ (1941) von Jean Boyer mit Arletty: „Der Film wird als guter Unterhaltungsfilm für den Export empfohlen. Es bestehen weder militärische noch politische Bedenken"864. Auch „Romance à trois" (1942) von Roger Richebé empfahl die Filmprüfstelle für den Export: „Eine im ganzen geglückte Filmkomödie mit reichen komischen Situationen, Tempo, guter Fotografie und guten schauspielerischen Leistungen " 865 . Die Zensurberichte zeigen, daß offenbar etliche französische Filme aufgrund ihrer angeblich schlechten Qualität für den Export nicht empfohlen wurden. „Montmartre sur Seine“ (1941), von Georges Lacombe, mit Edith Piaf und Jean Louis Barrault wurde zwar für die besetzte Zone zugelassen aber wegen seiner angeblich minderwertigen Qualität nicht für den Export empfohlen. Der Kommentar der Filmprüfstelle zur Leistung Edith Piafs lautete: „Schlecht geschminkt, ohne ihr sonst in Paris beliebtes Repertoire an Chansons, ohne darstellerische Begabung und mit einem äußerst inhaltslosen Dialog, kann sie diesen völlig mißlungenen Film auch nicht retten" 866 .

Abgesehen von einer guten Qualität mußte ein für den Export geeigneter Film auch als politisch unbedenklich eingestuft worden sein. Dem Film „Le Pavillon brûle" (1941) von Jacques de Baroncelli bescheinigten die Zensoren zwar neben schlechter Qualität wenig Exportwert, doch bestanden gegen eine Ausfuhr keine politischen Bedenken; nach Deutschland sollte er trotzdem nicht exportiert werden ${ }^{867}$. Der Film „La Maison des sept Jeunes Filles“ (1941) von Albert Valentin bezeichnete die Filmprüfstelle als mißlungen und

863 BA-MA, RW35 223, Prop.Abt., Ref.Film, Tätigkeitsbericht, 5. 9.-12. 9. 1941.

864 BA-MA, RW35 225, Gr.Film, Bericht Nr. 27 über das Ergebnis der am 20. 3. 1942 erfolgten Prüfung des franz. Filmes „Boléro“, Fpf. Nr. 6280.

865 BA-MA, RW35 226, Bericht Nr. 37 über das Ergebnis der am 9.6. 1942 erfolgten Prüfung des franz. Filmes „Romance à trois“, Fpf. Nr. 6644.

866 BA-MA, RW35 224, Prop.Abt., Ref.Film, Bericht Nr. 8, über das Ergebnis der am 19. 11. 1941 erfolgten Prüfung des franz. Filmes „Montmartre sur Seine“, Fpf. Nr. 5378. 867 Ibid. Bericht Nr. 10 über das Ergebnis der am 2. 12. 1941 erfolgten Prüfung des franz. Filmes „Le Pavillon Brûle“ Fpf. Nr. 5658. 
empfahl ihn wegen seiner schlechten Qualität nicht für den Export, während politisch keine Bedenken bestanden ${ }^{868}$. Der Film "Nous les gosses“ (1941) von Louis Daquin handelt von einer Gruppe von Kindern, die in den Schulferien einem Mitschüler helfen, Geld für eine zerbrochene Fensterscheibe zu verdienen. Die Filmprüfstelle, die dem Film generell eine gute Qualität zusprach, meinte: „Warum zwischen die Pariser Jungens und Mädels ein Negermädchen gesteckt wurde, ist auch nicht recht verständlich und könnte heute im Auslande leicht als Demonstration gegen Rassenideale aufgefaßt werden “869. Die Filmprüfstelle empfahl den Film trotzdem für den Export. Nur für Deutschland bestanden „wegen der gleichwertigen Behandlung des kleinen Negermädchens in der Reihe der weißen Kinder "870 Bedenken. Grundsätzlich empfahl die Filmprüfstelle einen Großteil der geprüften Filme nicht für einen Export nach Deutschland. Über „La Femme que j’ai le plus aimée" (1942) von Robert Vernay und Yves Mirande urteilte sie:

Der Film ist für deutsche und für unter deutschem Einfluß stehende Gebiete wegen seiner oberflächlichen Lebensauffassung, seiner vielfach negativen Einstellung und der stellenweise ablehnenden Beurteilung der Frau, nicht geeignet. Militärisch und politisch bestehen keine Bedenken gegen die sonstige Ausfuhr des Filmes ${ }^{871}$.

Mit dem Hinweis auf die Darstellung der Frau waren im allgemeinen die angeblich dekadenten Darstellungen von Frauen in französischen Filmen gemeint, welche sie etwa als Vamp oder Prostituierte und nicht als aufopferungsbereite Ehefrau und Mutter zeigten. Die Vorführung solcher Filme hätte dem in deutschen Filmen propagierten Frauenbild widersprochen ${ }^{872}$. Die obigen Beurteilungen französischer Filme zeigen, daß die Deutschen tatsächlich darauf bedacht waren, allein die Ausfuhr solcher Filme zu genehmigen, die ihrer Meinung nach qualitativ gut waren. Daraus ist aber nicht unbedingt zu schließen, daß auf deutscher Seite ein großes Interesse an einer qualitativ hochwertigen französischen Filmproduktion bestand. Drewniak vertritt im Gegensatz zu Ehrlich und Bertin-Maghit die Ansicht, der französische Film sei „von Berlin aus zum Absterben verurteilt“ ${ }^{\text {" } 733}$ gewesen. Er be-

868 Ibid. Bericht Nr. 16 über das Ergebnis der am 16. 12. 1941 erfolgten Prüfung des franz. Filmes „La Maison des sept Jeunes Filles“, Fpf. Nr. 6798.

869 Ibid. Bericht Nr. 9 über das Ergebnis der am 1. 12. 1941 erfolgten Prüfung des franz. Filmes „Nous les Gosses“ Fpf. Nr. 5626. Siehe auch FDI, VDP 1055.

870 Ibid.

871 BA-MA, RW35 225, Gr.Film, Bericht Nr. 26 über das Ergebnis der am 12. 3. 1942 erfolgten Prüfung des franz. Filmes „La Femme que j’ai le plus aimée“, Fpf. Nr. 6264. $872 \mathrm{Zu}$ diesen Frauenbildern siehe DREWNIAK, Der deutsche Film, S. 249-266. In seiner Rede auf dem Reichsparteitag 1934 meinte Hitler diesbezüglich: „Wenn man sagt, die Welt des Mannes ist der Staat, die Welt des Mannes ist sein Ringen, die Einsatzbereitschaft für die Gemeinschaft, so könnte man vielleicht sagen, daß die Welt der Frau eine kleinere ist. Denn ihre Welt ist ihr Mann, ihre Familie, ihre Kinder und ihr Haus. Wo wäre aber die größere Welt, wenn niemand die kleinere betreuen wollte"? (zit. n. DrEWNIAK, Der deutsche Film, S. 251f.).

873 Ibid. S. 732. 
gründet dies unter anderem damit, daß eine relativ geringe Anzahl französischer Filme exportiert wurde. Außerdem hätten aufgrund der knappen Materialzuteilung durch die Besatzungsbehörden nur wenige Kopien der Filme gezogen werden können. Demgemäß sei eine Amortisierung der während der Besatzungszeit hergestellten französischen Filme unmöglich gewesen ${ }^{874}$. Drewniak bezieht an dieser Stelle allerdings nicht mit ein, daß zumindest kurzfristig immerhin ein Interesse der Besatzer an einer französischen Filmproduktion bestand. Von den Pariser Dienststellen wurde eine dementsprechende Politik während der Okkupation verfolgt.

Außerdem waren die Rohfilmzuteilungen für französische Filmproduktionen nicht unbedingt deshalb gering bemessen, weil die Besatzer die Zerstörung des französischen Films herbeiführen wollten, sondern weil diese angesichts der Materialknappheit mehr und mehr Rohfilm für die deutsche Filmproduktion aus Frankreich abzogen. Sicherlich wurde auf diese Weise aber eine solche Entwicklung zugunsten der deutschen Filmindustrie bewußt in Kauf genommen. In einem Bericht vom Mai 1942 betonte die Propaganda Abteilung ausdrücklich, daß hinsichtlich der Rohfilmverteilung deutsche Filme vor französischen dann bevorzugt würden, wenn politische und militärische Rahmenbedingungen es verlangten ${ }^{875}$. Besonders viel Rohfilm wurde in Deutschland für das Material der Wochenschau benötigt. Die Propagandakompanien der Wehrmacht lieferten ständig eine große Menge an Filmstreifen zum Kriegsgeschehen, von denen nur ein Bruchteil auch tatsächlich für die Wochenschau verwendet wurde. In Paris war das Referat Film der Ansicht, die Deutsche Wochenschau müsse gekürzt werden, falls nicht das RMVP entscheiden wolle, daß zugunsten der Aufrechterhaltung der Wochenschau in Deutschland, sämtliche Filmvorhaben in Frankreich nicht mehr ausgeführt werden dürften. Sie bezog Stellung für die französische Filmproduktion und betonte, diese stelle im Augenblick in Frankreich ein Minimum dar, das „im Interesse der propagandistischen Erfassung der Bevölkerung und im Hinblick auf die Aufrechterhaltung der Ruhe und Ordnung im besetzten Frankreich unbedingt weitergeführt werden muß ${ }^{4876}$. 1943 hatte sich die Rohfilmlage noch weiter verschlechtert. Die Filmprüfstelle notierte in einem Bericht vom März, entsprechend eines „Führererlasses" solle nun aus Frankreich sämtlicher Rohfilm abgezogen werden, da die Deutsche Wochenschau unter allen Umständen auch weiterhin produziert werden müsse. Die Filmprüfstelle war hier anderer Ansicht:

Abgesehen davon, daß der Film in Frankreich ein unentbehrliches Mittel der politischen und kulturpolitischen Beeinflussung darstellt, hat er angesichts der sich verstärkenden Notlage der breiten Massen des franz. Volkes wesentliche militärische Sicherungsaufgaben, insofern es über den Film und die Filmtheater möglich ist, die Volksmassen abzulenken und zu zerstreuen. Es ist nicht von der Hand zu weisen, daß, wenn

874 Ibid. S. 732.

875 BA-MA, RW35 225, Prop.Abt., Gr.Film, Tätigkeitsbericht, 24. 4.-2. 5. 1942.

876 BA-MA, RW35 226, Tätigkeitsbericht, 1.6.-6.6. 1942. 
diese militärische Sicherungsaufgabe des Films nicht mehr erfüllt werden könnte weil aller Rohfilm nach Deutschland verbracht werden müßte, die Zahl der Sabotageakte und Attentate sich bedeutend steigern wird ${ }^{877}$.

Dieses Beispiel zeigt, daß Hitler offenbar wenig an einer Aufrechterhaltung der französischen Filmproduktion gelegen war, wenn es darum ging die Deutsche Wochenschau gleichsam zu retten. Allerdings war dies eine Reaktion auf die kriegsbedingte Rohfilmknappheit in Deutschland und kann deshalb nicht unbedingt als geplante Zerstörung der französischen Filmproduktion angesehen werden. Ferner wird hier deutlich, daß im Hinblick auf den Umfang der wirtschaftlichen Ausnutzung der französischen Filmindustrie das RMVP eine rigorosere Politik verfolgte als die Propaganda Abteilung. Die deutsche Besatzungsmacht war grundsätzlich an einer Aufrechterhaltung des französischen Filmbetriebes und somit auch an einem Filmexport interessiert und dies traf insbesondere auf die Propaganda Abteilung als Dienststelle vor Ort zu, die vor allem gegen Ende der Besatzung auch ein vitales Interesse an dem Erhalt des eigenen Arbeitsgebietes hatte, damit die Mitarbeiter nicht eingezogen würden. Dennoch sollte der französische Film möglichst keine zu starke Konkurrenz für den deutschen darstellen und diese Position überwog vor allem auf seiten von Goebbels und des Propagandaministeriums. 